\title{
Mucoricin is a Ricin-Like Toxin that is Critical for the Pathogenesis of Mucormycosis
}

2

Sameh S. M. Soliman, ${ }^{1,2 \ddagger}$ Clara Baldin, ${ }^{1,3 \ddagger}$ Yiyou Gu, ${ }^{1 \ddagger}$ Shakti Singh, ${ }^{1}{ }^{\ddagger}$ Teclegiorgis

Gebremariam, ${ }^{1}$ Marc Swidergall, ${ }^{1,4}$ Abdullah Alqarihi, ${ }^{1}$ Eman G. Youssef, ${ }^{1,5}$ Sondus Alkhazraji, ${ }^{1}$ Antonis Pikoulas, ${ }^{6}$ Christina Perske, ${ }^{7}$ Vivek Venkataramani, ${ }^{7,8}$ Abigail Rich, ${ }^{9}$ Vincent M.

Bruno, ${ }^{10}$ Julie Dunning Hotopp,${ }^{10}$ Nicolas J. Mantis,${ }^{11}$ John E. Edwards, Jr. ${ }^{1,4}$ Scott G. Filler, ${ }^{1,4}$ Georgios Chamilos, ${ }^{6}$ Ellen S. Vitetta, ${ }^{9}$ Ashraf S. Ibrahim ${ }^{1,4 *}$

${ }^{1}$ Division of Infectious Diseases, The Lundquist Institute for Biomedical Innovation at HarborUniversity of California at Los Angeles (UCLA) Medical Center , Torrance, CA, U.S.A.; ${ }^{2}$ College of Pharmacy and Research Institute for Medical and Health Sciences, University of Sharjah, P.O. Box 27272, Sharjah, United Arab Emirates; ${ }^{3}$ Department of Biological Chemistry, Medical University of Innsbruck, Innsbruck, Austria; ${ }^{4}$ David Geffen School of Medicine at UCLA, Los Angeles, Ca, U.S.A; ${ }^{5}$ Department of Biotechnology and Life Sciences, Faculty of Postgraduate Studies for Advanced Sciences, Beni-Suef University, Beni-Suef, Egypt;

${ }^{6}$ Department of Medicine, University of Crete, Foundation for Research and Technology, 71300 Heraklion, Crete, Greece; ${ }^{7}$ Department of Pathology, University Medicine Göttingen, Göttingen, Germany; ${ }^{8}$ Department of Hematology and Medical Oncology, University Medicine Göttingen, Göttingen, Germany; ${ }^{9}$ Departments of Immunology and Microbiology, UT Southwestern Medical Center, Dallas, Tx, U.S.A; ${ }^{10}$ Department of Microbiology and Immunology, University of Maryland School of Medicine, Baltimore, MD, U.S.A ${ }^{11}$ New York State Department of Health, Wadsworth Center, Albany, NY, U.S.A.

‡Equal contribution

*Corresponding Author: Ashraf S. Ibrahim 
24 Division of Infectious Diseases (MRL), 1124 W. Carson St., Torrance, CA 90502.

25 Tel: (310) 222-6424, Fax: (310) 782-2016, e-mail; ibrahim@lundquist.org

26 Short title: Mucormycosis involves a ricin-like toxin

27 
Abstract

Fungi of the order Mucorales cause mucormycosis, a lethal infection with an incompletely understood pathogenesis. We now demonstrate that Mucorales fungi produce a toxin that plays a central role in virulence. Polyclonal antibodies against this toxin inhibit its ability to damage human cells in vitro, and prevent hypovolemic shock, organ necrosis, and death in mice with mucormycosis. RNAi inhibition of the toxin in Rhizopus delemar, compromises the ability of the fungus to damage host cells and attenuates virulence in mice. This $17 \mathrm{kDa}$ toxin has structural and functional features of the plant toxin, ricin, including the ability to inhibit protein synthesis by its $\mathrm{N}$-glycosylase activity, the existence of a motif that mediates vascular leak, and a lectin sequence. Antibodies against the toxin inhibit $R$. delemar- or toxin-mediated vascular permeability in vitro and cross-react with ricin. A monoclonal anti-ricin B chain antibody binds to the toxin and also inhibits its ability to cause vascular permeability. Therefore, we propose the name "mucoricin" for this toxin. Not only is mucoricin important in the pathogenesis of mucormycosis but our data suggest that a ricinlike toxin is produced by organisms beyond the plant and bacterial kingdoms. Importantly, mucoricin should be a promising therapeutic target.

Keywords: Mucormycosis, Toxins, Ricin, Rhizopus, Virulence, Pathogenesis, Mucoricin 
Mucormycosis is a lethal fungal infection that usually afflicts immunocompromised hosts

50 such as diabetics in ketoacidosis (DKA), neutropenic patients, patients undergoing hematopoietic

51 cell or solid organ transplant, or patients receiving high-dose corticosteroids ${ }^{1-6}$.

52 Immunocompetent patients with severe trauma are also at risk of contracting mucormycosis by

53 direct inoculation of open wounds $s^{7,8}$. The overall mortality rate of mucormycosis is $>40 \%$ and it

54 approaches $100 \%$ in patients with disseminated disease, persistent neutropenia, or brain

55 infection ${ }^{1-6}$. The two most common forms of the disease are rhino-orbital/cerebral and

56 pulmonary mucormycosis. In both forms of the disease, infection is initiated by the inhalation of

57 spores that germinate in the host to form hyphae, which are capable of invading host tissues

58 while avoiding phagocytic killing ${ }^{6,9}$.

59 A characteristic feature of mucormycosis is the propensity of Mucorales to invade blood

60 vessels, resulting in thrombosis and subsequent tissue necrosis ${ }^{6}$. The massive tissue necrosis

61 associated with mucormycosis compromises the delivery of antifungal drugs to infected foci,

62 thereby necessitating radical surgical intervention to improve the outcome of therapy. We have

63 previously determined that Mucorales fungi invade human umbilical vein endothelial cells

64 (HUVECs) by expressing the fungal invasin, CotH3, which interacts with the 78kDa host

65 receptor, glucose regulated protein (GRP78). The interaction between CotH3 and GRP78

66 induces the endothelial cells to endocytose the fungi ${ }^{10-12}$. However, the mechanisms by which

67 Mucorales damage host cells and cause necrosis are unknown.

While studying the capacity of Rhizopus delemar, the most common cause of

69 mucormycosis, to damage HUVECs, we observed that killed hyphae of this organism and other

70 Mucorales caused considerable damage to host cells ${ }^{13}$. This experimental finding and the clinical 
71 observation of the extensive tissue necrosis observed in patients with mucormycosis led us to

72 speculate that a fungal-derived toxin may be involved in the pathogenesis of this disease.

Here, we identify and characterize a hyphal-associated and secreted/shed toxin produced

74 by Mucorales. This toxin damages host cells in vitro by inhibiting protein synthesis. The toxin is

75 required for the pathogenesis of mucormycosis in mice, where it induces inflammation,

76 hemorrhage and tissue damage resulting in apoptosis and necrosis. Suppression of toxin

77 production in $R$. delemar by RNAi attenuates virulence in DKA mice, and polyclonal anti-toxin

78 antibodies (IgG anti-toxin) protect mice from mucormycosis by reducing tissue inflammation

79 and damage. Thus, the toxin is a key virulence factor of Mucorales fungi and a promising

80 therapeutic target. Because this toxin shares structural and functional features with ricin

81 produced by the castor bean plant, Ricinus communis ${ }^{14}$, we named it "mucoricin".

\section{Results}

84 Mucorales damage host cells by a hyphal-associated toxin

We previously observed that $R$. delemar causes significant damage to HUVECs within 8

$86 \mathrm{~h}$ of infection ${ }^{11}$. This organism also damages the A549 alveolar epithelial cell line and primary

87 alveolar epithelial cells, but only after $30 \mathrm{~h}$ of incubation (Extended Data Fig. 1a). R. delemar-

88 mediated damage to both HUVECs and alveolar epithelial cells is associated with the formation

89 of extensive hyphae, suggesting that the hyphal form of this organism produces a factor(s) that

90 damage host cells ${ }^{13}$. To investigate whether viability is required for $R$. delemar hyphae to

91 damage host cells, we compared the extent of damage to A549 cells caused by live and heat-

92 killed hyphae. We found that while heat-killed hyphae caused less damage to these cells than live

93 hyphae, the extent of host cell damage was still significant (Extended Data Fig. 1b). These 
94 finding suggested that a hyphal-associated heat-stable toxin may be partially responsible for host

95 cell damage. To explore this hypothesis, we compared the ability of aqueous extracts from dead

R. delemar spores and/or hyphae to damage host cells. Extracts from either hyphae alone or from

97 a mixture of spores and hyphae damaged A549 cells, whereas an extract from spores alone suggest that Mucorales produce a hyphal-associated toxin that damages mammalian cells.

\section{Purification and activity of the toxin}

To purify the hyphal-associated toxin, $R$. delemar spores were grown in a liquid medium

for 4-7 days to generate a hyphal mat. The mat was ground in liquid nitrogen and extracted with

sterile water, concentrated and analyzed by size exclusion chromatography ${ }^{15}$. When the different fractions were analyzed for their ability to damage A549 cells, activity was found in the fractions with molecular masses of 10-30 kDa (Extended Data Fig. 2a). The concentrated water extract was then subjected to three dimensional chromatographic fractionations yielding a fraction that caused significant damage to A549 cells (Extended Data Fig. 2b-g). This fraction was further subjected to high-performance liquid chromatography (HPLC), using hydrophobic interaction

112 chromatography (HIC). The purified sample was trypsinized and sequenced using LC-MS/MS, 113 which identified a 17 kDa protein (RO3G_06568). others previously sequenced ${ }^{16-19}$ and that are reported to cause disease in humans (Mucor,

116 Cunninghamella, Lichtheimia), animals (Mortierella), or plants (Choanephora cucurbitarum). 
117 Orthologues were also found in the arbuscular mycorrhizal fungus Rhizophagus species, and

118 bacterial genera of Streptomyces and Paenibacillus (Supplementary Table 1). Since orthologues

119 were detected in other Mucorales known to cause mucormycosis, we examined the ability of

120 unfractionated hyphal extracts from various Mucorales fungi to damage A549 cells relative to

121 that induced by hyphal extracts from the $R$. delemar 99-880 reference strain. Hyphal extracts

122 from $R$. oryzae, another strain of R. delemar, Lichtheimia corymbifera, and Cunninghamella

123 bertholletiae all caused significant damage to A549 cells (Extended Data Fig. 1e).

We expressed the $17 \mathrm{kDa}$ putative toxin gene in $S$. cerevisiae and used the purified

125 recombinant toxin to raise polyclonal anti-toxin antibodies in rabbits. Although the IgG fraction

126 of the antisera (IgG anti-toxin) had no effect on the growth or germination of $R$. delemar in vitro

127 (Extended Data Fig. 3), it resulted in 50\%-70\% inhibition of the damage to A549 cells caused

128 by heat-killed hyphae of several Mucorales (Extended Data Fig. 1f). From these findings we

129 concluded that the putative toxin is responsible for host cell damage caused by most, if not all,

130 members of the Mucorales fungi.

We also used qRT-PCR to study the expression of this ORF in $R$. delemar. In accordance

132 with data showing a lack of toxin activity in spores (Extended Data Fig. 1c), there was minimal

133 expression of this gene during the first $3 \mathrm{~h}$ of incubation (prior to germination ${ }^{13}$ ). Expression of

134 this gene began to increase when the spores germinated at $4 h^{13}$, peaked by $5 \mathrm{~h}$, and plateaued for

135 at least 16 h of hyphal formation (Extended Data Fig. 4a). Protein expression in germlings and

136 hyphae, but not spores, was confirmed by immunostaining using the IgG anti-toxin (Extended

137 Data Fig. 4b). The expression of the putative toxin gene was high in hyphae growing under

138 aerated conditions, but not in hyphae grown in the absence of aeration (Extended Data Fig. 4c).

139 In addition, RNA expression was 5-10-fold higher following 2-5 h of co-culture with A549 
140 alveolar epithelial cells as compared to co-culture with HUVECs or human erythrocytes.

141 (Extended Data Fig. 4d).

\section{The toxin is capable of damaging host cells in vitro and in vivo}

We compared the ability of the purified toxin to damage primary lung epithelial cells,

145 A549 alveolar epithelial cells, and HUVECs. After $1 \mathrm{~h}$, the toxin caused significant damage to all

146 the host cells and especially to HUVECs (Fig. 1a). After $3 \mathrm{~h}$, there was almost 100\% damage to

147 all host cells. We also compared the ability of the purified toxin $v s$. the recombinant toxin to

148 damage A549 cells. Both caused significant damage (Fig. 1b). Therefore, the purified and the

149 recombinant protein act similarly and in a time dependent manner in damaging A549 cells.

150 We next tested the activity of the toxin in vivo. Toxin purified from $R$. delemar was

151 injected intravenously into mice every other day for a total of three doses and the mice were

152 monitored for behavioral changes, weight loss, and survival. Within 10-30 minutes after the

153 injection of $0.1 \mathrm{mg} / \mathrm{ml}(5.9 \mu \mathrm{M})$ purified toxin, we observed behavior highly suggestive of

154 sudden circulatory hypovolemic shock, including rapid and shallow breathing, weakness, and

155 cold skin. The mice lost $>25 \%$ of their original body weight (Fig. 1c); most eventually died.

156 These events were similar to those observed in mice infected with live $R$. delemar spores (Fig.

157 1d). Finally, histopathology of organs collected from the mice showed pathological changes that

158 included necrosis, hemorrhage, and infiltration of the pulmonary interstitium by macrophages in

159 the lungs. Liver changes included necrosis, clusters of mononuclear cells and the presence of

160 megakaryocytes in the organs, polymorphonuclear cell (PMN) infiltration and tissue calcification

161 indicative of uncontrolled inflammation, hemorrhage and necrosis (Fig. 1e). These data suggest 
162 that the toxin is sufficient to cause clinical symptoms often associated with disseminated

163 mucormycosis.

RNAi knockdown and antibody-mediated neutralization of the toxin reduced the virulence

To further confirm the role of this toxin in the pathogenesis of mucormycosis, we used

$168 \mathrm{RNAi}^{20}$ to down regulate the gene expression of the toxin. The extent of down regulation of the

169 toxin was measured by qRT-PCR using toxin specific primers and by Western blotting or

170 immunostaining of $R$. delemar with the IgG anti-toxin. This IgG anti-toxin specifically

171 recognized the toxin by ELISA and Western blotting. RNAi knockdown of the toxin caused

$172 \sim 90 \%$ inhibition in gene expression (Extended Data Fig. 5a). Furthermore, RNAi knockdown

173 resulted in $>80 \%$ reduction in protein expression (Extended Data Fig. 5b) and negligible

174 staining of toxin-RNAi $R$. delemar germlings compared to germlings of a control strain that have

175 been transformed with an empty plasmid (Extended Data Fig. 5c). In accord with the lack of an

176 effect by the IgG anti-toxin on the growth and germination of $R$. delemar, the RNAi knockdown

177 of the toxin had no effect on fungal germination or growth (Extended Data Fig. 6).

We next assessed the effect of downregulation of toxin expression on the ability of $R$.

179 delemar to damage A549 alveolar epithelial cells. R. delemar with RNAi targeting of the toxin

180 gene induced $\sim 40 \%$ reduction in epithelial cell damage relative to either the wild-type strain or

$181 R$. delemar transformed with the empty plasmid (Fig. 2a). Similarly, the IgG anti-toxin protected

182 alveolar epithelial cells from wild-type $R$. delemar-induced injury by $\sim 40 \%$, in vitro whereas normal rabbit IgG did not (Fig. 2b). 
Finally, we evaluated the effects of RNAi inhibition of toxin production on the virulence

of $R$. delemar in our model of pulmonary mucormycosis ${ }^{21}$. DKA mice infected with $R$. delemar harboring the empty plasmid had a median survival time of 6 days and $90 \%$ mortality by day 21 post-intratracheal infection, whereas mice infected with the toxin-attenuated expression strain had a median survival time of 21 days and mortality of $30 \%$ (Fig. 2c). Surviving mice had no residual fungal colonies in their lungs when the experiment was terminated on day 21 . Inhibition of toxin production appeared to have minimal effects on the early stages of infection because after 4 days of infection, the fungal burden of the lungs and brains (the primary and secondary target organs, respectively ${ }^{21}$ ) of mice infected with $R$. delemar toxin-attenuated strain and $R$. delemar harboring the empty plasmid were similar (Extended Data Fig. 7a). Reduced virulence without affecting tissue fungal burden has been reported for non-neutropenic mice infected with an Aspergillus fumigatus null mutant that does not produce the Asp f1 ribotoxin ${ }^{22}$, representing a classical feature of disease tolerance ${ }^{23}$. Collectively, our results indicate that while the toxin is dispensable for the initiation of mucormycosis, it plays a central role in the lethality of this disease.

\section{IgG anti-toxin protected mice from mucormycosis}

To further verify the role of the toxin in the pathogenesis of mucormycosis, we infected DKA mice intratracheally with wild-type $R$. delemar and then 24 h later, treated them with a single $30 \mu \mathrm{g}$ dose of either the IgG anti-toxin or normal rabbit IgG. While mice treated with normal IgG had a mortality rate of $95 \%$, treatment with the IgG anti-toxin resulted in $\sim 70 \%$ long-term survival (Fig. 2d). Surviving mice appeared healthy and had no detectable fungal colonies in their lungs when the experiment was terminated on day 21 . In accord with data from 
207

208

209

210

211

212

213

214

215

216

217

218

219

220

221

222

223

224

225

226

227

228

229

the fungal burden in tissues of mice infected with the toxin-attenuated strain, antibody treatment had no effect on the fungal burden of lungs or brains when tissues were harvested four days post infection (Extended Data Fig. 7b). These data further confirm the role of the toxin in the pathogenesis of mucormycosis and point to the potential of using anti-toxin antibodies to treat the disease.

We also performed histopathological examination of the tissues from all groups of mice sampled at the same time of tissue fungal burden studies (day 4) to gain insight into the mechanism of action of the toxin. While, uninfected mice had normal lung architecture with no signs of inflammation or infection (Fig. 2e), lungs from mice infected with $R$. delemar transformed with the RNAi empty plasmid (control) showed fungal and granulocyte infiltration (Fig. 2f left panel) and angioinvasion with thrombosis (Fig. 2f right panel). In contrast, lungs from mice infected with the toxin-attenuated mutant showed only mild signs of inflammation with no angioinvasion (Fig. 2g). Importantly, lungs of mice infected with wild-type $R$. delemar and treated with the IgG anti-toxin showed architecture that was similar to the lungs of the uninfected control mice; there were no signs of inflammation or infiltration with $R$. delemar (Fig. 2h).

\section{Down regulation of the toxin gene or treatment with IgG anti-toxin attenuated $R$. delemar-} mediated host cell damage in vivo

To determine whether the toxin contributed to host cell damage in vivo, we used the ApopTag in situ apoptosis kit to stain the lung tissues of the infected mice. While extensive lung damage was observed in mice infected with wild-type $R$. delemar, the lungs harvested from mice infected with the toxin-attenuated mutant (Extended Data Fig. 8a) or those infected with wild- 
type $R$. delemar and treated with the IgG anti-toxin (Extended Data Fig. 8b) had almost no detectable damage.

Finally, we have previously reported on a mucormycosis case in a human with disseminated mucormycosis ${ }^{9}$. Haemotoxylin and Eosin $(\mathrm{H} \& \mathrm{E})$ staining of lung tissues of this patient showed broad aseptate hyphae that caused necrosis and massive infiltration of tissues compared to thinner septated hyphae present in a patient suffering from invasive pulmonary aspergillosis (Extended Data Fig. 9a,b). Subsequent immunohistochemistry of the patient's

237 lungs using the IgG anti-toxin (vs. control IgG) showed association of the toxin with fungal hyphae and the surrounding tissues in a mucormycosis patient and lack of staining in tissues of an aspergillosis patient (Extended Data Fig. 9c,d). These results show that the toxin is also

240 involved in human mucormycosis, is cell-associated as well as secreted/shed into the

241 surrounding tissues, and confirm the specificity of the antibody used in these studies since the 242 putative toxin does not have an orthologue in Aspergillus (Supplementary Table 1).

249 RNAi targeting the toxin. In accord with secretion/shedding of the toxin by live hyphae,

250 supernatants collected from wild-type $R$. delemar hyphae in which further growth has been

251 hampered by $\mathrm{AmB}$ concentrations $\geq 2 \mu \mathrm{g} / \mathrm{ml}$ showed little to no secretion/shedding of the toxin 
252 (Extended Data Fig. 10). These results confirm that the toxin is secreted/shed into the growth

253 medium.

254

255 The hyphae-associated toxin has structural features of ricin

Given the critical role of the toxin in the pathogenesis of mucormycosis, we did structural and bioinformatics studies to understand its mechanism of action. As reported in

258

259

260

261

262

263

264

265

266

267

268

269

270

271

Supplementary Table 1, many of the toxin orthologues found in other organisms are annotated as ricin domain-containing proteins or ricin B chain-like lectins. Further detailed bioinformatic analysis of the $R$. delemar toxin sequence showed a two domain structure similar to that of ricin (Sequence ID: NP_001310630.1) ${ }^{24}$ (Fig. 3a). Specifically, the $R$. delemar toxin harbored a small region (amino acids 198-289) that resembled a sequence in ricin chain A, known to be involved in inactivating ribosomes (i.e. ribosome inactivating protein [RIP]), and two domains (amino acids 304-437 and 438-565) of the lectin-binding ricin chain B. Moreover, the R. delemar toxin contained an LDV-motif (Fig. 3a) that is present in ricin (Fig 3a, red colored amino acids) and that has been reported to cause damage to HUVECs in vitro ${ }^{25,26}$, and in vivo in models of vascular leak ${ }^{27}$ as well as postulated to cause ricin A chain-mediated vascular leak syndrome in humans $^{25}$. Furthermore, gene ontology studies predicted that $R$. delemar toxin would have functions similar to ricin including sugar binding (GO:0005529, score of 0.64), as well as rRNA glycosylase activity (GO:0030598, score of 0.49) and hydrolase activity (GO:0004553, score of 0.35) (Fig. 3a, table).

We produced a 3-D structural model of the R. delemar toxin by searching templates within the SWISS-Model template library (SMTL). The greatest resemblance was with sugarbinding proteins, especially galactose, the known lectin for $\operatorname{ricin}^{28}$. Other proteins with predicted 
275 resemblance to mucoricin included those with cell adhesion, toxin and hydrolase (glycosylase)

276 activities (Supplementary Table 2). The rRNA glycosylase activity is a feature of ricin and is

277 required for inactivating ribosomes ${ }^{29}$. Finally, the structures of the $R$. delemar toxin and ricin $\mathrm{B}$

278 chain were superimposable with a highly significant Tm-align score of 0.81 and a score of 0.78

279 for ricin B domain I (amino acids 304-437) and domain II (438-565 amino acid), respectively

280 (Fig. 3b). However, the $17 \mathrm{kDa}$. delemar toxin is much smaller than either the A or B chains of

281 ricin (32 kDa each). Nevertheless, the fungal toxin appears to share structural homology with

282 portions of ricin that are responsible for inactivating ribosomes, inducing vascular leak and

283 binding to galactose.

284

\section{R. delemar toxin is immunologically cross-reactive with ricin}

To further explore the similarities between $R$. delemar toxin and ricin, we used the IgG

anti-R. delemar toxin in an ELISA to determine whether the toxin and ricin were

immunologically cross-reactive. Plates were coated with ricin or $R$. delemar toxin, and then

delemar toxin also recognized ricin, and a murine monoclonal antibody (8A1) against the ricin B

293 delemar toxin reacted with both the $R$. delemar toxin and ricin in a Western blot (Fig. 3e).

294 Importantly, the IgG anti-R. delemar toxin protected A549 alveolar epithelial cells from ricin-

295 induced damage in a manner similar to that of the $\mathrm{IgG}$ anti-ricin B chain (8A1 clone) or

296 galactose [the lectin for the ricin chain B (Fig. 3f)]. Collectively, these data demonstrate the

297 similarities between the two toxins. 
After ricin is internalized by cells via its lectin-binding B chain, it's A chain exerts its toxic activity by irreversibly inactivating ribosomes via its $\mathrm{N}$-glycosylase activity. This result in the inhibition of protein synthesis ${ }^{31}$. The enzyme activity cleaves the $\mathrm{N}$-glycosidic bond between the adenine nucleobase in the $\alpha$-sarcin-ricin loop and its ribose causing the release of adenine (depurination) ${ }^{32}$. To determine whether the $R$. delemar toxin had similar activity, we compared the ability of the two toxins to inhibit protein synthesis in a cell-free rabbit reticulocyte assay ${ }^{33}$. As reported previously ${ }^{34}$, ricin concentration that caused $50 \%$ inhibition in protein synthesis $\left(\mathrm{IC}_{50}\right)$ was $\sim$ at $2.2 \times 10^{-11} \mathrm{M}$ (Fig. 4a). The recombinant toxin of $R$. delemar also inhibited protein synthesis, albeit with $\sim 800$-fold weaker activity than ricin (i.e. an $\mathrm{IC}_{50}$ of $1.7 \times 10^{-8} \mathrm{M}$ ) measure the amount of adenine released from template RNA extracted from A549 alveolar epithelial cells ${ }^{32}$. In contrast to RNA exposed to the buffer control, RNA incubated with mucoricin released detectable amounts of adenine (Fig. 4c). The depurination is due to rRNA Nglycosylase activity since in contrast to the negative control, ovalbumin (OVA) which did not adding aniline, albeit at a concentration of $10^{4}$ higher than ricin and after incubation with the

317 ribosomes for a longer period of time (Fig. 4d). Thus, like ricin, the $R$. delemar toxin is a RIP. vitro $^{25,26}$ and in vivo ${ }^{27}$ mediated by its LDV sequence, a motif that is also present in the $R$. integrity, we grew HUVECs on membrane inserts in transwells prior to treating the confluent 
322

323

324

325

326

327

328

329

330

331

332

333

334

335

monolayers with either $R$. delemar spores or $R$. delemar toxin for $5 \mathrm{~h}$ at concentrations that did not kill the HUVECs (Supplementary Fig. 1). The permeability of HUVECs was determined by measuring the amount of fluorescent dextran migrating from the upper chamber to the lower chamber of the transwells after adding $R$. delemar spores (Fig. 4e) or recombinant $R$. delemar toxin (Fig. 4f). Both $R$. delemar and the toxin induced permeability, which was equivalent to that induced by E. coli lipopolysaccharide (LPS), a potent inducer of vascular permeability ${ }^{35}$. Furthermore, IgG anti-R. delemar toxin blocked this enhanced permeability by $50-60 \%$.

Importantly, IgG anti-ricin B chain (8A1 clone) almost completely abrogated the permeability induced by $R$. delemar or its toxin (Fig. 4e,f). These results confirm that $R$. delemar induces permeability in HUVECs via its toxin and that IgG anti-ricin B chain blocks this $R$. delemarmediated virulence trait.

Ricin is also known to cause cell damage by inducing both necrosis and apoptosis ${ }^{36,37}$. To determine whether the $R$. delemar toxin did the same, we used an Apoptosis/Necrosis detection kit to compare the abilities of $R$. delemar toxin and ricin to damage alveolar epithelial cells. As compared to the control, after $2 \mathrm{~h}$ both toxins caused comparable apoptosis and necrosis (Fig. $\mathbf{4 g , h}$ ). Collectively, these results demonstrate the functional similarities between ricin and $R$. delemar toxin as RIPs that inhibits protein synthesis via $\mathrm{N}$-glycosylase activity. Both toxins also cause cell death by apoptosis and necrosis. Based on the structural and functional similarity to ricin, we named the $R$. delemar toxin mucoricin and the corresponding gene $\underline{\text { Ricin-Like }}$ Toxin $(R L T 1)$.

\section{Discussion}


344 Mucormycosis is a lethal fungal infection often associated with extensive tissue damage. We

345 have now identified a cell-associated/secreted/shed toxin that is widely present in pathogenic

346 Mucorales fungi. We used genetic and biochemical techniques to show that the toxin gene, RLT1

347 and its encoded protein (mucoricin) are required for the full virulence of $R$. delemar. In addition

348 to being produced by pathogenic Mucorales, this toxin appears to be present in other fungi and

349 bacteria. For example, orthologues in Rhizophagus were identified to have 30-40\% identity with

350 RLT1. Rhizophagus lives symbiotically with plants and is recognized as an integral part of the

351 natural ecosystem and was shown to delay plant disease symptoms caused by Phytophthora

352 infestans ${ }^{38}$. Similarly, RLT1 orthologues were identified in the bacterial genera of Streptomyces

353 and Paenibacillus ( $30 \%$ identity). Both bacteria are known inhabitants of soil, present in

354 rhizosphere of various plants, and are used as biological control agents for crops because of their

355 ability to secrete secondary metabolites ${ }^{39}$.

356 Mucoricin has structural and functional similarities to ricin, a prototypic Type 2 RIP

357 consisting of two polypeptide chains (A and B) that are linked by a disulfide bond ${ }^{24}$. The A-

358 chain of ricin is an $\mathrm{N}$-glycosidase that is responsible for inactivating ribosomes, and the B chain

359 is a galactose-specific lectin ${ }^{29}$ that enables the toxin to bind to target cells ${ }^{28}$. In contrast, Type I

360 RIPs are monomeric A-chain-like RIPs ${ }^{29}$. Mucoricin appears to have the activities of both ricin

361 A and B chains (and Type I RIPS) and both activities are present in a single $17 \mathrm{kDa}$ protein (Fig.

362 3e). Several other RIPs isolated from plants consist of low molecular weight single chain

363 proteins including a $26 \mathrm{kDa}$ TRIP isolated from tobacco leaves ${ }^{40}$ and a $7.8 \mathrm{kDa}$ protein isolated

364 from sponge gourd seeds (Luffa cylindrica $)^{41}$.

The strong sequence and structural similarity between mucoricin and ricin lies in the ricin

366 B-chain, although mucoricin inhibits protein synthesis via $\mathrm{N}$-glycosylase activity leading to 
depurination, albeit with lower activity than ricin. A possible explanation for the ability of mucoricin to inhibit protein synthesis is likely predicted by its conserved rRNA glycosidase activity. Specifically, the EAARF motif in ricin A chain is known to be responsible for the RIP activity of ricin. It is known to depurinate adenosine 4324 in $28 \mathrm{~S}$ rRNA with the glutamic acid

371 residue (E, shaded) responsible for this activity ${ }^{42}$. Furthermore, the arginine residue (R, shaded)

372 separated by two amino acids from the glutamic acid residue (Fig. 3a, green brackets), is also

373 required for the activity of the bacterial Shiga toxin, a potent ricin-like A chain with a fully

374 conserved EAARF domain of ricin $^{43}$. Mucoricin has the EEGRL, in which the glutamic acid and 375 arginine residues are conserved (Fig. 3a, green brackets).

377 activity is the WGRLS ${ }^{44}$ (Fig. 3a, cyan underline). This sequence also aligns with the EEGRL

378 motif of mucoricin (Fig. 3a, green brackets; and Supplementary Table 3). Furthermore,

379 mucoricin contains the EAANQ motif (Fig. 3a, purple overline) which resembles the ricin

380 sequence of EAARF, with the glutamic acid residue conserved and the arginine residue replaced

381 by asparagine, a conserved amino acid with properties that are weakly similar to arginine. The

382 lack of fully conserved functional residues (i.e. arginine) between mucoricin and ricin/Shiga

383 toxins likely explains the 800-fold weaker RIP activity of mucoricin as compared to ricin (Fig.

384 4a,b). Finally, mucoricin also has sequence homology with several other RIPs including saporin 385 of Saponaria officinalis, a Type 1 RIP with $19 \%$ overall identity and 10 out of the 17 conserved 386 amino acid residues in the functional domain of EAARF (Supplementary Fig. 2). Notably, the 387 EEGRL and EAANQ are widely present in Mucorales fungi known to cause human disease 388 (Supplementary Table 3). Thus, mucoricin appears to be a RIP that functionally resembles ricin 
A chain and Type-1 RIPs such as saporin ${ }^{45}$. The contribution of the EEGRL and EAANQ motifs to the RIP activity is being further investigated.

Our in vitro studies suggest that $R L T 1$ is expressed most strongly when the hyphal matt is aeriated and in response to alveolar epithelial cells (Extended Data Fig. 4c,d). These results further suggest that mucoricin may be highly active during pulmonary mucormycosis and potentially in rhinoorbital disease, when hyphae are exposed to epithelial cells in the presence of ambient levels of oxygen. It is of interest that, mitochondria are believed to play a central role in RIPs' (e.g. ricin, Shiga toxin and abrin) ability to induce host cell apoptosis ${ }^{46}$. Although the expression of $R L T 1$ in $R$. delemar is higher in response to alveolar epithelial cells than to HUVECs (Extended Data Fig. 4d), the latter host cells are damaged much more rapidly by $R$. delemar (i.e. significant $R$. delemar-induced HUVEC injury occurs at $8 \mathrm{~h} v s .48 \mathrm{~h}$ for $R$. delemar-induced alveolar epithelial cells [Extended Data Fig. 1] ${ }^{13}$, and by purified mucoricin (Fig. 1a). In accord with these results, it has been shown that HUVECs are rapidly damaged and their permeability affected by small peptides containing the LDV-motif but lacking the sequences responsible for $\mathrm{N}$-glycosidase activity ${ }^{26}$. In this study we show that $R$. delemar compromises the permeability of HUVEC monolayers in vitro by the direct effect of mucoricin. The LDV and other (x)D(y) motifs (with known vascular leak effector function) are widely present in pathogenic Mucorales (Supplementary Table 3) ${ }^{25}$. Thus, it is possible that the LDVmotif is responsible for angioinvasion and rapid hematogenous dissemination in mucormycosis ${ }^{6}$ by inducing damage to vascular endothelial cells.

The exact mechanism by which mucoricin enters a target cell to exert its lethal effect is not yet known. However, our data strongly indicate that it is cell-associated as well as secreted/shed by Mucorales. The amount of toxin in the medium (27 nM, Extended Data Fig. 
412 10b) from a small-scale growth in a 96-well plate was sufficient to exceed the $\mathrm{IC}_{50}$ in RIP

413 activity of $17 \mathrm{nM}$ (Fig. 4b). Thus, secreted/shed toxin likely exerts its toxicity by binding to and

414 then entering the host cells in the absence of invading hyphae. Alternatively, invading $R$.

415 delemar hyphae release the toxin once they are phagocytosed by immune ${ }^{9}$ cells or barrier 416 cells ${ }^{13,47,48}$.

417 Our in vivo studies clearly demonstrate the contribution of mucoricin to pathogenesis by 418 enhancing angioinvasion, inflammation and tissue destruction. There is also evidence that the

419 lethality of ricin in vivo is related at least in part to its ability to induce a massive inflammatory

420 immune response accompanied by infiltration of $\mathrm{PMN}^{49}$ in many settings such as acute lung

421 injury ${ }^{49,50}$ and gastrointestinal disease ${ }^{51}$. This is likely due to activation of the innate arm of the

422 immune system by the toxin itself or by toxin-damaged cells. Indeed, our histopathological

423 examination of organs harvested from mice injected with purified mucoricin shows inflammation

424 and recruitment of PMNs (Fig. 1e). Neutralizing the effect of the toxin either by RNAi or by

425 anti-mucoricin antibodies decreased inflammation and host tissue damage (Fig. 2e-h and

426 Extended Data Fig. 8). These results confirm the critical role of mucoricin in the pathogenesis

427 of mucormycosis and suggest that it is involved in mediating inflammation and tissue damage,

428 both of which are clinical features of mucormycosis. Of note, treatment of mucormycosis

429 patients with antifungal agents is often hampered by the extensive tissue necrosis that prevents

430 optimal delivery of drugs into the site of infection. Hence, antifungal treatment alone (without

431 surgical intervention) is often non-curative ${ }^{6}$. Thus, antibody-mediated neutralization of

432 mucoricin might reduce tissue necrosis, decrease the need for disfiguring surgery, and maximize

433 the effect of antifungal therapy. 
Based on these results, we propose a model of pathogenesis and the role of mucoricin in

435

this process. We suggest the following events.

i. Infection is initiated when fungal spores are inhaled, and in the absence of phagocytes (or presence of dysfunctional phagocytes such as in patients with DKA). Fungal spores express $\mathrm{CotH}^{10-12}$ and bind to either GRP78 on nasal epithelial cells ${ }^{48}$, or to integrin $\beta 1^{48}$ which activates epidermal growth factor receptor (EGFR) ${ }^{47}$ on alveolar epithelial cells to induce invasion.

ii. Under aerobic conditions, the calcineurin pathway is activated in the inhaled spores, causing them to germinate ${ }^{52,53}$, a process that leads to the production of mucoricin. iii. Mucoricin binds to tissue cells by its lectin receptor, inhibits protein synthesis, and causes apoptosis and necrosis. The toxin can also compromise vascular permeability resulting in rapid hematogenous dissemination and tissue edema often seen in patients with mucormycosis.

iv. While tissue damage is occurring, and because the toxin and debris from necrotic cells are recognized by the immune system, an inflammatory immune response leads to the recruitment of PMNs and other tissue-resident phagocytes.

v. Although the recruited phagocytes damage some of the invading hyphae, both the dead and live hyphae release mucoricin, resulting in more host cell death and more inflammation.

vi. In the necrotic tissue, the fungus can proliferate, protected from both phagocytes and anti-fungal drugs.

Our finding that mucoricin remains active even in dead organisms offers an explanation for why antifungal therapy alone has limited efficacy in patients with mucormycosis, and why 
457 the fungal lesions must frequently be surgically excised. Importantly, other toxins/mechanisms

458 of host cell damage likely exist in Mucorales, since antibody blocking studies and

459 downregulation of toxin gene expression do not fully abrogate the ability of $R$. delemar to

460 damage host tissues.

461 In summary, we have identified a ricin-like toxin (mucoricin) that is widely present in

462 Mucorales fungi, where it plays a central role in the pathogenesis of mucormycosis. We postulate

463 that strategies to neutralize mucoricin will have significant therapeutic benefits. 
464 Correspondence and requests for materials should be addressed to Ashraf S. Ibrahim:

465 ibrahim@lundquist.org

467 Acknowledgments

468 This work was supported by a Public Health Service grant R01AI063503 and R01AI141360 to

469 ASI. MS is supported by R00DE026856, ESV by R01A11752861, VMB by U19AI110820 and

470 R01AI141360, and SGF by R01AI124566 and R01DE022600. ESV is also supported by the

471 Simmons Patigian Distinguished Chair and a Distinguished Teaching Chair. AR is sponsored by

472 the SURF program at UT Southwestern and is currently at Vanderbilt University.

474 histopathological slides of the purified mucoricin, Ms. Heewon Jeon, Ms. Ayesha Ahmed, and

475 Mr. Stephen Ruback for technical assistance. We thank Dr. David Vance and Ms. Greta Van

476 Slyke for their work on the 8A1 monoclonal antibody and Dr. Robert Munford, NIH for his

477 insightful suggestions concerning the nature of the toxin.

\section{Author contributions}

480 S.S.M.S. conceived, designed and performed studies to purify and identify the toxin, and screen

481 its activity in vitro and in vivo and wrote the manuscript. C.B. generated mucoricin mutants and

482 characterized their virulence in vitro and in vivo and conducted the antibody efficacy studies.

483 Y.G. helped in animal studies, conducted confocal microscopy, cross reactivity studies, and RIP

484 activity studies. S.S. designed and performed homology modeling, cross reactivity studies, and

485 toxin secretion studies. T.G. helped in the animal studies. M.S. performed the necrosis/apoptosis

486 assay and the mouse immunohistochemistry studies. A.A. performed permeability studies, 
487 E.G.Y. performed sequence alignment and gene ontology studies. S.A. purified recombinant

488 toxin and polyclonal antibodies. A.P. and G.C. provided and performed the human

489 immunohistochemistry studies. C.P. and V.V. performed and interpreted the mouse histology

490 studies. AR carried out studies on cross-reactivity of mucoricin and ricin. V.M.B. and J.D.H.

491 performed phylogenetic studies and blast search of mucoricin in Mucorales. N.J.M. generated

492 and characterized the 8A1 monoclonal antibody. J.E.E. and S.G.F. provided intellectual advice,

493 designed studies, and edited the manuscript. E.S.V. conceived, designed and carried out studies

494 of cross reactivity, provided reagents and expertise on ricin and helped write the manuscript.

495 A.S.I. conceived, designed, coordinated and supervised the studies, performed experiments, 496 analyzed data, and wrote the manuscript along with comments from co-authors.

498 Materials and Correspondence:

499 Reprints and permissions information is available at www.nature.com/reprints

\section{Competing interests}

502 A.S.I. owns shares in Vitalex Biosciences, a start-up company that is developing

503 immunotherapies and diagnostics for mucormycosis. The remaining authors declare no

504 competing interests.

505 The Lundquist Institute has filed intellectual property rights concerning mucoricin. Vitalex

506 Biosciences has an option to license the technology from The Lundquist Institute for Biomedical

507 Innovation.

508 Other authors declare no conflict of interest.

509 Correspondence and requests for materials should be addressed to ibrahim@lundquist.org. 


\section{Methods}

511 Organisms, culture conditions and reagents. $R$. delemar 99-880 and $R$. oryzae 99-892 were

512 isolated from the brain and lungs of patients with mucomycosis and obtained from the Fungus

513 Testing Laboratory, University of Texas Health Science Center at San Antonio which had its 514 genome sequenced $^{19}$. Cunninghamella bertholletiae 182 is a clinical isolate and is a kind gift

515 from Thomas Walsh (Cornell University). Lichtheimia corymbifera is also a clinical isolate 516 obtained from the DEFEAT Mucor clinical study ${ }^{54}$. R. delemar M16 is a pyrf null mutant derived

517 from $R$. delemar 99-880 and was used for transformation to attenuate mucoricin expression ${ }^{55}$.

518 The organisms were grown on potato dextrose agar (PDA, Becton Dickinson) plates for 5-7 days

519 at $37^{\circ} \mathrm{C}$. For $R$. delemar M16, PDA was supplemented with $100 \mathrm{mg} / \mathrm{ml}$ uracil. The

520 sporangiospores were collected in endotoxin free Dulbecco's phosphate buffered saline (PBS)

521 containing $0.01 \%$ Tween 80 , washed with PBS, and counted with a hemocytometer to prepare

522 the final inoculum. To form germlings, spores were incubated in YPD (Becton Dickinson)

523 medium at $37^{\circ} \mathrm{C}$ with shaking for different time periods. Finally, for growth studies $10^{5}$ spores of

$524 R$. delemar wild-type, or mutant strains were plated in the middle of PDA agar plates. The plates

525 were incubated at $37^{\circ} \mathrm{C}$ and the diameter of the colony was calculated every day for 6 days. The

526 monoclonal anti-ricin B chain antibody (clone 8A1) ${ }^{30}$ and affinity purified rabbit anti-ricin

527 antibodies were prepared and characterized in the Vitetta and Mantis laboratories. Galactose was 528 obtained from Fisher Scientific (Cat \# BP656500) and used for blocking the damaging effect of 529 ricin holotoxin.

531 Host cells. Human alveolar epithelial cells (A549 cells) were obtained from a 58-year-old male

532 Caucasian patient with carcinoma and procured from American Type Culture Collection 
533 (ATCC). The cells were propagated in F-12K Medium developed for lung A549 epithelial cells.

534 Primary alveolar epithelial cells were obtained from ScienCell (Cat \# 3200) and propagated in 535 Alveolar Epithelial Cell Medium (Cat\#3201) and passaged once.

536 HUVECs were collected by the method of Jaffe et al. ${ }^{56}$. The cells were harvested by

537 using collagenase and were grown in M-199 (Gibco BRL) enriched with 10\% fetal bovine

538 serum, 10\% defined bovine calf serum, L-glutamine, penicillin, and streptomycin (all from

539 Gemini Bio-Products, CA). Second-passage cells were grown to confluency in 24- or 96-well

540 tissue culture plates (Costar, Van Nuys, CA) on fibronectin (BD Biosciences). All incubations

541 were in $5 \% \mathrm{CO}_{2}$ at $37^{\circ} \mathrm{C}$. The reagents were tested for endotoxin using a chromogenic limulus

542 amebocyte lysate assay (BioWhittaker, Inc.), and the endotoxin concentrations were less than

$543 \quad 0.01 \mathrm{IU} / \mathrm{ml}$

Fresh red blood cells were isolated from blood samples collected from healthy volunteers

545 after obtaining a signed informed consent form and processed as previously described ${ }^{57}$.

546 Endothelial cell and red blood cell collection was approved by Institutional Review Board at The

547 Lundquist Institute at Harbor-UCLA Medical Center.

Purification and characterization of ricin. Two sources of ricin were used. One was purified

550 from a large stock of pulverized castor beans in the Vitetta laboratory ${ }^{58}$. Its $\mathrm{IC}_{50}$ and toxicity were 551 tested on Daudi lymphoma cells (ATCC® CCL-213 ${ }^{\mathrm{TM}}$ ), HUVECs, and in cell free reticulocyte 552 assays ${ }^{25,34,59}$. The other source was purchased from Vector Laboratories (Burlingame, CA; Cat 553 No. L-1090). Both sources were similar in purity and activity. 
555 Purification and identification of mucoricin. To purify mucoricin, Rhizopus fungal spores

$556\left(10^{3} / \mathrm{ml}\right)$ were grown for 5 days at $37^{\circ} \mathrm{C}$ in YPD culture medium. The supernatant was separated

557 from the fungal mat by filtration and the fungal mycelia was ground in liquid nitrogen and

558 extracted with sterile water, concentrated and analyzed through size exclusion columns ${ }^{15}$. Host

559 cell damage assay showed that substances $>10 \mathrm{kDa}$ and $<30 \mathrm{kDa}$ is responsible for injuring the

560 host cells (Extended Data Fig. 1a). The concentrated water extract was then subjected to 3D

561 chromatographic separations (Extended Data Fig. 1). For the first dimension, the concentrated

562 extract run on native polyacrylamide gel under electrophoretic force (Extended Data Fig. 1b).

563 The gel was cut into 6 pieces and then eluted separately in PBS buffer prior to testing for their

564 damaging activity. Only fraction \#6 corresponding to 15-20 kDa showed damaging effect to host

565 cells (Extended Data Fig. 1c). Next, this fraction was concentrated and subjected to separation

566 using methanol:water (4:1) as a solvent on cellulose plates. Fractions were scraped from the

567 cellulose plate and dissolved in irrigation water, followed by incubation with host cell after filter

568 sterilization. A third dimensional fractionation was applied to the fraction that caused damage

569 using cellulose plates and with the solvent system as above. This round of fractionation resulted

570 in one fraction causing damage to host cells.

571

572 Structural modeling of mucoricin. For amino acid sequence comparisons, mucoricin and ricin

573 (Sequence ID: NP_001310630.1) protein sequences were aligned using MUSCLE/CLUSTAL-

574 W. We searched the SWISS-MODEL template library (SMTL) (https://swissmodel.expasy.org/)

575 to find templates for building 3-D structural model of mucoricin. Briefly, a BLAST search of the

576 SMTL against the primary amino acid sequence identified the target sequence. To build the

577 model, we performed target-template alignment using ProMod3, and templates with the highest 
578 quality were selected for model building. Insertions and deletions were re-modeled using a

579 fragment library, and the side chains were rebuilt. Finally, the geometry of the resulting model is

580 regularized by using a force field. In case loop modeling with ProMod3 fails, an alternative

581 model is built with PROMOD-II. The models showing high accuracy values were finalized for

582 similarity comparisons. Ricin 3-D structure models were also built using ricin chain B amino

583 acids $313-435$ and 440-565 $60-62$. Ricin and mucoricin 3-D protein models were aligned using

584 MacPyMOL software and Tm align score was calculated by webtool Tm Align

585 (https://zhanglab.ccmb.med.umich.edu/TM-align $)^{63}$. Using gene ontology term prediction,

586 mucoricin was predicted to have carbohydrate-binding, hydrolase activity and negative

587 regulation of translation functions.

588

589

Expression and purification of mucoricin. Heterologous expression of mucoricin gene in $S$.

590 cerevisiae was performed to ensure the production of a functional toxin since we used this yeast

591 to generate functional $R$. delemar proteins before ${ }^{11,64}$. The heterologous expression was

592 conducted as follows; total RNA was isolated from $R$. delemar hyphae grown on YPD broth and

593 reverse transcribed into cDNA. The entire ORF of mucoricin was PCR amplified from cDNA

594 using Phusion High-Fidelity PCR Kit (New England Biolabs) using the primers 5'-

595 GATAAGACTAGTATGTATTTCGAAGAAGGC-3' and 5'-

596 GGTGATGCACGTGTCCTTCAAATGGCACTA-3'. The amplified PCR product was verified

597 by sequencing and then cloned into modified XW55 yeast dual expression vector ${ }^{65}$ in the

598 highlighted SpeI and PmlI sites downstream of the ADH2 promoter by yeast recombinase

599 technology [protocolYeastmaker ${ }^{\mathrm{TM}}$ YeastTransformation System 2 (Clontech)] and according to

600 the manufacturer's instructions. The generated yeast expression vector was transformed into $S$. 
601

602

603

604

605

606

607

608

609

610

611

612

613

614

615

616

617

618

619

620

621

622

623

cerevisiae strain BJ5464 using protocol Yeastmaker ${ }^{\mathrm{TM}}$ Yeast Transformation System 2

(Clontech). The transformants were screened on yeast nitrogen base (YNB) medium lacking

uracil. S. cerevisiae transformed with empty plasmid was served as negative control.

Transformants were grown on YNB without uracil for 1-3 days then transformed into YPD medium for 3 days at $30^{\circ} \mathrm{C}$ with shaking. The expression of mucoricin was induced once the glucose was exhausted from the medium and yielded a recombinant mucoricin that was both $6 \mathrm{x}$ His- and Flag-tagged. Purification of the recombinant mucoricin was performed by Ni-NTA matrix affinity purification according to the manufacturers' instructions (Sigma-Aldrich). The purity of the protein was confirmed by SDS-PAGE and quantified by a modified Lowry protein assay (Pierce).

Anti-mucoricin and anti-ricin antibodies. Rabbit and mouse monoclonal antibodies against recombinant mucoricin coupled to KLH were raised by ProMab Biotechnologies Inc. ${ }^{11}$. The IgG fraction was purified from the antisera using protein A/G spin column (Thermo Fisher Scientific) according to the manufacturer's instructions. Normal IgG was purified from the sera of nonimmunized rabbits and used as a control. Rabbit and monoclonal antibodies against ricin and ricin B chain were prepared as described previously ${ }^{27,30}$. Hybridoma cells producing antimuroricin antibodies were propagated in WHEATON CELLine bioreactor 350 using protein-free hybridoma medium $1 \times(\mathrm{Gibco})$ for 5 to 7 days at $37^{\circ} \mathrm{C}$ in $5 \% \mathrm{CO}_{2}$. The antibody-containing supernatant was collected and purified using protein G spin columns (Thermo Fisher Scientific). Eluted purified IgG were dialyzed in PBS using a dialysis cassette (Thermo Fisher Scientific), and the purity of the antibodies was confirmed by SDS-PAGE prior to determining the concentration using the Bradford protein assay (Bio rad, Hercules, CA). Endotoxin levels were 
624

625

626

627

628

629

630

631

632

633

634

635

636

637

638

639

640

641

642 643 once.

644

645

646

measured by the Limulus Amebocyte Lysate (LAL) kit (Charles River) and determined to be $<0.8 \mathrm{EU} / \mathrm{ml}$ which is below the $5 \mathrm{EU} / \mathrm{kg}$ body weight set for intraperitoneal injection ${ }^{66}$.

Mouse monoclonal antibody clone 8A1 was raised against the ricin B chain ${ }^{30}$, which has $33 \%$ sequence identify with mucoricin. Clone $8 \mathrm{~A} 1$ recognizes an epitope mapped to ricin B chain $(2 \gamma$, amino acids 221-262).

Cell damage assay. The damage of epithelial cell [A549 and Primary (ScienCell, Cat \# 3200)] and HUVECs was quantified using a ${ }^{51}$ Cr-release assay ${ }^{67}$. Briefly, confluent cells grown in 24well tissue culture plates were incubated with $1 \mu \mathrm{Ci} /$ well $\mathrm{Na}_{2}{ }^{51} \mathrm{CrO}_{4}(\mathrm{ICN}$ ) in $\mathrm{F} 12 \mathrm{~K}$-medium (for epithelial cells) or M-199 medium (HUVECs) for $16 \mathrm{~h}$. On the day of the experiment, the media was aspirated, and cells were washed twice with pre-warmed Hanks' balanced salt solution (HBSS, ScienCell). Cells were treated with toxin suspended in either $1 \mathrm{ml}$ of F12K-medium (for epithelial cells) or RPMI 1640 medium (for endothelial cells) supplemented with glutamine and incubated at $37^{\circ} \mathrm{C}$ in a $5 \% \mathrm{CO}_{2}$ incubator. Spontaneous ${ }^{51} \mathrm{Cr}$ release was determined by incubating the untreated cells in the same volume of the culture medium supplemented with glutamine. At different time points, and after data were corrected for variations in the amount of tracer incorporated in each well, the percentage of specific cell release of ${ }^{51} \mathrm{Cr}$ was calculated as follows: $[($ experimental release $)-($ spontaneous release $)] /[1-(\text { spontaneous release })]^{68}$. Each experimental condition was tested at least in triplicate, and the experiment was repeated at least

In some experiments, the effect of mucoricin gene silencing on damage to HUVECs or A549 cells was measured by incubating $1.0 \times 10^{6} / \mathrm{ml}$ or $2.5 \times 10^{5} / \mathrm{ml}$ spores of $R$. delemar and incubated for 6 or $48 \mathrm{~h}$, respectively. In other experiments the protective effect of IgG anti- 
647 mucoricin was measured by incubating the fungal cells with either $50 \mu \mathrm{g} / \mathrm{ml}$ of IgG anti-

648

649

650

651

652

653

654 662 above.

663

664

665 h.

mucoricin or normal rabbit $\mathrm{IgG}$ ( $\mathrm{R} \& \mathrm{D}$ Systems, Cat \# AB-105-C) for $1 \mathrm{~h}$ on ice prior to adding the mixture to A549 cells radiolabeled with ${ }^{51} \mathrm{Cr}$. The assay was carried out for $48 \mathrm{~h}$. The amount of damage was quantified as above.

To study the effect of fungal cell viability on host cell damage, fungal spores $\left(10^{6} / \mathrm{ml}\right)$ were cultured in $\mathrm{F} 12 \mathrm{~K}$ media and left to grow overnight at $37^{\circ} \mathrm{C}$. The fungal hyphae were collected by filtration, dried by padding with a sterile filter paper, weighed and then aseptically cut into four equal small pieces of $0.1 \mathrm{mg}$ wet weight. The fungal hyphal matt was suspended in $1 \mathrm{ml} \mathrm{F} 12 \mathrm{~K}$ and heated at $60^{\circ} \mathrm{C}$ in a water bath for $4 \mathrm{~h}$ and then cooled down. To check the viability of the hyphal matt, a loop full of the hyphae was plated on PDA plates. The other two groups of fungal hyphae were suspended in preheated and cooled in F12K culture media. Another group of $\mathrm{F} 12 \mathrm{~K}$ culture media was prepared by heating at $60^{\circ} \mathrm{C}$ and then cooled to represent spontaneous control. The fungal samples were incubated with ${ }^{51} \mathrm{Cr}$-labelled A549 alveolar epithelial cells previously seeded into 24 -well plates as above and the damage assay was carried out for $24 \mathrm{~h}$ at $37^{\circ} \mathrm{C}$ and the amount of ${ }^{51} \mathrm{Cr}$ released in the supernatant was measured as

To determine whether IgG anti-mucoricin protected cells against ricin-induced damage, 5 $\mu \mathrm{g} / \mathrm{ml}(\sim 77 \mathrm{nM})$ of ricin was incubated with either $10 \mu \mathrm{g} / \mathrm{ml}$ of the monoclonal $\mathrm{IgG}$ anti-ricin B chain (clone 8A1) ${ }^{69}, 10 \mu \mathrm{g} / \mathrm{ml}$ of IgG anti-mucoricin, or normal rabbit IgG (R \& D Systems, Cat \# AB-105-C) or $10 \mathrm{mM}$ of galactose on ice for $1 \mathrm{~h}$ prior to adding to ${ }^{51} \mathrm{Cr}$-labelled confluent A549 alveolar epithelial cells in 24-well plate. The damage assay was conducted as above for 24 
670 Western blotting. Hyphal expression of mucoricin was determined in R. delemar wild-type, or

671 RNAi mutants from hyphal matt grown for overnight at $37^{\circ} \mathrm{C}$ in YNB without uracil medium ${ }^{70}$.

672 Briefly, mycelia were collected by filtration, washed briefly with PBS, and then ground

673 thoroughly in liquid nitrogen using mortar and pestle for $3 \mathrm{~min}$. The ground powder was

674 immediately transferred to microfuge tube containing $500 \mu 1$ extraction buffer which consisted of

$67550 \mathrm{mM}$ Tris-HCl, pH 7.5, $150 \mathrm{mM} \mathrm{NaCl}, 10 \mathrm{mM} \mathrm{MgCl}_{2}$. The extraction buffer was

676 supplemented with 1X Halt Protease Inhibitor Cocktails (Thermo Scientific) and $1 \mathrm{mM}$

677 phenylmethylsulfonyl fluoride (PMSF). The sample was vortexed vigorously for $1 \mathrm{~min}$, then

678 centrifuged for $5 \mathrm{~min}$ at $21000 \mathrm{~g}$ at $4^{\circ} \mathrm{C}$. The supernatant was filtered with PES syringe filters

679 (Bioland Scientific, Cat\# SF01-02) and transferred to a new tube and the protein concentration

680 determined using Bradford method.

For Western blotting, $10 \mu \mathrm{g}$ of each sample was used to separate proteins on an SDS-

682 PAGE. Separated proteins were transferred to PVDF membranes (GE Water \& Process

683 Technologies) and treated with Western blocking reagent (Roche) for overnight at $4^{\circ} \mathrm{C}$. The IgG

684 anti-mucoricin $(2 \mu \mathrm{g} / \mathrm{ml})$ and the murine $8 \mathrm{~A} 1$ monoclonal anti-ricin B chain were used as

685 primary antibodies. After 1 h, $0.5 \mu \mathrm{g} / \mathrm{ml}$ of HRP- IgG anti-rabbit IgG (Jackson ImmunoResearch,

686 Product number 111-035-144) (when rabbit IgG anti-mucoricin was used as a primary) or HRP-

687 IgG anti-mouse (Invitrogen, Cat \#31450) (when murine 8A1 antibody anti-ricin B chain used as

688 a primary) secondary antibodies (Jackson Immuno Research) were added for another $1 \mathrm{~h}$ at room

689 temperature. Mucoricin bands were visualized by adding the HRP substrate (SuperSignal West

690 Dura Extended Duration Substrate, Thermo Scientific), and the chemiluminescent signal was

691 detected using an In-gel Azure Imager c400 fluorescence system (Azure Biosystems). The

692 intensity of the bands was quantified by ImageJ software. 
To examine the cross reactivity of ricin with $\mathrm{IgG}$ anti-mucoricin, $5 \mu \mathrm{g}$ of ricin $(77 \mathrm{pmol})$ or recombinant mucoricin (294 pmol) were submitted to SDS-PAGE under reducing and denaturing conditions. Western blotting was conducted as above using IgG anti-mucoricin as a primary

696 followed by HRP- IgG anti-rabbit IgG as secondary (Jackson ImmunoResearch, Product number 111-035-144).

698

Gene expression analysis. Expression of the mucoricin gene was studied in R. delemar as spores $\left(10^{3} / \mathrm{ml}\right)$ germinated into hyphae in YPD medium for $16 \mathrm{~h}$ at $37^{\circ} \mathrm{C}$. At selected times, cells or mycelia were collected by centrifugation, followed by filtration using $0.22 \mu \mathrm{m}$ membrane units. The cells were washed once with PBS, and ground in liquid nitrogen using mortar and pestle. RNA was extracted using RNeasy Plant Mini kit (Qiagen). To quantify the expression of the mucoricin gene in response to host cells, fungal spores $\left(10^{6} / \mathrm{ml}\right)$ were incubated with either epithelial, HUVECs or human erythrocytes in 24-well plate using F12K, RPMI, or PBS, respectively. The fungal cells were collected at different time intervals including zero, 2 and $5 \mathrm{~h}$

707 and directly ground with liquid nitrogen followed by RNA extraction using RNeasy Plant Mini

708 Kit. Contaminating genomic DNA was removed from RNA samples by treatment with $1 \mu 1$ of

709 Turbo-DNase (Ambion) for $30 \mathrm{~min}$ at room temperature. DNase was then removed using an

710 RNA Clean-Up kit (Zymo Research). First-strand cDNA synthesis was performed using the

711 Retroscript first-strand synthesis kit (Ambion). Toxin specific primers were designed with the

712 assistance of online primer design software (Genscript). Mucoricin gene primers include G7F1;

714 amplification efficiency was determined by serial dilution experiments, and the resulting 715 efficiency coefficient was used for the quantification of the products ${ }^{71}$. Gene expression was 
716

717

718

719

720

721

722

723

724

725

726

727

728

729

730

731

732

733

734

735

736

737

738

analyzed by an ABI Prism 7000 Sequence Detection System (Applied Biosystems) using the QuantiTect Sybr Green PCR kit (Qiagen). PCR conditions were $10 \mathrm{~min}$ at $90^{\circ} \mathrm{C}$ and 40 cycles of $15 \mathrm{~s}$ at $95^{\circ} \mathrm{C}$ and $1 \mathrm{~min}$ at $60^{\circ} \mathrm{C}$. Single PCR products were confirmed with the heat dissociation protocol at the end of the PCR cycles. The amount of gene expression was normalized to actin [ACT1-RT5'; 5'-TGAACAAGAAATGCAAACTGC-3' and ACT1-RT3'; 5'-

CAGTAATGACTTGACCATCAGGA-3'] and then quantified using the $2(-\Delta \Delta C(T))$ method ${ }^{72}$. All reactions were performed in triplicate, and the mixture included a negative no-reverse transcription (RT) control in which reverse transcriptase was omitted.

In vitro apoptosis/necrosis assay. A549 lung epithelial cells were grown to confluency on fibronectin-coated circular glass coverslips in 24-well tissue culture plates and then incubated with $50 \mu \mathrm{g} / \mathrm{ml}(2.9 \mu \mathrm{M})$ mucoricin or $5 \mu \mathrm{g} / \mathrm{ml}(77 \mathrm{nM})$ ricin (concentrations shown to cause in vitro damage to alveolar epithelial cells [Fig. 3f]) for 2 hours after which the cells were washed and stained with 1x Apoxin Green Indicator and 1x 7-AAD (Apoptosis/Necrosis detection kit, Abcam) for 45 min. The cells were fixed and mounted in ProLong Gold antifade containing DAPI (Life Technologies) to visualize cells. Microscopic z-stack pictures were taken using a Leica SP8confocal laser scanning platform. Apoptotic cells $v$ s. necrotic cells were identified by their green and red fluorescence, respectively. The number of apoptotic and necrotic events per high-power field (HPF) was determined, counting 10 HPF per coverslip. The experiment was performed three times in triplicate.

In vitro protein translation assay. The ability of the two toxins to inhibit protein synthesis was measured by using a modification of a previously described method ${ }^{33}$. Briefly, a rabbit 
739

740

741

742

743

744

745

746

747

748

749

750

751

752

753

754

755

756

757

758

759

760

761

reticulocyte lysate (Promega, Cat: $\mathrm{L} 4151)$ was thawed at $37^{\circ} \mathrm{C}$ immediately before use and supplemented with $40 \mu \mathrm{l}$ of $1 \mathrm{mM}$ hemin stock solution and $10 \mu \mathrm{l}$ of $1 \mathrm{M}$ creatine phosphate (Sigma-Aldrich, Cat: 27920) and $10 \mu \mathrm{l}$ of $5 \mathrm{mg} / \mathrm{ml}$ creatine phosphokinase (Sigma-Aldrich, Cat:C7886) before the lysate had fully thawed. The reaction mixture was prepared into 96-well plates as follows: $1 \mu \mathrm{l}$ of $1 \mathrm{mM}$ amino acid mixture minus methionine (Promega, Cat: L9961), $35 \mu \mathrm{l}$ of rabbit reticulocyte lysate, $1 \mu \mathrm{l}$ of 7 -fold dilutions of ricin, mucoricin, control OVA, or cycloheximide (Fisher Scientific, Cat: AC357420010). Diluted distilled water was added to a final volume of $48 \mu \mathrm{l}$. Two replicates were employed in all experiments and the experiments were repeated at least three times. After a pre-incubation period of $30 \mathrm{~min}$ at $37^{\circ} \mathrm{C}, 2 \mu{ }^{35} \mathrm{~S}$ Methionine (1,200 Ci/mmol) (PerkinElmer) was added to a final volume of $50 \mu \mathrm{l}$. The 96-well plate was incubated at $30^{\circ} \mathrm{C}$ for $60 \mathrm{~min}$. Two $\mu \mathrm{l}$ from each well was added per well of a 24 -well plate containing $98 \mu \mathrm{l}$ of $0.5 \mathrm{M} \mathrm{H}_{2} \mathrm{O}_{2}$. Proteins were precipitated with $900 \mu \mathrm{l}$ of $25 \%$ trichloroacetic acid (TCA) before harvesting precipitates on Whatman filter strips (SigmaAldrich, Cat: WHA1823035). Filter paper disks were placed in Biofluor scintillation fluid (Perkin Elmer, Cat: 6013329), and $\left[{ }^{35} \mathrm{~S}\right]$ Methionine incorporation was quantitated by scintillation counting. Background counts determined from well containing all reagents without rabbit reticulocyte lysate were subtracted from all CPMs.

The depurination activity assay of mucoricin. The depurination activity of mucoricin was measured by the release of adenine when mammalian RNA was treated with mucoricin for $24 \mathrm{~h}$ at $37^{\circ} \mathrm{C}^{32}$. Mammalian RNA extracted from A549 alveolar epithelial cells by Qiagen RNasy mini kits according to manufacturer's instruction were treated with $20 \mu \mathrm{g} / \mathrm{ml}$ of mucoricin in $0.01 \mathrm{M}$ HEPES/10 mM ammonium acetate buffer containing $1 \mathrm{mg} / \mathrm{ml} \mathrm{BSA} \mathrm{for} 24 \mathrm{~h}$ at $37^{\circ} \mathrm{C}$. The solution 
762

763

764

765

766

767

768

769

770

771

772

773

774

775

776

777

778

779

780

781

782

783

784

was then filtered through a $10 \mathrm{kDa}$ size exclusion column and $40 \mu \mathrm{l}$ was injected into HPLC using Phenomenex Luna C18 reverse phase column $(10 \times 250 \mathrm{~mm})$ attached to a Varian ProStar HPLC 218 system (Varian, Walnut Creek, CA). Solvent A was $20 \mathrm{mM}$ ammonium acetate, and solvent B was $100 \%$ acetonitrile. The column gradient was as follows: $97 \%$ to $60 \%$ solvent A in 10 min at flow rate of $1 \mathrm{ml} / \mathrm{min}$. The column effluent was monitored at $260 \mathrm{~nm}$.

Glycosylase activity assay. The N-glycosylase activity of toxins were determined by using rabbit reticulocyte lysate ${ }^{73,74}$. Briefly, $40 \mu$ of lysate was incubated with ricin $(1 \mathrm{nM})$, mucoricin $(10 \mu \mathrm{M})$ or control OVA $(1 \mathrm{nM}$ or $10 \mu \mathrm{M})$ in the presence of $10 \mathrm{mM} \mathrm{MgCl}_{2}$ at $30^{\circ} \mathrm{C}$ for 1 or 4 hours. After the treatment, ribosomal protein was denatured by $50 \mathrm{mM}$ Tris/0.5\% SDS to release RNA. The RNA was purified by phenol-Tris extraction followed by ethanol precipitation. Half of each purified RNA sample was subjected to $2 \mathrm{M}$ aniline acetate ( $\mathrm{pH} 4.5)$ treatment for 10 minutes on ice, while the other half of RNA was incubated without aniline treatment. rRNA were further extracted using water saturated ether followed by ethanol precipitation. Three micrograms of each rRNA sample were resolved on 7 M Urea Polyacrylamide gel electrophoresis and RNA fragment bands were visualized by staining with ethidium bromide.

Transwell permeability assay ${ }^{75}$. HUVECs were seeded on 24-Corning transwell plate with permeable polyester inserts $(0.4 \mu \mathrm{m}$, Fisher) coated with fibronectin $(15 \mu \mathrm{g} / \mathrm{ml}$ in PBS, Fisher). HUVECs were grown to confluency in M-199 medium with phenol red. $R$. delemar spores $\left(10^{5}\right)$ in M-199 (without phenol red) were added to the upper chamber, and the plate was incubated for $5 \mathrm{~h}$ at $37^{\circ} \mathrm{C}$. As a positive control for the permeability of HUVECs, E. coli LPS (Sigma-Aldrich) was added at $2 \mu \mathrm{g} / \mathrm{ml}$ to uninfected HUVECs. Following incubation, $3 \mu \mathrm{l}$ of $50 \mathrm{mg} / \mathrm{ml}$ FITC- 
785 786

787

788

789

790

791

792

793

794

795

796

797

798

799

800

801

802

803

804

805

806

807

dextran-10K (Sigma) was added to the upper chamber of the trans-well and the migration of the dextran through the HUVEC monolayer to the lower trans-well was determined $1 \mathrm{~h}$ later by quantifying the concentration of the dye in the bottom chamber using florescence microplate reader at $490 \mathrm{~nm}^{75}$. To determine the direct effect of mucoricin on the permeability of the HUVEC monolayer, $50 \mu \mathrm{g} / \mathrm{ml}(2.9 \mu \mathrm{M})$ mucoricin or control OVA were added to the HUVECseeded wells instead of $R$. delemar. To determine the effect of antibodies on permeability induced by $R$. delemar or mucoricin, $50 \mu \mathrm{g} / \mathrm{ml}$ of normal rabbit IgG (R \& D Systems, Cat \# AB105-C), IgG anti-mucoricin, or $10 \mu \mathrm{g} / \mathrm{ml}$ of $\mathrm{IgG}$ anti-ricin toxin chain B (clone 8A1) were incubated for 30 min on ice with $R$. delemar spores or mucoricin prior to their addition to the upper chamber of the trans-well.

In vivo effects induced by mucoricin. To test the effect of the purified toxin in vivo, male (ICR mice, $27-32 \mathrm{~g}$ ) were immunosuppressed by intraperitoneal injection of $200 \mathrm{mg} / \mathrm{kg}$ of cyclophosphamide and subcutaneous injection of $250 \mathrm{mg} / \mathrm{kg}$ cortisone acetate on day -2 and +3 , relative to toxin injection. This regimen results in approximately 10 days of leucopenia with reduction in neutrophils, lymphocytes and monocytes as described previously ${ }^{76}$. Mouse gender has no effect on the pathogenesis of mucormycosis, or antifungal treatment as determined by an NIH Contract No. HHSN272201000038I/Task Order HHSN27200008, unpublished data. Mice were given irradiated food and sterile water containing $50 \mu \mathrm{g} / \mathrm{ml}$ baytril (Bayer) ad libitum. 100 $\mu l$ of purified mucoricin $(0.1 \mathrm{mg} / \mathrm{ml})$ was then injected into the tail vein on days $0,+2$, and +4 . The differences in survival between normal mice receiving vehicle (i.e. PBS) and those received toxin were compared by the Log Rank test. The primary efficacy endpoint was time to morbidity. 
Mouse tissues were fixed in $10 \% \mathrm{ZnCl}_{2}$ formalin solution prior to histopathological

809

810

811

812

813

814

815

816

817

818

819 examination. The fixed organs were dehydrated in graded alcohol solutions, embedded in paraffin, and 5- $\mu \mathrm{m}$ sections were cut and stained with $\mathrm{H} \& \mathrm{E}^{77}$. Cumulative histopathological scores of hemorrhages, neutrophil infiltration (inflammation), and edema were used to determine the effects of toxin by observing 5 fields per slide. The observer was not told the origin of the samples.

Mucoricin RNAi knockdown. RNAi knockdown of mucoricin was employed using our previously described RNAi method ${ }^{20}$. Briefly, a 330-bp mucoricin transcript was PCR amplified using 5'-AAATTTAAAAGCATGCACACACAAAAGTATGAAGATTGCT-3' and 5'CTGCTTACCATGGCGCGCCCAAATGGCACTAATTCCCAGC-3' primers and cloned into the $S p h \mathrm{I}$ and $A s c \mathrm{I}$ sites of pRNAi-pdc ${ }^{78}$. The inverted repeat fragment was PCR amplified by 5'TTAAGCGATCGCTAGCACACACAAAAGTATGAAGATTGCT-3' and 5'-

TTATTCTTATAGCCCGCGGCAAATGGCACTAATTCCCAGC-3' at cloned downstream the intro fragment at the NheI and SacII sites. The developed construct was transformed into $R$. delemar pyrF mutant (strain M16) ${ }^{55}$ using the biolistic delivery system (BioRad), and the homogenous transformants were selected on minimal medium lacking uracil ${ }^{11}$. The down regulation of mucoricin expression was confirmed by qRT-PCR using primers 5'-

CTTGGATATCCGTGGAGGTGA-3' and 5'-GGCAGCTTCTTCGACCATCT-3' as described before $^{12}$ and by confocal microscopy using immunostaining (see below) ${ }^{11}$.

Secretion/shedding of mucoricin into the culture supernatant. Wild-type $R$. delemar spores

( $2 \times 10^{4} / 100 \mu 1 /$ well), $R$. delemar transformed with the empty plasmid or those transformed with mucoricin RNAi were grown in 96-well plates for $24 \mathrm{~h}$ at $37^{\circ} \mathrm{C}$ followed by additional $24 \mathrm{~h}$ of 
832 incubation in the presence or absence of 2-fold serially diluted amphotericin B (0.06-32 $\mu \mathrm{g} / \mathrm{ml})$.

$833100 \mu \mathrm{l}$ of culture supernatant samples from each well were collected and stored at $-20^{\circ} \mathrm{C}$ until

834 used for toxin detection by ELISA. To determine corresponding fungal growth, $100 \mu \mathrm{l} /$ well XTT

835 substrate $(0.20 \mathrm{mg} / \mathrm{ml}$ activated with $6.25 \mu \mathrm{M}$ menadione $)$ was added to the remaining $R$.

836 delemar culture plate. ${ }^{79}$ After a $2 \mathrm{~h}$ incubation at $37^{\circ} \mathrm{C}$, absorbance at $450 \mathrm{~nm}$ was measured for

837 metabolized XTT. Sandwich ELISAs were used to detect and quantify mucoricin in the cell-free

838 supernatants. Briefly, 96-well plates were coated with $2 \mu \mathrm{g} / \mathrm{ml}$ mouse anti-R. delemar toxin

839 monoclonal antibodies at $4^{\circ} \mathrm{C}$ overnight. After washing the plate with $1 \mathrm{X}$ PBST $(\mathrm{PBS}+0.05 \%$

840 Tween-20) 5 times, diluted recombinant mucoricin or undiluted culture supernatant samples

841 were added to the ELISA plate. Bound mucoricin was detected by the IgG anti-toxin antibodies

$842(2 \mu \mathrm{g} / \mathrm{ml})$, and subsequently by HRP- IgG anti-rabbit IgG (Jackson ImmunoResearch, product

843 number 111-035-144) and a TMB substrate detection system (Invitrogen). A standard curve was

844 generated using linear regression of $\mathrm{OD}_{450}$ of known recombinant mucoricin concentrations and

845 the concentrations of toxin in the medium were extrapolated from the standard curve.

847 Confocal microscopy. IgG anti-toxin was used to localize the toxin in the Rhizopus fungus ${ }^{10}$.

848 Fungal spores $\left(10^{5} / \mathrm{ml}\right)$ were pre-germinated in YPD media at 1, 4, or $12 \mathrm{~h}$. Each fungal stage

849 was fixed in $4 \%$ paraformaldehyde followed by permeabilization for $10 \mathrm{~min}$ in $0.1 \%$ Triton X-

850 100. The permeabilized fungal growth stages were incubated with the IgG anti-toxin for $2 \mathrm{~h}$ at

851 room temperature. The fungal stages were then washed 3 times with Tris-buffered saline (TBS,

$8520.01 \mathrm{M}$ Tris $\mathrm{HCl}[\mathrm{pH} 7.4], 0.15 \mathrm{M} \mathrm{NaCl}$ ) containing $0.05 \%$ Tween 20 and counterstained with

853 anti-rabbit IgG Alexa Fluor 488 (Life Technologies, Cat \# A-11034). The stained fungi were

854 imaged with Leica confocal microscope at excitation wavelength of $488 \mathrm{~nm}$. The final confocal 
855 images were produced by combining optical sections taken through the $\mathrm{z}$ axis.

In vivo virulence studies and immunohistochemistry. Male ICR mice ( $\geq 20 \mathrm{~g})$ were rendered

858 DKA with a single intraperitoneal injection of $210 \mathrm{mg} / \mathrm{kg}$ streptozotocin in $0.2 \mathrm{ml}$ citrate buffer

85910 days prior to fungal challenge. On days -2 and +3 relative to infection, mice were given a

860 dose of cortisone acetate $(250 \mathrm{mg} / \mathrm{kg})$. Diabetic ketoacidotic (DKA) mice were given irradiated

861 food and sterile water containing $50 \mu \mathrm{g} / \mathrm{ml}$ Baytril (Bayer) ad libitum. DKA mice were infected

862 intratracheally with fungal spores with a target inoculum of $2.5 \times 10^{5}$ spores of RNAi-empty

863 plasmid (Control strain) or RNAi-mucoricin (targeting mucoricin gene expression) in $25 \mu 1$. To

864 confirm the fidelity of the inoculum, three mice were sacrificed immediately after inoculation,

865 their lungs were homogenized in PBS and quantitatively cultured on PDA plates containing $0.1 \%$

866 triton, and colonies were counted after a 24-hour incubation period at $37^{\circ} \mathrm{C}$. Average inhaled

867 inoculum for RNAi-empty plasmid and RNAi-mucoricin were $8.6 \times 10^{3}$ and $3.3 \times 10^{3}$ spores

868 from two experiments, respectively. Primary endpoint was time to moribundity analyzed by

869 Kaplan Meier plots. In another experiment, DKA mice were infected as above and then

870 sacrificed on Day +4 relative to infection, when their lungs and brains (primary and secondary

871 target organs) were collected and processed for determination of tissue fungal burden by $\mathrm{qPCR}^{21}$.

872 The ability of the IgG anti-toxin to protect against Rhizopus infection was also evaluated in the

873 DKA mouse model. Briefly, DKA mice were infected with $R$. delemar 99-880 as above (average

874 inhaled inoculum of $5.6 \times 10^{3}$ spores from two experiments) and $24 \mathrm{~h}$ later were injected

875 intraperitoneally with either a $30 \mu \mathrm{g}$ of $\mathrm{IgG}$ anti-toxin or normal rabbit IgG (R \& D Systems, Cat

876 \# AB-105-C). The survival of mouse and tissue fungal burden of target organs collected on Day

$877+4$ post infection served as endpoints as above. Furthermore, histopathological examination was 
878 carried out on sections of the organs harvested on Day +4 post infection. These organs were

879 fixed in $10 \%$ zinc formalin and processed as above for histological examination with H\&E, PAS 880 or Grocott staining.

Apoptotic cells in the lung were detected by immunohistochemistry using the ApopTag in situ apoptosis detection kit (EMD Millipore) following the manufacturer's directions. Briefly,

883 paraffin-embedded sections were rehydrated in Histo-Clear II (National Diagnostics) and

884 alcohols followed by washing with phosphate-buffered saline (PBS). The sections were pre-

885 treated with $20 \mu \mathrm{g} / \mathrm{ml}$ Proteinase K (Ambion) in PBS for $15 \mathrm{~min}$ at room temperature.

886 Endogenous peroxidases were blocked by incubation of the slides for $15 \mathrm{~min}$ in $3 \%$ hydrogen

887 peroxide. Sections were incubated with equilibration buffer (EMD Millipore) for $30 \mathrm{sec}$ at RT,

888 followed by terminal deoxynucleotidyl transferase (TdT; EMD Millipore) at $37^{\circ} \mathrm{C}$ for $1 \mathrm{~h}$.

889 Sections were further exposed to anti-Digoxignenin for $30 \mathrm{~min}$ at RT, and the positive reaction

890 was visualized with DAB 3, 3-diaminobenzidine (DAB) substrate (Thermo Scientific). After

891 counterstaining the specimens with $0.5 \%$ methyl green (Sigma), they were imaged by bright field

892 microscopy. For quantification, apoptotic areas were quantified using PROGRES GRYPHAX

893 software (Jenoptik).

Immunofluorescence staining for mucoricin in human tissue samples. Paraffin-embedded

896 human lung tissue from a patient diagnosed with disseminated_mucormycosis ${ }^{9}$ or a patient with

897 proven invasive pulmonary aspergillosis were cut into $5 \mu \mathrm{m}$ sections that were then mounted

898 onto glass slides. Organ sections on slides were deparaffinized and rehydrated with an ethanol

899 gradient (100\%-70\%) followed by incubation of the slides in water and heat-induced antigen

900 retrieval in sodium citrate buffer $(10 \mathrm{mM}, \mathrm{pH}$ 6). Sections were blocked with $3 \%$ bovine serum 
901 albumin (BSA) in PBS (BSA-PBS), incubated for $1 \mathrm{~h}$ with 1:50 dilution of the IgG anti-

902 mucoricin in PBS, washed twice in PBS, stained with 1:500 dilution of the appropriate goat anti-

903 rabbit IgG Alexa Fluor ${ }^{\circledR} 488$ (Life Technologies, Cat \#A-11034) in 1x PBS, followed by DNA

904 staining with $1 \mu \mathrm{M}$ TOPRO-3 iodide (642/661; Invitrogen) and staining of the fungal hyphae

905 with $100 \mu \mathrm{g} / \mathrm{ml}$ Fluorescent Brightener 28 (Sigma-Aldrich, Cat \#475300). After washing with 1x

906 PBS, slides were mounted in Prolong Gold antifade media (Molecular Probes). Images were

907 acquired using a laser-scanning spectral confocal microscope (TCS SP8; Leica), LCS Lite

908 software (Leica), and a 40× Apochromat 1.25 NA oil objective using identical gain settings. A

909 low fluorescence immersion oil (11513859; Leica) was used, and imaging was performed at

910 room temperature. Serial confocal sections at $0.5 \mu \mathrm{m}$ steps within a $\mathrm{z}$-stack spanning a total

911 thickness of 10 to $12 \mu \mathrm{m}$ of tissue, and 3D images were generated using the LCS Lite software.

912 Corresponding tissue sections from the same area were also stained with hematoxylin and eosin.

914 Statistical analysis. The data was collected and graphed and statistically analyzed using

915 Microsoft Office 360 and Graph Pad 8.0 for Windows or Mac (GraphPad Software, La Jolla,

916 CA, USA). Cell damage and gene expression were analyzed using one-way analysis of variance

917 (ANOVA) using Dunnett's Multiple Comparison Test. The non-parametric log-rank test was

918 used to determine differences in mouse survival times. Differences in tissue fungal burdens were

919 compared by the non-parametric Wilcoxon rank sum test for multiple comparisons. $P<0.05$ was

920 considered as significant. All in vitro experiments were performed at least in triplicate and

921 replicated at least once. 
923 Study approval. All procedures involving mice were approved by the IACUC of The Lundquist

924 Institute for Biomedical Innovations at Harbor-UCLA Medical Center, according to the NIH

925 guidelines for animal housing and care. Human endothelial cell collection was approved by the

926 IRB of The Lundquist Institute for Biomedical Innovations at Harbor-UCLA Medical Center.

927 Because umbilical cords are collected without donor identifiers, the IRB considers them medical

928 waste not subject to informed consent. The purification and testing of ricin were approved by the

929 IRB at UT Southwestern and carried out under BSL3 guidelines. Approval for the collection of

930 tissue samples from the patients with mucormycosis and invasive pulmonary aspergillosis was

931 obtained and the Ethics Committee of the University Hospital of Heraklion, Crete, Greece

932 (5159/2014). The patients provided written informed consent in accordance with the Declaration

933 of Helsinki.

935 Data availability. Source data are provided with this paper. 


\section{References}

9391 Gleissner, B., Schilling, A., Anagnostopolous, I., Siehl, I. \& Thiel, E. Improved outcome (2004).

9422 Kauffman, C. A. Zygomycosis: reemergence of an old pathogen. Clin Infect Dis 39, 588590 (2004).

9443 Kontoyiannis, D. P., Wessel, V. C., Bodey, G. P. \& Rolston, K. V. Zygomycosis in the 1990s in a tertiary-care cancer center. Clin Infect Dis 30, 851-856 (2000). of mould infections in hematopoietic stem cell transplant recipients. Clin Infect Dis 34,

9516 Spellberg, B., Edwards Jr., J. \& Ibrahim, A. Novel perspectives on mucormycosis: 909-917 (2002).

9537 Neblett Fanfair, R. et al. Necrotizing cutaneous mucormycosis after a tornado in Joplin,

954 Missouri, in 2011. N Engl J Med 367, 2214-2225, doi:10.1056/NEJMoa1204781 (2012).

9558 Tribble, D. R. \& Rodriguez, C. J. Combat-Related Invasive Fungal Wound Infections.

956 Curr Fungal Infect Rep 8, 277-286, doi:10.1007/s12281-014-0205-y (2014).

9579 Andrianaki, A. M. et al. Iron restriction inside macrophages regulates pulmonary host

958 defense against Rhizopus species. Nature communications 9, 3333-3333,

959 doi:10.1038/s41467-018-05820-2 (2018).

96010 Liu, M. et al. The endothelial cell receptor GRP78 is required for mucormycosis

961 pathogenesis in diabetic mice. J Clin Invest 120, 1914-1924, doi:42164

962 [pii]10.1172/JCI42164.

96311 Gebremariam, T. et al. CotH3 mediates fungal invasion of host cells during

964 mucormycosis. J Clin Invest 124, 237-250, doi:10.1172/JCI71349 (2014).

96512 Gebremariam, T. et al. Bicarbonate correction of ketoacidosis alters host-pathogen 966 interactions and alleviates mucormycosis. J Clin Invest, doi:10.1172/JCI82744 (2016). 
967

968

969

970

971

972

973

974

$975 \quad 16$

976

977

978

979

980

$981 \quad 18$

982

983

984

985

986

987

988

989

990

991

992

993

994

995

996

13 Ibrahim, A. S., Spellberg, B., Avanessian, V., Fu, Y. \& Edwards, J. E., Jr. Rhizopus oryzae adheres to, is phagocytosed by, and damages endothelial cells in vitro. Infect Immun 73, 778-783 (2005).

14 Bozza, W. P., Tolleson, W. H., Rivera Rosado, L. A. \& Zhang, B. Ricin detection: Tracking active toxin. Biotechnology Advances 33, 117-123, doi:http://dx.doi.org/10.1016/j.biotechadv.2014.11.012 (2015).

15 Bradshaw, T. A user's guide: introduction to peptide and protein HPLC, $\langle$ http://www.phenomenex.com/lib/4672_Intro2Peptide_Protein_Guide.pdf $>$ (2006).

16 Chibucos, M. C. et al. An integrated genomic and transcriptomic survey of mucormycosis-causing fungi. Nat Commun 7, 12218, doi:10.1038/ncomms12218 (2016).

17 Schwartze, V. U. et al. Gene expansion shapes genome architecture in the human pathogen Lichtheimia corymbifera: an evolutionary genomics analysis in the ancient terrestrial mucorales (Mucoromycotina). PLoS Genet 10, e1004496, doi:10.1371/journal.pgen.1004496 (2014).

18 Lee, S. C. et al. Analysis of a Food-Borne Fungal Pathogen Outbreak: Virulence and Genome of a Mucor circinelloides Isolate from Yogurt. mBio 5, e01390-01314, doi:10.1128/mBio.01390-14 (2014).

19 Ma, L. J. et al. Genomic analysis of the basal lineage fungus Rhizopus oryzae reveals a whole-genome duplication. PLoS Genet 5, e1000549, doi:10.1371/journal.pgen.1000549 (2009).

20 Ibrahim, A. S. et al. The high affinity iron permease is a key virulence factor required for Rhizopus oryzae pathogenesis. Mol Microbiol 77, 587-604, doi:10.1111/j.13652958.2010.07234.x (2010).

21 Luo, G. et al. Efficacy of liposomal amphotericin B and posaconazole in intratracheal models of murine mucormycosis. Antimicrob Agents Chemother 57, 3340-3347, doi:10.1128/AAC.00313-13 (2013).

22 Liu, H. et al. Functional convergence of gliP and aspf1 in Aspergillus fumigatus pathogenicity. Virulence 9, 1062-1073, doi:10.1080/21505594.2018.1482182 (2018).

23 Medzhitov, R., Schneider, D. S. \& Soares, M. P. Disease tolerance as a defense strategy. Science (New York, N.Y.) 335, 936-941, doi:10.1126/science.1214935 (2012). 
Endo, Y. \& Tsurugi, K. RNA N-glycosidase activity of ricin A-chain. Mechanism of action of the toxic lectin ricin on eukaryotic ribosomes. J Biol Chem 262, 8128-8130 (1987).

25 Baluna, R., Rizo, J., Gordon, B. E., Ghetie, V. \& Vitetta, E. S. Evidence for a structural motif in toxins and interleukin-2 that may be responsible for binding to endothelial cells and initiating vascular leak syndrome. Proceedings of the National Academy of Sciences 96, 3957-3962, doi:10.1073/pnas.96.7.3957 (1999).

26 Baluna, R., Coleman, E., Jones, C., Ghetie, V. \& Vitetta, E. S. The effect of a monoclonal antibody coupled to ricin A chain-derived peptides on endothelial cells in vitro: insights into toxin-mediated vascular damage. Exp Cell Res 258, 417-424, doi:10.1006/excr.2000.4954 (2000).

27 Baluna, R. \& Vitetta, E. S. An in vivo model to study immunotoxin-induced vascular leak in human tissue. J Immunother 22, 41-47, doi:10.1097/00002371-199901000-00006 (1999).

28 Earl, R. \& D., R. J. Structure of ricin B-chain at 2.5 Å resolution. Proteins: Structure, Function, and Bioinformatics 10, 260-269, doi:doi:10.1002/prot.340100310 (1991).

29 Schrot, J., Weng, A. \& Melzig, M. F. Ribosome-inactivating and related proteins. Toxins 7, 1556-1615, doi:10.3390/toxins7051556 (2015).

30 Rong, Y. et al. Spatial location of neutralizing and non-neutralizing B cell epitopes on domain 1 of ricin toxin's binding subunit. PLOS ONE 12, e0180999, doi:10.1371/journal.pone.0180999 (2017).

31 Walsh, M. J., Dodd, J. E. \& Hautbergue, G. M. Ribosome-inactivating proteins: potent poisons and molecular tools. Virulence 4, 774-784, doi:10.4161/viru.26399 (2013).

32 Becher, F., Duriez, E., Volland, H., Tabet, J. C. \& Ezan, E. Detection of Functional Ricin by Immunoaffinity and Liquid Chromatography-Tandem Mass Spectrometry. Analytical Chemistry 79, 659-665, doi:10.1021/ac061498b (2007).

33 Press, O. W., Vitetta, E. S. \& Martin, P. J. A simplified microassay for inhibition of protein synthesis in reticulocyte lysates by immunotoxins. Immunol Lett 14, 37-41, doi:10.1016/0165-2478(86)90017-9 (1986).

34 Fulton, R. J. et al. Purification of ricin A1, A2, and B chains and characterization of their toxicity. Journal of Biological Chemistry 261, 5314-5319 (1986). 
102835 Davis, C. T. et al. ARF6 inhibition stabilizes the vasculature and enhances survival during endotoxic shock. J Immunol 192, 6045-6052, doi:jimmunol.1400309

1030 [pii]10.4049/jimmunol.1400309.

1031

36 Licastro, F., Morini, M. C., Bolognesi, A. \& Stirpe, F. Ricin induces the production of

1032 tumour necrosis factor-alpha and interleukin-1 beta by human peripheral-blood mononuclear cells. Biochem J 294 ( Pt 2), 517-520, doi:10.1042/bj2940517 (1993).

1034

37 Korcheva, V. et al. Role of apoptotic signaling pathways in regulation of inflammatory

1035

1036 responses to ricin in primary murine macrophages. Mol Immunol 44, 2761-2771,

1037 doi:10.1016/j.molimm.2006.10.025 (2007).

1038

1039

1040

Alaux, P.-L., César, V., Naveau, F., Cranenbrouck, S. \& Declerck, S. Impact of Rhizophagus irregularis MUCL 41833 on disease symptoms caused by Phytophthora infestans in potato grown under field conditions. Crop Protection 107, 26-33,

1042 doi:https://doi.org/10.1016/j.cropro.2018.01.003 (2018). Paenibacillus elgii B69. FEMS Microbiology Letters 310, 32-38, doi:10.1111/j.15746968.2010.02040.x (2010).

1047

Sharma, N. et al. Isolation and characterization of an RIP (ribosome-inactivating protein)-like protein from tobacco with dual enzymatic activity. Plant Physiol 134, 171181, doi:10.1104/pp.103.030205 (2004).

1050

42

1051

Parkash, A., Ng, T. B. \& Tso, W. W. Isolation and characterization of luffacylin, a ribosome inactivating peptide with anti-fungal activity from sponge gourd (Luffa cylindrica) seeds. Peptides 23, 1019-1024, doi:10.1016/s0196-9781(02)00045-1 (2002).

43 Basu, D. et al. The A1 Subunit of Shiga Toxin 2 Has Higher Affinity for Ribosomes and Higher Catalytic Activity than the A1 Subunit of Shiga Toxin 1. Infect Immun 84, 149-

1055 161, doi:10.1128/iai.00994-15 (2016).

105644 Jackson, M. P., Deresiewicz, R. L. \& Calderwood, S. B. Mutational analysis of the Shiga 1057 toxin and Shiga-like toxin II enzymatic subunits. J Bacteriol 172, 3346-3350, doi:10.1128/jb.172.6.3346-3350.1990 (1990). 
1059

45

1060

1061

1062

1063

1064

1065

1066

1067

1068

1069

1070

1071

1072

1073

1074

1075

1076

1077

1078

1079

1080

1081

1082

1083

1084

1085

1086

1087

1088

1089

46 Narayanan, S., Surendranath, K., Bora, N., Surolia, A. \& Karande, A. A. Ribosome

Polito, L., Bortolotti, M., Mercatelli, D., Battelli, M. G. \& Bolognesi, A. Saporin-S6: a useful tool in cancer therapy. Toxins 5, 1698-1722, doi:10.3390/toxins5101698 (2013). inactivating proteins and apoptosis. FEBS Letters 579, 1324-1331, doi:https://doi.org/10.1016/j.febslet.2005.01.038 (2005).

47 Watkins, T. N. et al. Inhibition of EGFR Signaling Protects from Mucormycosis. mBio 9, e01384-01318, doi:10.1128/mBio.01384-18 (2018).

48 Alqarihi, A. et al. GRP78 and Integrins Play Different Roles in Host Cell Invasion during Mucormycosis. mBio 11, e01087-01020, doi:10.1128/mBio.01087-20 (2020).

49 Gonzalez, T. V., Farrant, S. A. \& Mantis, N. J. Ricin induces IL-8 secretion from human monocyte/macrophages by activating the p38 MAP kinase pathway. Mol Immunol 43, 1920-1923, doi:10.1016/j.molimm.2005.11.002 (2006).

50 Lindauer, M. L., Wong, J., Iwakura, Y. \& Magun, B. E. Pulmonary inflammation triggered by ricin toxin requires macrophages and IL-1 signaling. J Immunol 183, 14191426, doi:10.4049/jimmunol.0901119 (2009).

51 Yoder, J. M., Aslam, R. U. \& Mantis, N. J. Evidence for widespread epithelial damage and coincident production of monocyte chemotactic protein 1 in a murine model of intestinal ricin intoxication. Infect Immun 75, 1745-1750, doi:10.1128/IAI.01528-06 (2007).

52 Lee, S. C., Li, A., Calo, S. \& Heitman, J. Calcineurin Plays Key Roles in the Dimorphic Transition and Virulence of the Human Pathogenic Zygomycete Mucor circinelloides. PLOS Pathogens 9, e1003625, doi:10.1371/journal.ppat.1003625 (2013).

53 Lee, S. C. et al. Calcineurin orchestrates dimorphic transitions, antifungal drug responses and host-pathogen interactions of the pathogenic mucoralean fungus Mucor circinelloides. Mol Microbiol 97, 844-865, doi:10.1111/mmi.13071 (2015).

54 Spellberg, B. et al. The Deferasirox-AmBisome Therapy for Mucormycosis (DEFEAT Mucor) study: a randomized, double-blinded, placebo-controlled trial. J Antimicrob Chemother 67, 715-722, doi:dkr375 [pii]10.1093/jac/dkr375.

55 Skory, C. D. \& Ibrahim, A. S. Native and modified lactate dehydrogenase expression in a fumaric acid producing isolate Rhizopus oryzae 99-880. Curr Genet 52, 23-33, doi:10.1007/s00294-007-0135-0 (2007). 
109056 Jaffe, E. A., Nachman, R. L., Becker, C. G. \& Minick, C. R. Culture of human

1091 endothelial cells derived from umbilical veins. Identification by morphologic and

1092 immunologic criteria. J Clin Invest 52, 2745-2756 (1973).

$109357 \quad$ Farowski, F. et al. Quantitation of azoles and echinocandins in compartments of

1094 peripheral blood by liquid chromatography-tandem mass spectrometry. Antimicrobial

1095 agents and chemotherapy 54, 1815-1819, doi:10.1128/AAC.01276-09 (2010).

109658 Simmons, B. M. \& Russell, J. H. A single affinity column step method for the

1097 purification of ricin toxin from castor beans (Ricinus communis). Analytical

1098 Biochemistry 146, 206-210, doi:https://doi.org/10.1016/0003-2697(85)90417-8 (1985).

109959 Press, O. W., Vitetta, E. S. \& Martin, P. J. A simplified microassay for inhibition of

1100 protein synthesis in reticulocyte lysates by immunotoxins. Immunology Letters 14, 37-41,

1101 doi:https://doi.org/10.1016/0165-2478(86)90017-9 (1986).

110260 Bertoni, M., Kiefer, F., Biasini, M., Bordoli, L. \& Schwede, T. Modeling protein

1103 quaternary structure of homo- and hetero-oligomers beyond binary interactions by

1104 homology. Scientific reports 7, 10480-10480, doi:10.1038/s41598-017-09654-8 (2017).

110561 Guex, N., Peitsch, M. C. \& Schwede, T. Automated comparative protein structure modeling with SWISS-MODEL and Swiss-PdbViewer: a historical perspective. Electrophoresis 30 Suppl 1, S162-173, doi:10.1002/elps.200900140 (2009). TM-score. Nucleic Acids Res 33, 2302-2309, doi:10.1093/nar/gki524 (2005).

$111264 \mathrm{Fu}$, Y. et al. Cloning and functional characterization of the Rhizopus oryzae high affinity iron permease (rFTR1) gene. FEMS Microbiol Lett 235, 169-176, doi:10.1016/j.femsle.2004.04.031S0378109704002903 [pii] (2004). synthase product chain-length control by partnering thiohydrolase. ACS chemical biology 9, 1576-1586, doi:10.1021/cb500284t (2014).

111866 Malyala, P. \& Singh, M. Endotoxin limits in formulations for preclinical research. $J$ Pharm Sci 97, 2041-2044, doi:10.1002/jps.21152 (2008). 
67 Ibrahim, A. S. et al. Bacterial endosymbiosis is widely present among zygomycetes but does not contribute to the pathogenesis of mucormycosis. J Infect Dis 198, 1083-1090, doi:10.1086/591461 (2008).

112368 Ghannoum, M. A., Filler, S. G., Ibrahim, A. S., Fu, Y. \& Edwards, J. E., Jr. Modulation of interactions of Candida albicans and endothelial cells by fluconazole and amphotericin B. Antimicrobial agents and chemotherapy 36, 2239-2244, doi:10.1128/aac.36.10.2239 (1992).

69 Caillot, D. et al. Is It Time to Include CT "Reverse Halo Sign" and qPCR Targeting Mucorales in Serum to EORTC-MSG Criteria for the Diagnosis of Pulmonary Mucormycosis in Leukemia Patients? Open Forum Infect Dis 3, ofw190, doi:10.1093/ofid/ofw190 (2016). via Facilitating Iron Uptake from Ferrioxamine. PLoS Pathog 11, e1004842, doi:10.1371/journal.ppat.1004842 (2015).

71 Pfaffl, M. W. A new mathematical model for relative quantification in real-time RT-PCR. Nucleic Acids Res 29, e45 (2001).

Livak, K. J. \& Schmittgen, T. D. Analysis of relative gene expression data using realtime quantitative PCR and the 2(-Delta Delta C(T)) Method. Methods 25, 402-408,

114274 Tumer, N. E., Hwang, D. J. \& Bonness, M. C-terminal deletion mutant of pokeweed doi:10.1006/meth.2001.1262S1046-2023(01)91262-9 [pii] (2001). antiviral protein inhibits viral infection but does not depurinate host ribosomes. synthesis in rabbit reticulocyte lysate. European Journal of Biochemistry 193, 401-407, Proceedings of the National Academy of Sciences of the United States of America 94, 3866-3871, doi:10.1073/pnas.94.8.3866 (1997).

75 Gebremariam, T. et al. Preserving Vascular Integrity Protects Mice Against MultidrugResistant Gram-Negative Bacterial Infection. Antimicrobial Agents and Chemotherapy, AAC.00303-00320, doi:10.1128/aac.00303-20 (2020). aspergillosis. Antimicrob Agents Chemother 48, 1908-1911 (2004). 
115177 Kap, M. et al. Histological assessment of PAXgene tissue fixation and stabilization 1152 reagents. PloS one 6, e27704-e27704, doi:10.1371/journal.pone.0027704 (2011).

115378 Mertens, J. A., Skory, C. D. \& Ibrahim, A. S. Plasmids for expression of heterologous 1154 proteins in Rhizopus oryzae. Arch Microbiol 186, 41-50 (2006).

115579 Gebremariam, T. et al. Anti-CotH3 antibodies protect mice from mucormycosis by 1156 prevention of invasion and augmenting opsonophagocytosis. Science Advances $\mathbf{5}$, 1157 eaaw1327, doi:10.1126/sciadv.aaw1327 (2019). 


\section{Figure Legends}

1161 Figure 1. $R$. delemar toxin is sufficient to cause damage in vitro and in vivo. (a) The effect of

1162 toxin on different cell lines ( $\mathrm{n}=7$ wells /time point pooled from three independent experiments).

1163 Data are median \pm interquartile range. Statistical analysis was performed by using the non-

1164 parametric Mann-Whitney (two-tailed) test comparing HUVECs vs. primary alveolar epithelial

1165 cells or A549 alveolar cells. (b) Damage of extracted or recombinant toxin $(\sim 500 \mu \mathrm{g} / \mathrm{ml}$ or 29.4

$1166 \mu \mathrm{M})$ on epithelial cells at different time points ( $n=3$ wells/time point). Data are representative of

1167 three independent experiments and presented as median \pm interquartile range. (c) Mouse ( $n=3$

1168 mice/group) weight loss (data are median \pm interquartile range) and (d) percent survival ( $\mathrm{n}=3$

1169 mice/group) following intravenous injection with $0.1 \mathrm{mg} / \mathrm{ml}(5.9 \mu \mathrm{M})$ toxin QOD x 3. (e) Mouse

1170 organ H\&E histomicrographs showing the effects of the toxin. Livers showed necrosis (white

1171 arrow), infiltration and calcification of PMNs (black arrow) due to inflammation and a cluster of

1172 mononuclear cells (cyan arrow). Lungs showed megakaryocytes (black arrow) and hemorrhage

1173 (yellow arrow). Data in each group are representative of 2 mice. Scale bar $50 \mu \mathrm{m}$ for first liver

1174 micrograph and $100 \mu \mathrm{m}$ for all other. For lung micrographs scale bar $50 \mu \mathrm{m}$.

1175 Figure 2. Inhibition of $\boldsymbol{R}$. delemar toxin attenuates virulence of $\boldsymbol{R}$. delemar. (a) RNAi toxin

1176 shows reduced damage to A549 cells compared to wild type or empty plasmid $R$. delamar ( $\mathrm{n}=6$

1177 wells/group pooled from three independent experiments). Data are median \pm interquartile range.

1178 Statistical comparisons are by the non-parametric Mann-Whitney (two-tailed) test. (b) IgG anti-

1179 toxin antibodies reduced $R$. delemar-induced injury of A549 cells compared to $R$. delamar without

1180 IgG or normal rabbit $\operatorname{IgG}(\mathrm{n}=13$ wells/group pooled from three independent experiments). Data

1181 are median \pm interquartile range. Statistical comparisons are by the non-parametric Mann-Whitney

1182 (two-tailed) test. (c) RNAi toxin inhibition prolonged survival of mice ( $\mathrm{n}=18$ mice) compared to 
R. delamar with empty plasmid $(\mathrm{n}=17$ mice $)$. Data were pooled from two independent experiments. Survival data were analyzed by Log-rank (Mantel-Cox) test. (d) IgG anti-toxin prolonged survival of mice compared to normal rabbit $\operatorname{IgG}$ ( $\mathrm{n}=20$ mice/group). Data were pooled

1186 from two independent experiments. Survival data were analyzed by Log-rank (Mantel-Cox) test.

1187 (e) Histopathological sections of lungs from uninfected mice, (f) mice infected with the RNAi 1188 empty plasmid $R$. delemar strain showed hyphae and granulocyte infiltration (left panel, arrows) 1189 and angioinvasion (right panel, arrow), vs. (g) mild signs of inflammation and no angioinvasion 1190 for mice infected with RNAi toxin. (h) IgG anti-toxin group had normal lung tissue architecture. 1191 Data in e-h are representative of 3 mice and scale bar is $20 \mu \mathrm{m}$.

1192 Figure 3. R. delemar toxin and ricin share structural features. (a) R. delemar toxin has $29 \%$ 1193 amino acid sequence identity with ricin. Both toxins share similar motifs and molecular functions. 1194 (b) 3-D structure model of $R$. delemar toxin shows similarities to ricin B chain. Protein 3D 1195 structure models of $R$. delamar toxin and ricin chain B (amino acids 304-437, and 338-565) were 1196 aligned residue-to-residue based on structural similarity using heuristic dynamic programming 1197 iterations and sequence independent TM-align score (0-1) were calculated based on structural 1198 similarity. TM-align score $>0.5$ considered significant similarity. (c) IgG anti-R. delemar toxin 1199 binds to ELISA plates coated with either $R$. delemar toxin or ricin. (d) Ricin is recognized on a 1200 dot blot by IgG anti-R. delemar toxin. (e) Western blot of $R$. delemar toxin and ricin using $\operatorname{IgG}$ 1201 anti-R. delemar toxin IgG. (f) $\mathrm{IgG}$ anti-R. delemar toxin, $\mathrm{IgG}$ anti-ricin (8A1 clone) $(10 \mu \mathrm{g} / \mathrm{ml}$ 1202 each) or galactose $(10 \mathrm{mM})$ inhibit ricin $(77 \mathrm{nM})$-mediated A549 cell damage ( $\mathrm{n}=9$ wells for 1203 normal rabbit IgG and Anti-ricin toxin B chain (8A1) group, $\mathrm{n}=8$ for IgG anti-R. delemar toxin 1204 and galactose group pooled from three independent experiments). Data are median \pm interquartile 
range. Statistical comparisons were made by using the non-parametric Mann-Whitney (two-tailed)

test.

1207

1208

1209

1210

1211

1212

1213

1214

1215

1216

1217

1218

1219

1220

1221

1222

1223

1224

1225

1226

1227

Figure 4. $R$. delemar toxin and ricin have functional similarities. (a,b) Cell-free rabbit reticulocyte assay showing protein synthesis inhibition by ricin $\left(\mathrm{IC}_{50}\right.$ of $\left.2.2 \times 10^{-11} \mathrm{M}\right)(\mathbf{a})$ and $R$. delemar toxin $\left(\mathrm{IC}_{50}\right.$ of $\left.1.7 \times 10^{-8} \mathrm{M}\right)$ (b). Data ( $\mathrm{n}=7$ wells/concentrations for ricin; and $\mathrm{n}=6$ wells/concentration for $R$. delemar toxin, pooled from three experiments) are presented as median \pm interquartile range. (c) Representative HPLC chromatograms demonstrating the depurination activity of $R$. delemar toxin of A549 RNA at 3.6 min similar to adenine standard. (d) A representative gel (from three experiments) showing rRNA glycosidase activity of $R$. delemar toxin $(1 \mu \mathrm{M})$ compared to ricin $(1 \mathrm{nM})$ and control OVA $(1 \mathrm{nM}$ or $1 \mu \mathrm{M})$. Ribosomes were treated with ricin for $1 \mathrm{~h}$ or $R$. delemar toxin for $4 \mathrm{~h}$. Extracted RNA were treated with (+) or without (-) aniline prior to running the gel. Arrows point to endo fragment at $\sim 500 \mathrm{bp}$. (e, f) $R$. delemarinduces HUVEC permeability via its toxin. $R$. delemar $(\mathbf{e})$ or recombinant toxin $(2.9 \mu \mathrm{M})(\mathbf{f})$ were incubated with HUVEC for $5 \mathrm{~h}$ with or without $50 \mu \mathrm{g} / \mathrm{ml}$ of IgG isotype-matched or anti- $R$. delemar toxin or $10 \mu \mathrm{g} / \mathrm{ml}$ of IgG anti-ricin chain B (clone 8A1). LPS or OVA were added as a positive and negative controls, respectively. For e, $n=13$ wells except for IgG anti-ricin 8A1 which $\mathrm{n}=12$ wells pooled from three independent experiments. For $\mathbf{f}, \mathrm{n}=6$ wells for Ova, $\mathrm{n}=10$ wells for $R$. delamar toxin alone and $R$. delamar toxin $+\operatorname{IgG}$ anti-R. delmar toxin, $\mathrm{n}=11$ wells for $R$. delamar toxin + Isotype $\operatorname{IgG}, \mathrm{n}=12$ wells for $R$. delamar toxin $+\operatorname{IgG}$ anti-ricin (8A1), and $\mathrm{n}=13$ wells for HUVECs and LPS. Data in e and $\mathbf{f}$ were pooled from three independent experiments and presented as median \pm interquartile range. (g) Detection of apoptosis/necrosis of A549 cells incubated for 2 h with $50 \mu \mathrm{g} / \mathrm{ml}(2.9 \mu \mathrm{M})$ of $R$. delemar toxin or $5 \mu \mathrm{g} / \mathrm{ml}(77 \mathrm{nM})$ ricin. Apoptotic cells (closed triangle) were identified by green fluorescence while necrotic cells (open triangle) are shown in 
1228 red. Scale bar is $50 \mu \mathrm{m}$. (h) The number of apoptotic and necrotic events per high-power field

1229 (HPF) was determined, counting 10 HPF per coverslip. The data is combined from 3 independent

1230 experiments with each group in triplicate (total $n=9$ wells) and presented as median \pm interquartile

1231 range. Kruskal-wallis test was used to compare control vs. R. delamar toxin or ricin. 


\section{Extended Data Figures Legends}

\section{Extended Data Figure 1. A heat stable and hyphae-associated Mucorales extract damages}

mammalian host cells in vitro. (a) $R$. delemar caused time dependent alveolar epithelial cell damage ( $n=9$ wells/time point, pooled from three independent experiments). Data are median \pm interquartile range. (b) Heat-killed $R$. delemar hyphae showed $\sim 50 \%$ damage to mammalian cells compared to $\sim 100 \%$ damage caused by living hyphae ( $\mathrm{n}=6$ wells/group, pooled from three independent experiments). Data are median \pm interquartile range. Statistical analysis was performed by using Mann-Whitney non-parametric (two-tailed) test comparing live vs killed hyphae. (c) Extracts from comparable wet weight of $R$. delemar hyphae/spores, or hyphae, but not spores, damaged alveolar epithelial cells ( $\mathrm{n}=6$ wells/group, pooled from three independent experiments). Data are median \pm interquartile range. Statistical analysis was performed by using Mann-Whitney non-parametric (two-tailed) test comparing spores vs spore/hyphae or hyphae. (d) Disrupted pellet from Mucorales germlings containing the cell-associated fraction was compared to live or heat-killed cells in causing injury to HUVECs ( $n=3$ wells/group, pooled from three independent experiments). Data are median \pm interquartile range. (e) Fungal hyphae from representative clinical Mucorales isolates ground in liquid nitrogen and extracted with mammalian cell culture caused significant A549 alveolar epithelial cell damage ( $\mathrm{n}=3$ wells/Mucorales, pooled from three independent experiments). Data are median \pm interquartile range. (f) $\operatorname{IgG}$ anti- $R$. delemar toxin but not normal rabbit $\operatorname{IgG}(50 \mu \mathrm{g} / \mathrm{ml})$ blocked host cell damage caused by heatkilled hyphae from different Mucorales ( $\mathrm{n}=8$ or 9 replicates/treatment/Mucorales, pooled from three independent experiments). Data presented as median \pm interquartile range. Statistical analysis was performed by Mann-Whitney non-parametric (two-tailed) test comparing IgG antitoxin $v s$. without $\mathrm{IgG}$ or normal rabbit IgG. 
Extended Data Figure 2. Fractionation and purification of $\boldsymbol{R}$. delemar toxin. (a) Size exclusion of hyphae extracts indicating a $10-30 \mathrm{kDa}$ fraction causing A549 cell damage ( $\mathrm{n}=6$ wells/fraction, pooled from three independent experiments). Data are median \pm interquartile range. (b) Native polyacrylamide fractionation of hyphae extract and (c) its corresponding A549 cell damage, showing fraction \# 6 causing injury. (n=6 wells/fraction, pooled from three independent experiments). Data are median \pm interquartile range. (d) Cellulose plate separation of fraction \# 6 purified from the polyacrylamide gel and (e) its corresponding A 549 cell damage, showing a high polar fraction \#6 causing injury. Data are $n=6$ wells/fraction, and pooled from three independent experiments. Data are median \pm interquartile range. (f) Third dimension fractionation of the previous fraction \# 6 on cellulose plates and (g) its corresponding A549 cell injury ( $\mathrm{n}=6$ wells/fraction, pooled from three independent experiments). Data are median \pm interquartile range.

\section{Extended Data Figure 3. IgG anti-toxin had no effect on growth or germination of $\boldsymbol{R}$. delemar.}

(a) Fungal spores $\left(10^{4} / \mathrm{ml}\right)$ were inoculated in 96 -well plates with or without $50 \mu \mathrm{g} / \mathrm{ml} \mathrm{IgG} \mathrm{anti-}$ toxin or normal rabbit IgG for $6 \mathrm{~h}$ prior to measuring absorbance at $450 \mathrm{~nm}$. $(\mathrm{n}=12$ wells, data pooled from three independent experiments) Data presented as median + interquartile range. Statistical analysis was performed by Mann-Whitney non-parametric (two-tailed). (b) R. delemar spores $\left(10^{4} / \mathrm{ml}\right)$ were germinated at $37^{\circ} \mathrm{C}$ for $6 \mathrm{~h}$ prior to measuring the germ tube length using light microscopy equipped with a micometer lens. Each data point represents 20-50 germ tubes/HPF. ( $\mathrm{n}=12$ wells, data pooled from three independent experiments) Data presented as median + interquartile range from three experiments. Statistical analysis was performed by MannWhitney non-parametric (two-tailed). 


\section{Extended Data Figure 4. Putative toxin gene expression is cell-, time- and oxygen-dependent.}

(a) Toxin gene expression in $R$. delemar germinating cells in YPD medium. Data ( $\mathrm{n}=3$ wells/timepoint, pooled from three independent experiments) are presented as median \pm interquartile range. Statistical analysis was performed by using unpaired t-test (two-tailed). (b) Confocal imaging of Alexa Flour 488-labelled IgG anti-toxin (green) during the growth of $R$. delemar from spores to hyphae. Scale bar is $50 \mu \mathrm{m}$. (c) Toxin gene expression from $R$. delemar hyphae grown in YPD culture in sufficient versus limited oxygen ( $\mathrm{n}=6$ wells, data pooled from three independent experiments). Data presented as median \pm interquartile range. Statistical analysis was performed by using unpaired t-test (two-tailed). (d) Toxin gene expression analysis of fungal germlings on different cell types showed a time dependent expression on alveolar epithelial cells compared to HUVECs and erythrocytes ( $n=3$ wells/group, pooled from three independent experiments). Data presented as median \pm interquartile range. Statistical analysis was performed by using unpaired t-test (two-tailed).

\section{Extended Data Figure 5. RNAi targeting the putative $R$. delemar toxin inhibits its expression.}

(a) $R$. delemar spores were transformed with RNAi plasmids targeting the putative toxin (RNAitoxin) or empty plasmid (Empty-plasmid) using biolistic delivery system. Cells were grown in minimal medium without uracil for $24 \mathrm{~h}$ prior to extracting RNA ( $\mathrm{n}=6 /$ group, pooled from three independent experiments). Data presented as median \pm interquartile range. Statistical analysis was performed by using Mann-Whitney non-parametric (two-tailed) test comparing RNAi- $R$. delemar toxin vs wild-type or empty plasmid (b) Representative Western blot and densitometry analyses of the wild-type, empty plasmid, or RNAi toxin strains ( $\mathrm{n}=4$ pictures data pooled from four 
independent experiments) Data presented as median \pm interquartile range. Statistical analysis was performed by using Mann-Whitney non-parametric (two-tailed) test comparing RNAi- $R$. delemar toxin $v s$. wild-type or empty plasmid. (c) confocal images showing reduced expression of the toxin in the RNAi toxin mutant. Scale bar is $50 \mu \mathrm{m}$.

Extended Data Figure 6. Down regulation of $R$. delemar toxin by RNAi did not affect germination or the growth of the fungus. (a) Wild-type $R$. delemar, RNAi empty plasmid, or RNAi toxin strains were germinated in minimal medium without uracil at $37^{\circ} \mathrm{C}$ with shaking. At times, samples were taken from the medium and examined by light microscopy. Scale bar is $5 \mu \mathrm{m}$. (b) $10^{5}$ spores of wild-type R. delemar, RNAi empty plasmid, or RNAi toxin strains were plated in the middle of the minimal medium without uracil agar plates for several days at $37^{\circ} \mathrm{C}$ and the colony diameter measured ( $n=6$ plates/group, pooled from three independent experiments). Data are presented as median \pm interquartile range.

\section{Extended Data Figure 7. Effect of blocking the expression or the function of $R$. delemar toxin}

on fungal burdens in mice. (a) Inhibition of the toxin by RNAi did not affect the fungal burden in the lungs or brain of mice harvested on Day +4 post infection (average inoculum from two experiments of $1.4 \times 10^{4}$ for empty plasmid [ $\mathrm{n}=22$ mice] $v s .1 .3 \times 10^{4}$ for RNAi toxin mutants $[\mathrm{n}=20$ mice]). Data are pooled from two independent experiments and presented as median \pm interquartile range. Statistical analysis was performed by using Mann-Whitney non-parametric (two-tailed) test comparing RNAi-R.delemar toxin vs. Empty plasmid. (b) The IgG anti-R. delemar toxin had no effect on the fungal burden of lungs or brains of DKA mice harvested on Day +4 post intratracheal infection with wild-type $R$. delemar (average inhaled inoculum of $5.6 \mathrm{x}$ 
$10^{3}$ spores from two experiments $[\mathrm{n}=20$ mice]). Data are pooled from two independent experiments and presented as median \pm interquartile range). Statistical analysis was performed by using MannWhitney non-parametric (two-tailed) test comparing IgG anti-R.delemar toxin $v s$. normal rabbit $\operatorname{IgG}$.

Extended Data Figure 8. Histology of organs showing involvement of the toxin in tissue damage. (a) Damaged lung tissues (brown color) of mice infected with $R$. delemar transformed with RNAi empty plasmid ( $n=31$ field counts) or RNAi toxin. Statistical analysis was performed by using Mann-Whitney non-parametric (two-tailed) test. Scale bar is $200 \mu \mathrm{m}$. (b) Damaged lung tissues from mice infected with wild-type $R$. delemar and treated with either normal rabbit IgG ( $\mathrm{n}=18$ field counts) or IgG anti-toxin ( $\mathrm{n}=18$ field counts) were quantified by ApopTag kit. Data were pooled from two independent experiments, are presented as median + interquartile range. Statistical analysis was performed by using Mann-Whitney non-parametric (two-tailed) test. Scale bar is $200 \mu \mathrm{m}$.

\section{Extended Data Figure 9. $R$. delemar toxin is expressed in lung tissue collected from a mucormycosis patient but not in lung samples from an aspergillosis patient. H\&E staining of} lung tissues from mucormycosis (a) or aspergillosis (b) patients showing broad aseptate hyphae with angioinvasion (Mucorales) and thinner septated hyphae of Aspergillus. Scale bar is $10 \mu \mathrm{m}$. Box magnification $1400 \mathrm{X}$. Staining of a mucormycosis (c) or aspergillosis (d) patient lungs using IgG anti-toxin (green color). Mucorales or Aspergillus hyphae are shown in yellow (stained with calcofluor white) and nuclei are shown in magenta. $R$. delemar toxin staining is shown in 
association with hyphae (grey arrow) and released in the tissue (white arrow). Scale bar is $10 \mu \mathrm{m}$ in all micrographs.

\section{Extended Data Figure 10. Secretion/shedding of $R$. delemar toxin in culture supernatant of}

growth media. (a) Cell-free culture supernatants were collected from $R$. delemar hyphae grown in the presence or absence of 2-fold dilutions of amphotericin B. The XTT assay was used to determine growth of $R$. delemar (left axis, blue bar, $\mathrm{n}=8$ wells/amphotericin B concentration), while toxin release assayed by sandwich ELISA using anti-R. delemar mouse monoclonal IgG1 as the capture antibody and rabbit anti-R. delemar toxin $\mathrm{IgG}$ as the detector antibody (right axis, red bar, $\mathrm{n}=2$ wells/amphotericin $\mathrm{B}$ concentration). Data in are representative of three independent experiments and presented as mean $\pm \mathrm{SD}$. (b) The released toxin concentration from $R$. delemar wild-type, $R$. delemar transformed with empty plasmid RNAi or $R$. delemar with RNAi-toxin was extrapolated from a standard curve using recombinant toxin in the same ELISA assay. Toxin concentrations $(\mathrm{n}=3$ samples from three independent experiments tested in duplicate in ELISA for each strain) are presented as mean $\pm \mathrm{SD}$. 


\section{Supplementary Figure Legends}

\section{Supplementary Figure 1. Incubation of lower inoculum of $R$. delemar with HUVECs induces} minimal to no host cell injury. Data are presented as $\%{ }^{51} \mathrm{Cr}$-released from HUVECs challenged

with $1 \times 10^{5}$ spores of $R$. delemar for 5 hours after subtracting the amount of ${ }^{51} \mathrm{Cr}$-released from HUVECs without $R$. delemar challenge. ( $\mathrm{n}=10$ data pooled from three independent experiments). Data presented as median + interquartile range.

Supplementary Figure 2. CLUSTAL multiple sequence alignment by MUSCLE (3.8) between mucoricin and saporin from Saponaria officinalis. The predicted Type 1 RIP domain in saporin (shown in yellow) aligned with sequence from mucoricin with 10 out of 17 amino acid residues conserved. 
Supplementary Table 1: Results of BLAST search of a ricin-like toxin gene from $R$. delemar 99-880.

Supplementary Table 2. Ten proteins that are structurally similar to mucoricin. The 3-D model of mucoricin was used to identify structurally similar proteins in the protein data bank (PDB) by Tm align.

Supplementary Table 3: Ricin orthologues in different Mucorales and the presence of vascular leak and RIP motifs. 
a

- Primary alveolar epithelial cells

b

ㄴ A549 alveolar epithelial cells

$\triangle$ HUVECs
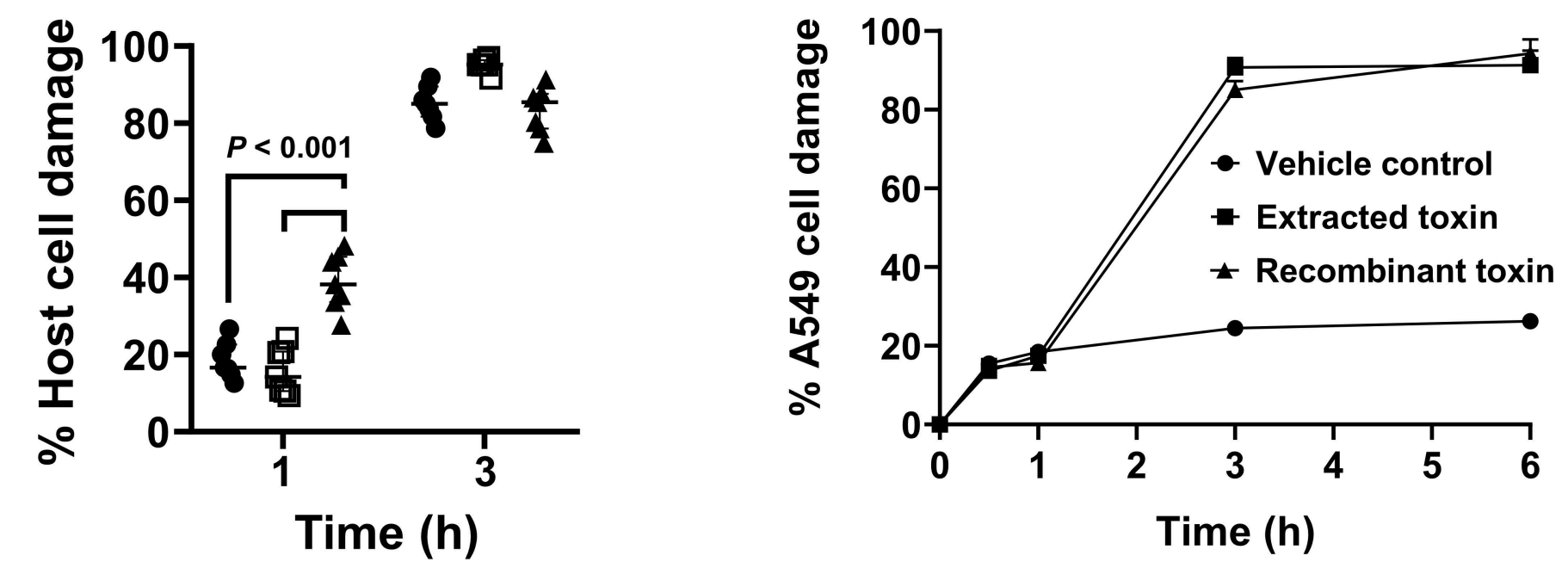

C

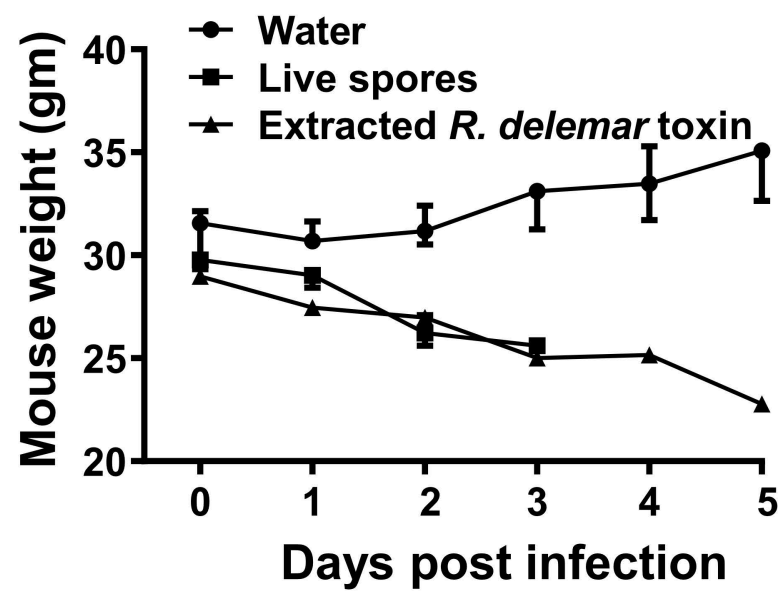

d

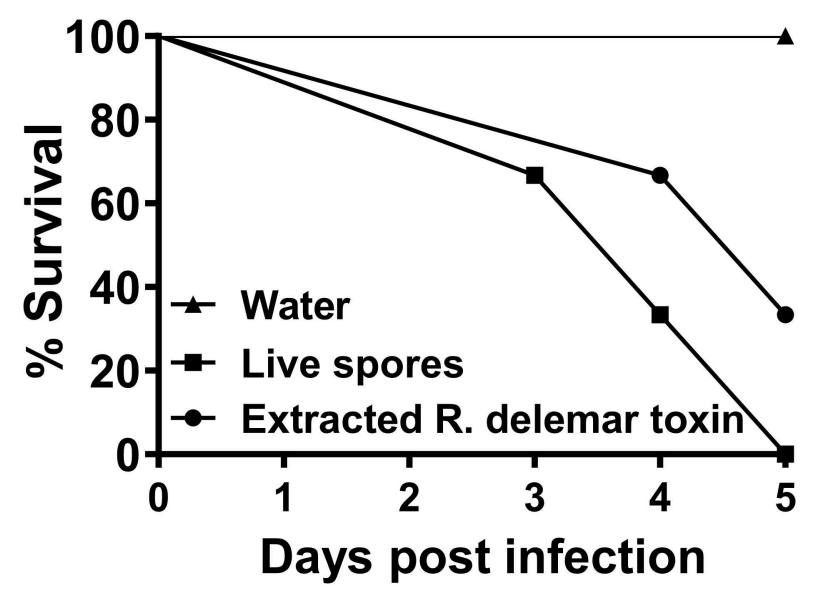

Extracted $R$. delemar toxin

Vehicle
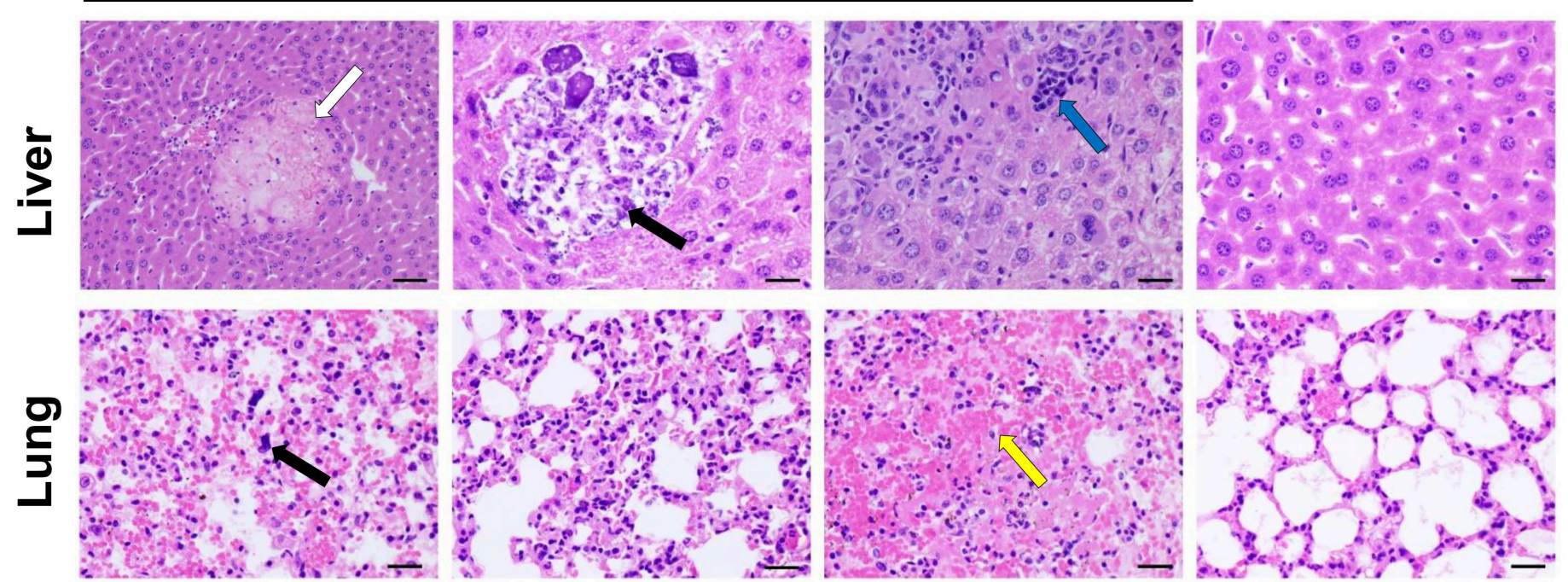
R. delemar toxin

R. communis ricin 101 TNAYVVGYRAGNSAYFFHPDNQEDAEAITHLFTDVQNRYTFAFGGNYDRLEQLAGNLRENIELGNGPLEEAISALYYYSTGGTQLPTLARSFI ICIQMI

R. delemar toxin

R. communis ricin 201

R. delemar toxin $16------------N G R V L D V E G S T E D D A N I I V Y T Q K Y E D C L N Q L W R Y-$

R. communis ricin 301 NFNADVCMDPEPIVRIVGRNGLCVDVRDGRFHNGNAIQLWCKSNTDANQLWTLKRDNTIRSNGKCLTTYGYSPGVYVMIYDCNTAATDATRWQIWDNGT

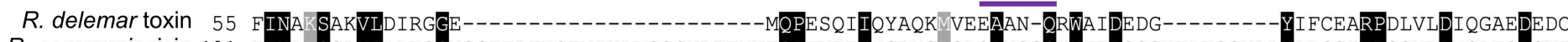
R. communis ricin 401 IINPRSSLVLAATS GNSGTTLTVQTNIYAVSQGWLPTNNTQPFVTTIVGLYGLCLQANSGQVWIEDCSSEKAEQQWALYADGS IRPQQNRDNCLTSDSNI

R. delemar toxin 122 VPVIIYERREGEVSANQRWEI

R. communis ricin 501 RETVVKILSCGPASSGQRWMFKNDGTILNLYSGLVLDVRRSDPSLKQI ILYPLHGDPNQIWLPLF

\begin{tabular}{|c|c|c|c|c|c|c|c|c|c|c|c|}
\hline \multirow{2}{*}{$\begin{array}{l}\text { NCBI } \\
\text { Sequence ID }\end{array}$} & \multirow[t]{2}{*}{ Name } & \multicolumn{5}{|c|}{ Protein sequence homology } & \multirow{2}{*}{$\begin{array}{c}\text { Vascular } \\
\text { leak motif } \\
\text { (LDVI } \\
\text { VDV) }\end{array}$} & \multicolumn{4}{|c|}{ Predicted molecular functions } \\
\hline & & Length & $\begin{array}{l}\text { Max } \\
\text { Score }\end{array}$ & $\begin{array}{l}\text { Total } \\
\text { Score }\end{array}$ & $\begin{array}{l}\text { Query } \\
\text { Cover }\end{array}$ & Identity & & $\begin{array}{l}\text { Sugar } \\
\text { Binding }\end{array}$ & $\begin{array}{l}\text { Lectin } \\
\text { Receptor } \\
\text { Binding }\end{array}$ & $\begin{array}{l}\text { rRNA N- } \\
\text { glycosylase } \\
\text { activity }\end{array}$ & $\begin{array}{l}\text { Hydrolase } \\
\text { activity }\end{array}$ \\
\hline NP_001310630.1 & Ricin precursor [R. communis] & 565 & \multirow{2}{*}{26.6} & \multirow{2}{*}{105} & \multirow{2}{*}{$87 \%$} & \multirow{2}{*}{$29 \%$} & Yes & Yes & Yes & Yes & Yes \\
\hline EIE81863.1 & R. delemar toxin & 147 & & & & & Yes & Yes & Yes & Yes & Yes \\
\hline
\end{tabular}

b

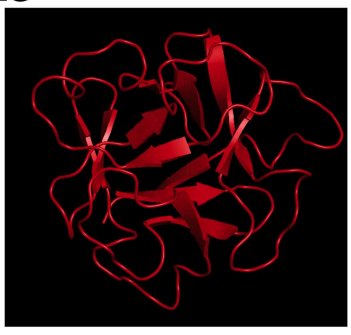

R. delemar toxin

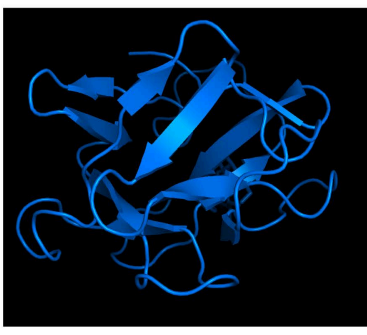

Ricin B chain (304-437 a.a.)

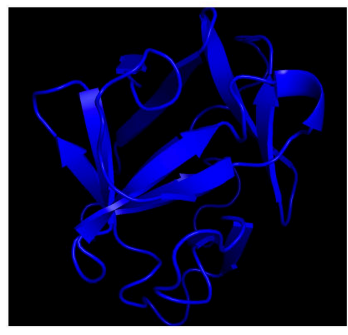

Ricin B chain (438-565 a.a.)

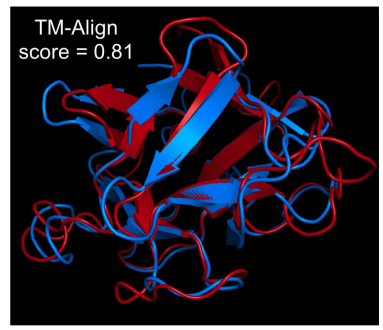

Superimposed R. delemar toxin vs Ricin B (R. delemar toxin vs Ricin B chain [304-437 a.a.])

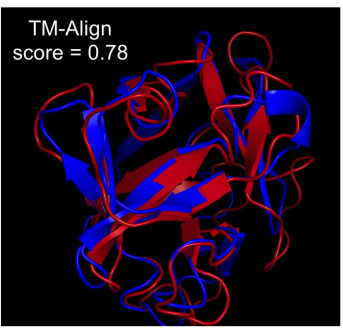

chain [438-565 a.a.])
C

Binding of IgG anti-R. delemar toxin to the toxin or ricin on ELISA

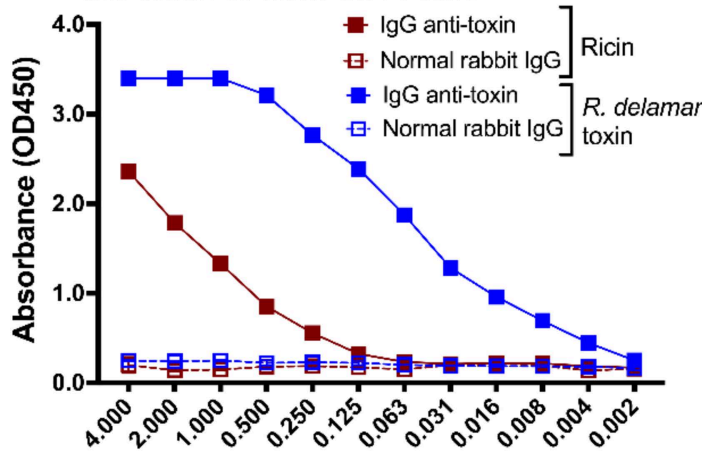

Detection antibody concentration $(\mu \mathrm{g} / \mathrm{ml})$

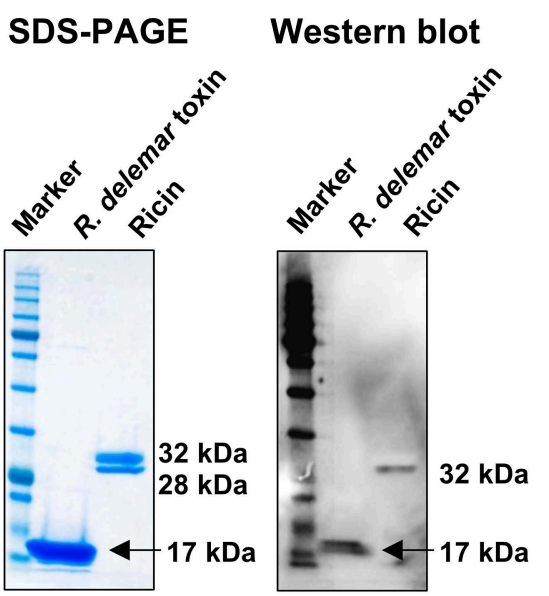

0
Ricin ( $\mu \mathrm{g} / \mathrm{dot})$

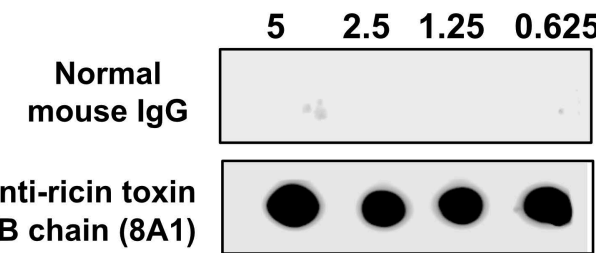

B chain (8A1)

Normal rabbit IgG

IgG anti-R. delemar toxin
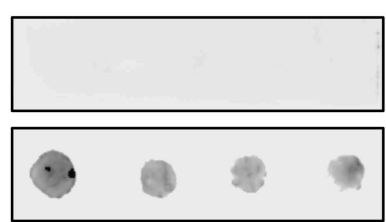

R. delemar toxin ( $\mu \mathrm{g} / \mathrm{dot})$

$\begin{array}{llll}5 & 2.5 & 1.25 & 0.625\end{array}$
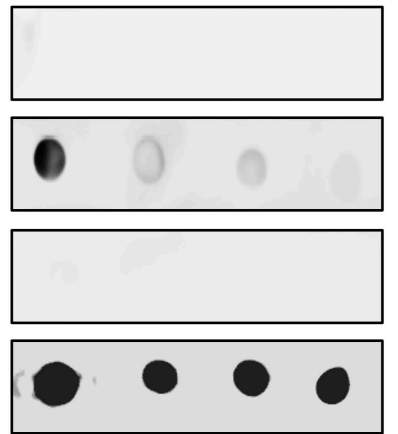

f Ricin-mediated cell damage inhibition by IgG anti-R. delemar toxin

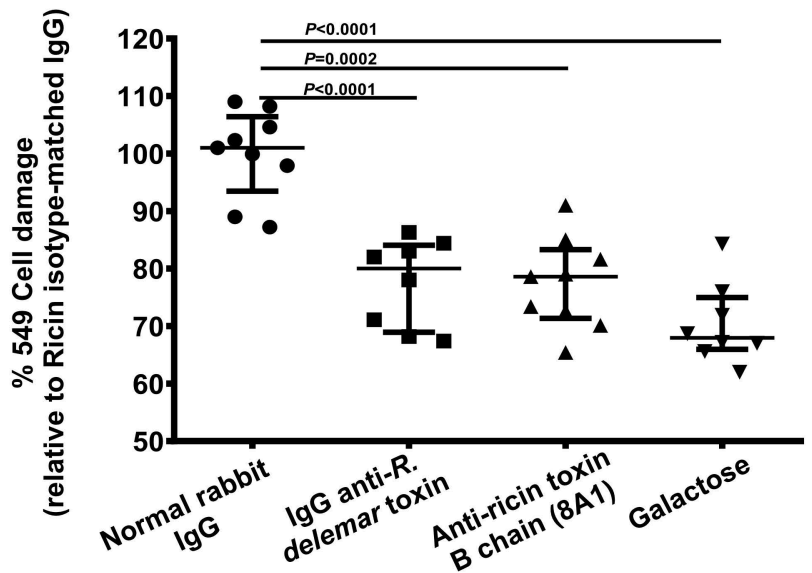




\section{2 \\ Ricin}

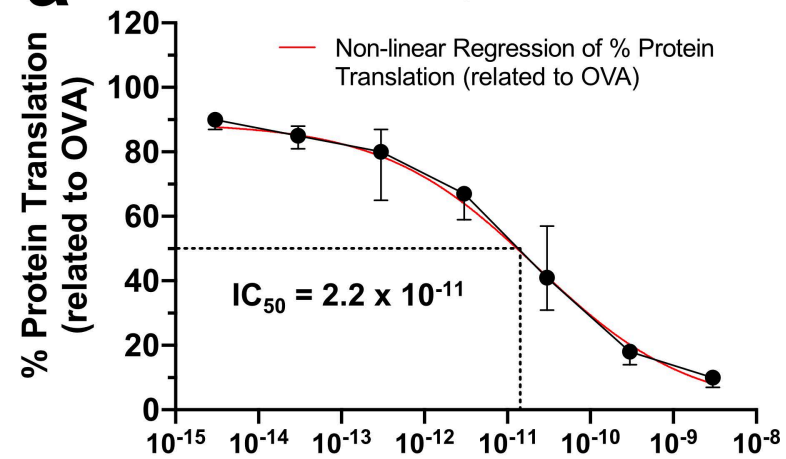

Concentration (M)
0

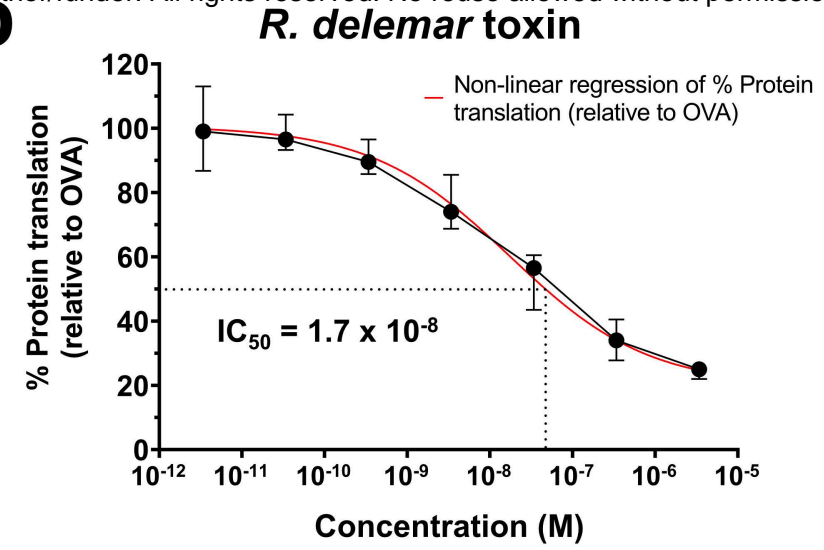

d

$300 \mathrm{bp}$

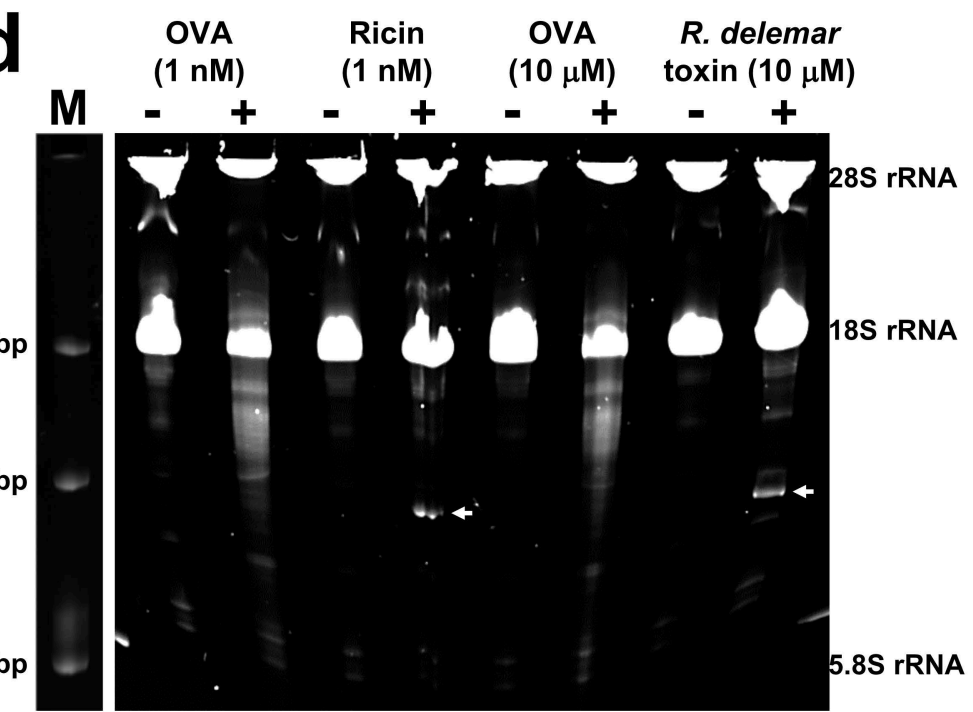

R. delemar toxin

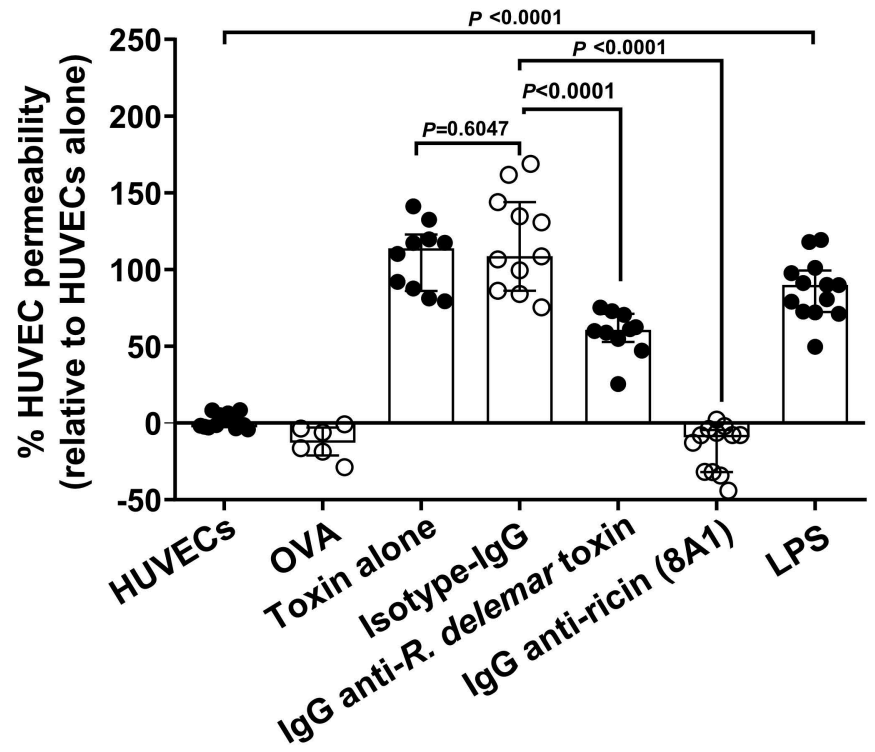

Ricin

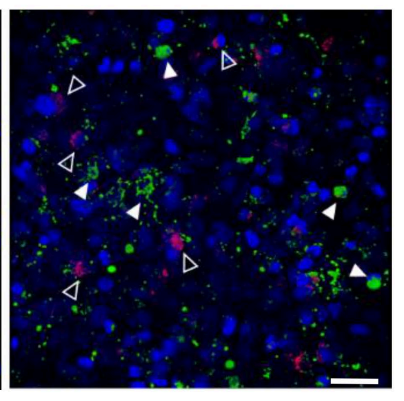

- Apoptosis - Necrosis

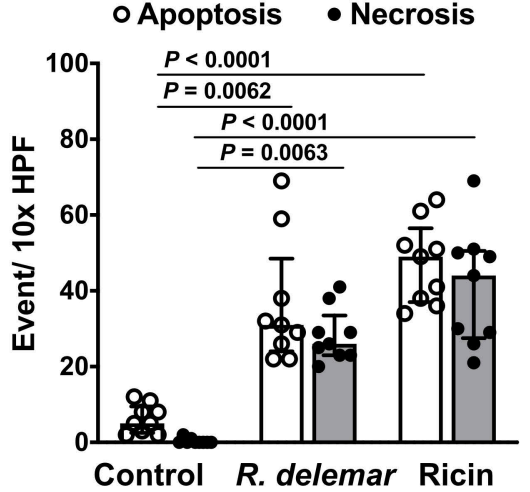

toxin

h

\section{R. delemar toxin}

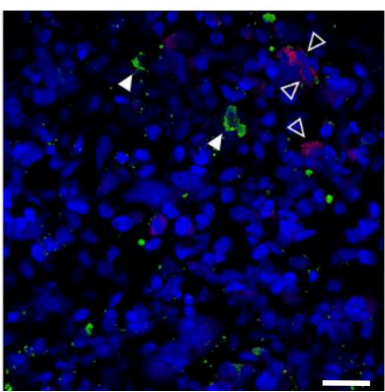


a

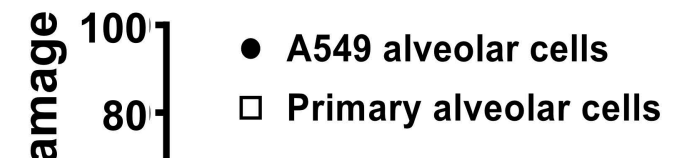

C

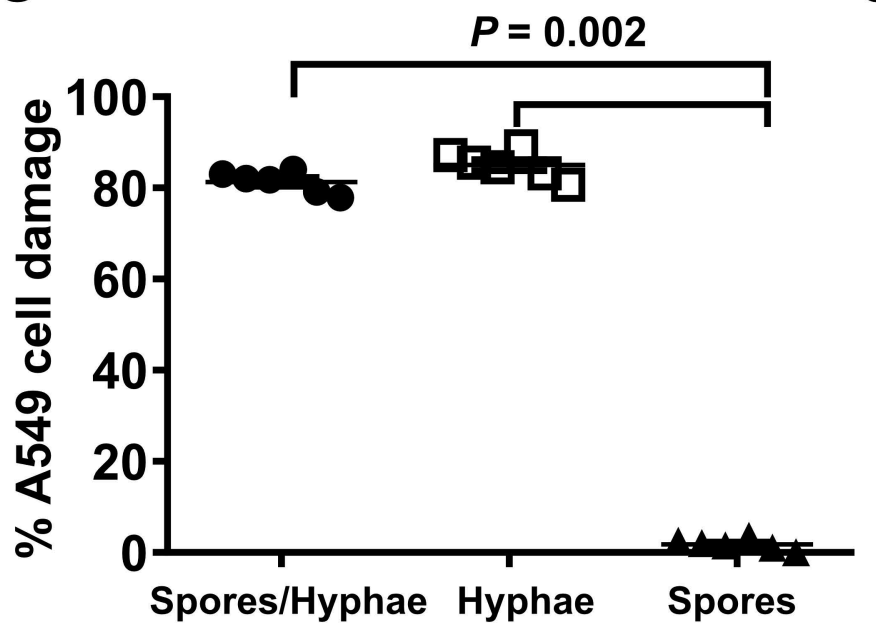

R. delemar extract

e

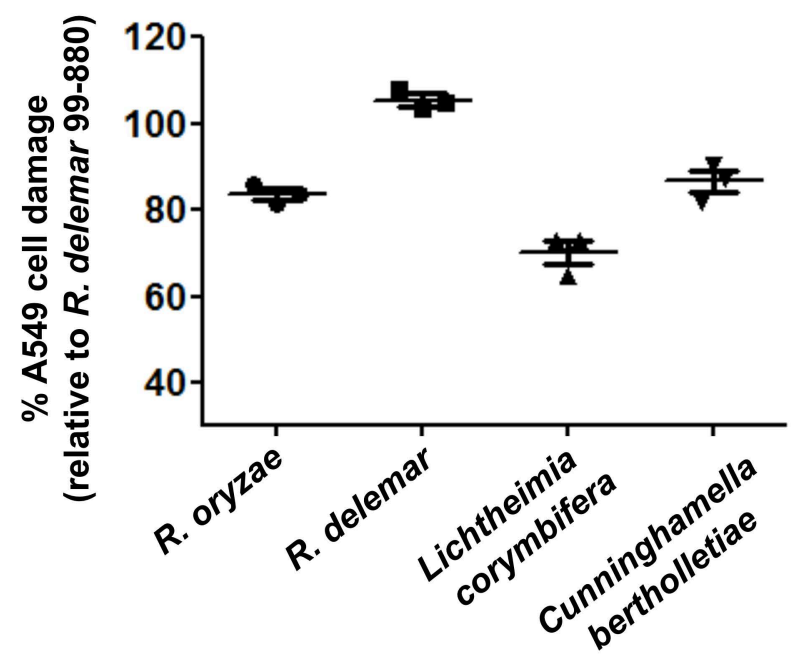

Hyphal extract

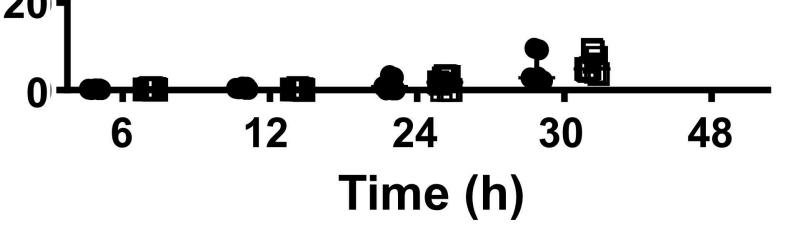

b

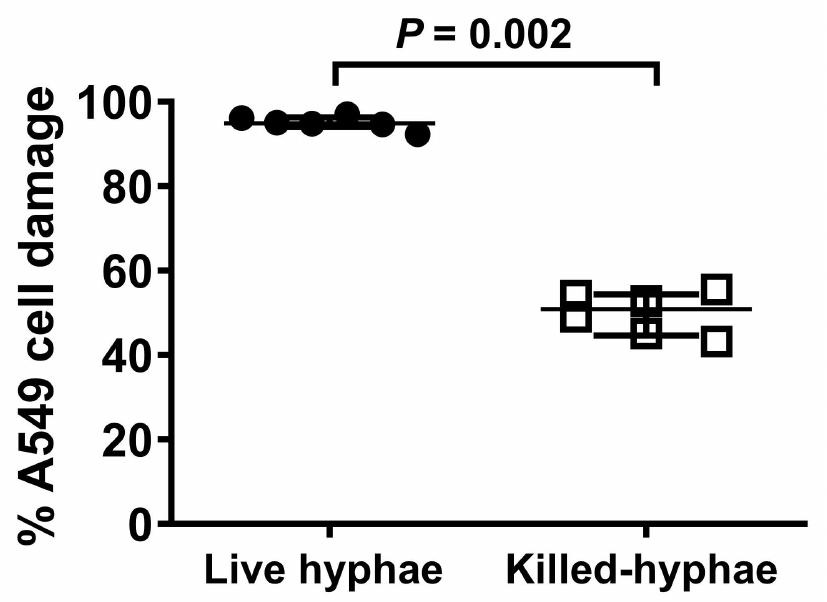

d

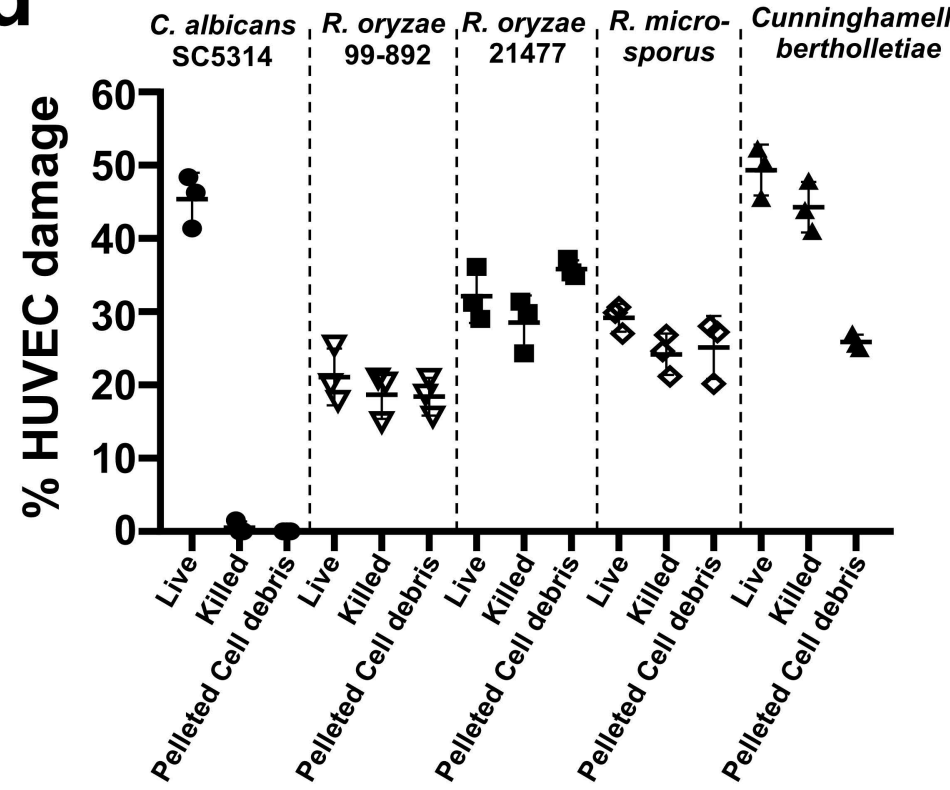

$f$

R. delemar $R$. oryzae C. bertholletiae L. corymbifera
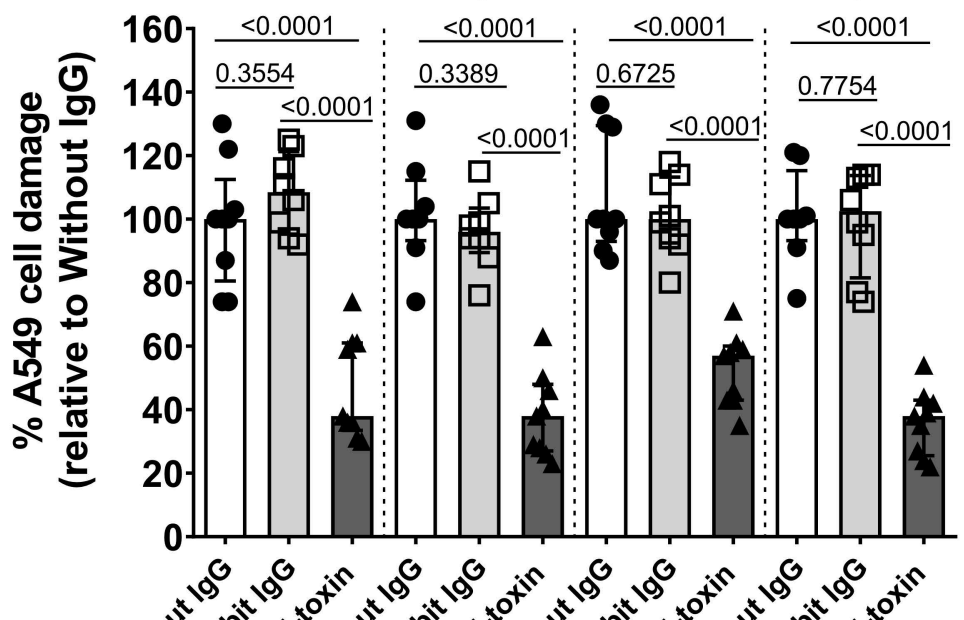

C. albicans, $R$. oryzae , $R$. oryzae , R. micro- , Cunninghamella 
a
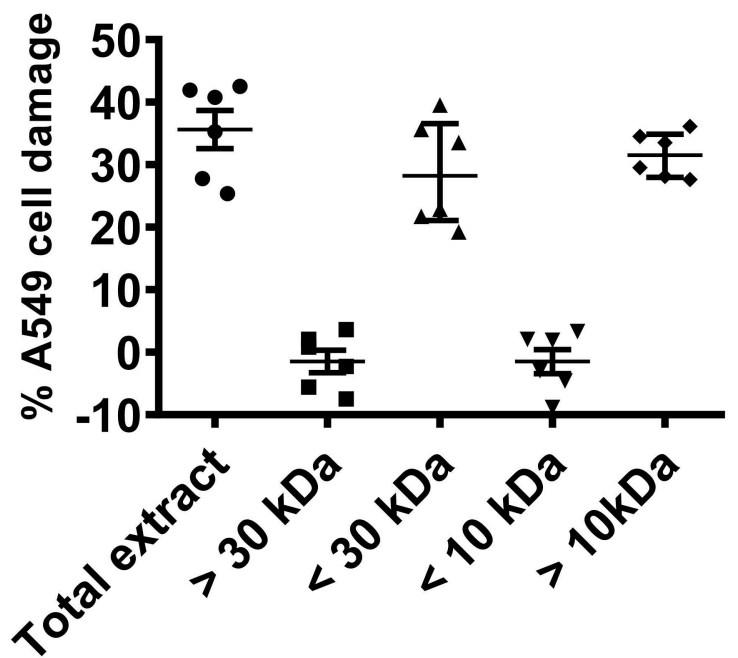

C

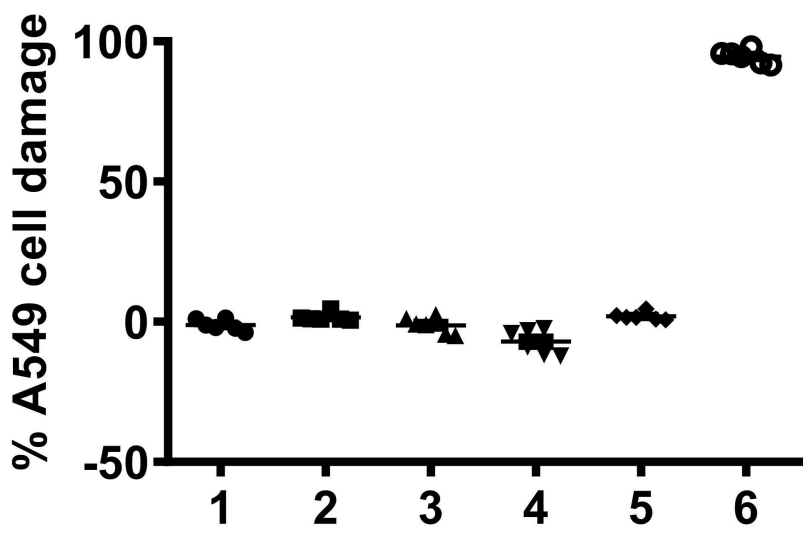

Fraction number

e

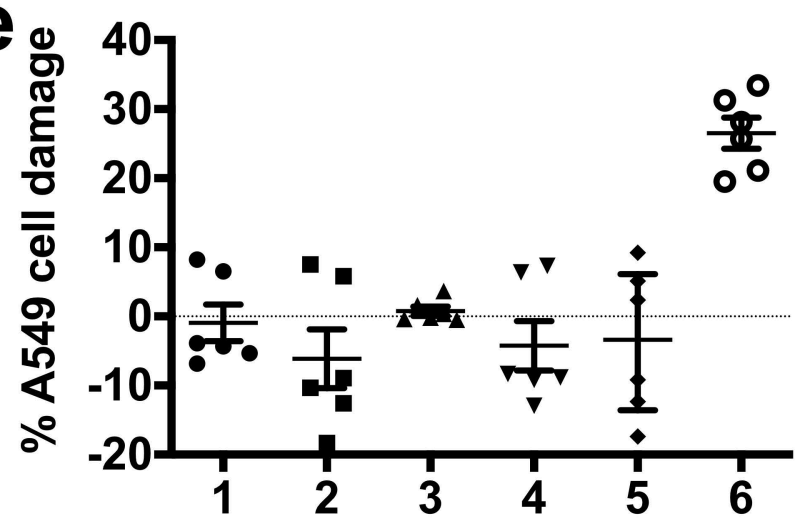

g

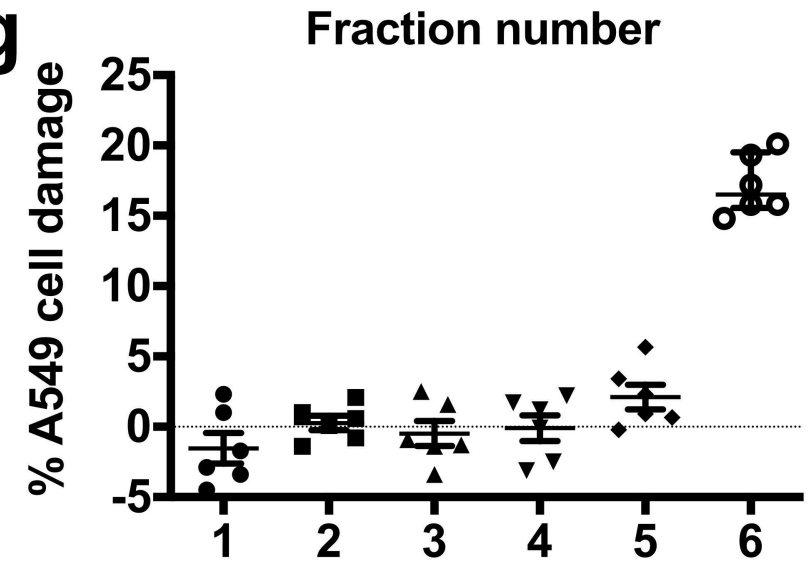

Fraction number

\section{b Fractionation Size Total \\ Marker extract}

Fract. 1

Fract. 2

Fract. 3

Fract. 4

Fract. 5

Fract. 6

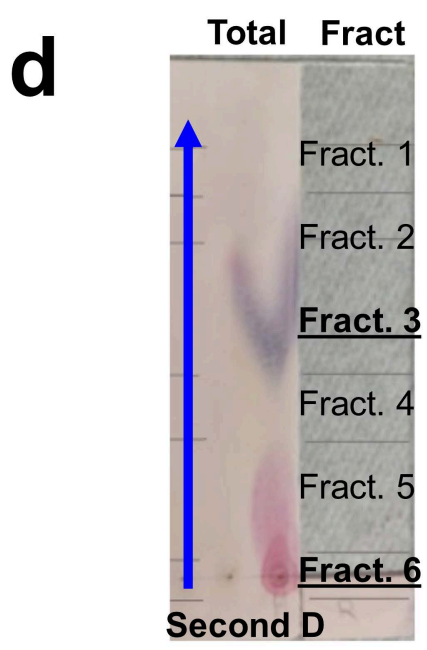

$f$

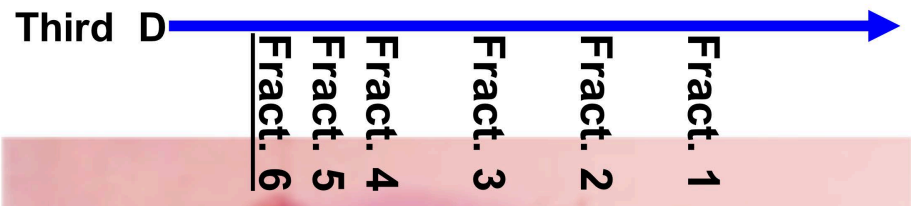

First D

11 koa

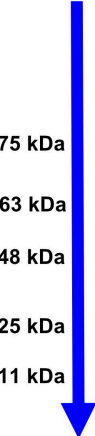




\section{Extended Data Figure 3}

a
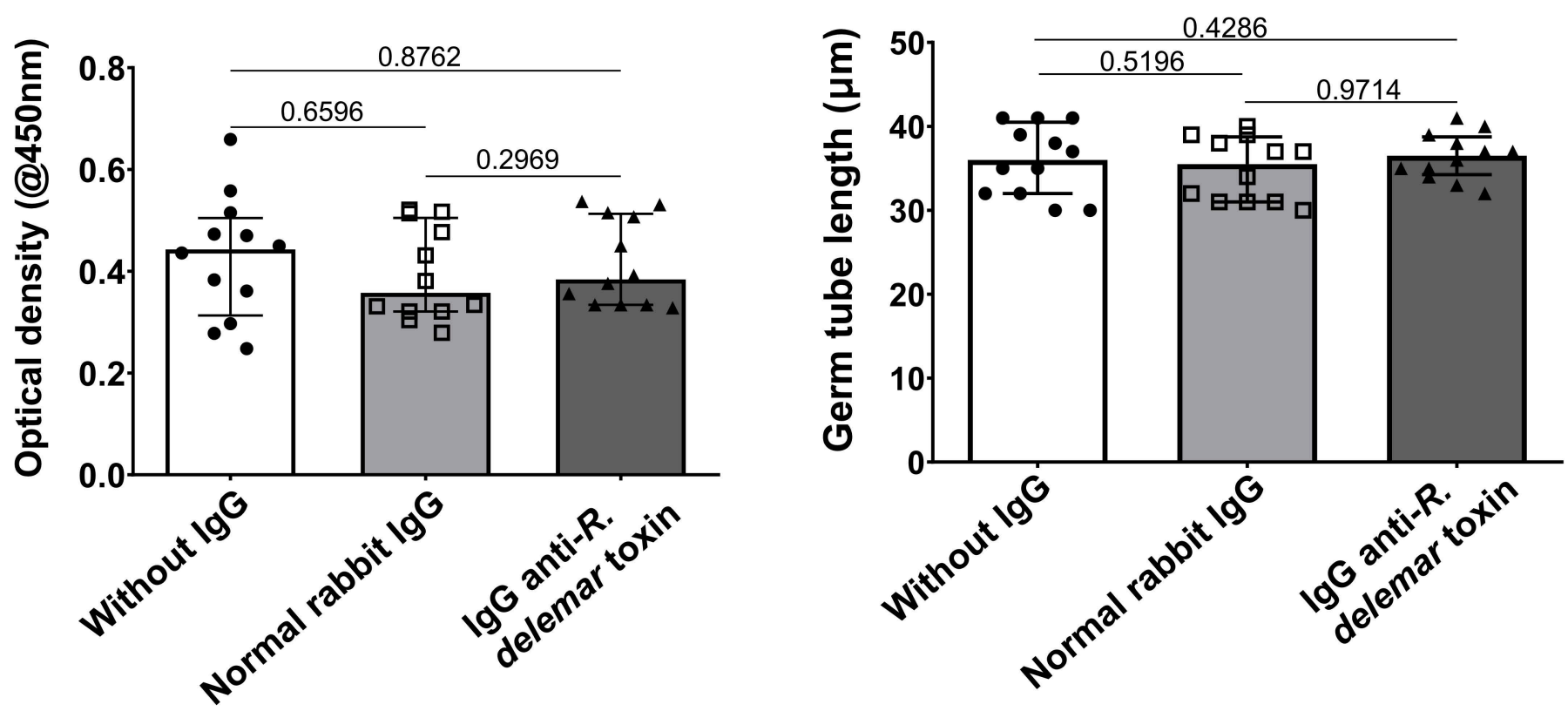


\section{Extended Data Figure 4}

a

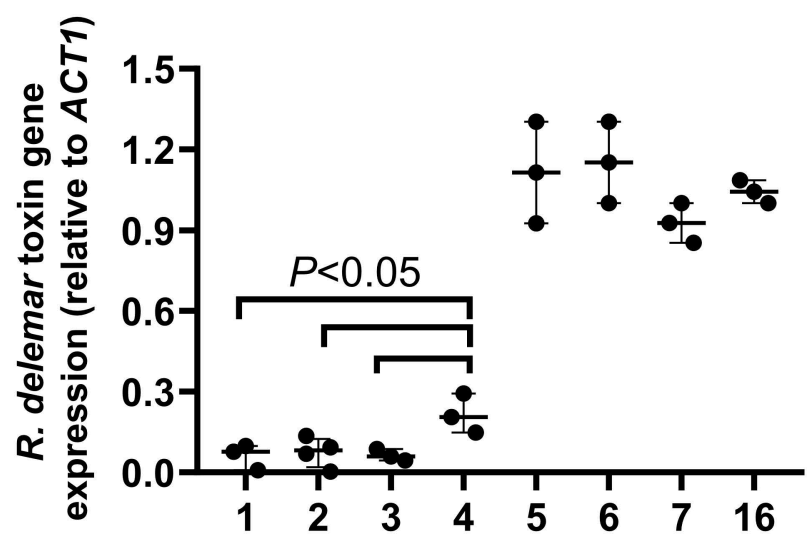

Time (h)

b

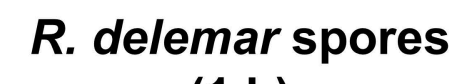

(1 h)

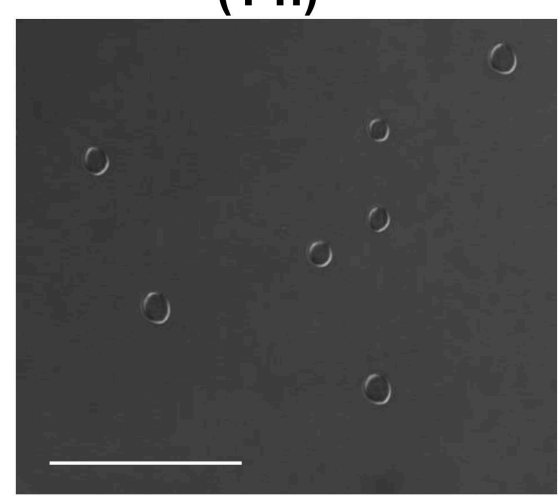

R. delemar germlings (4 h)
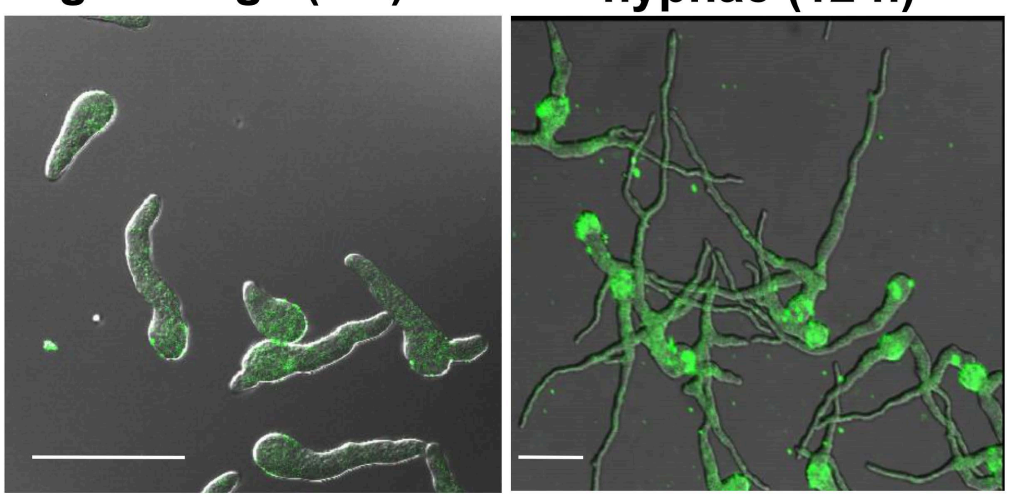

C

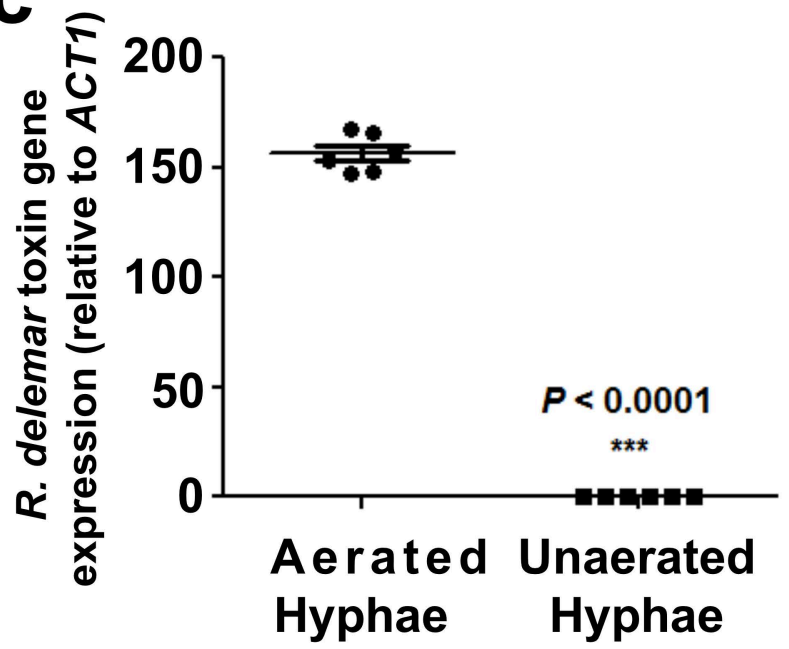

d

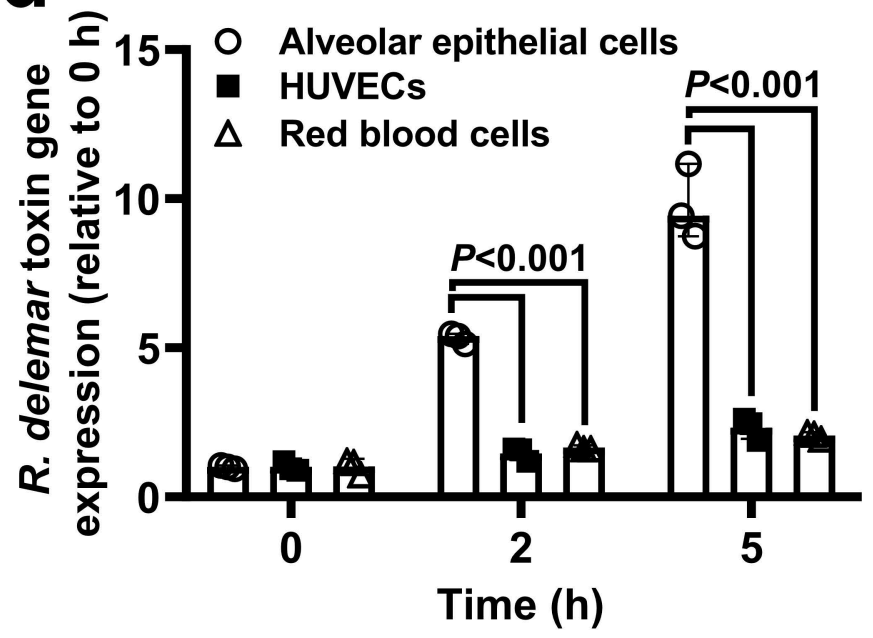




\section{Extended Data Figure 5}

2

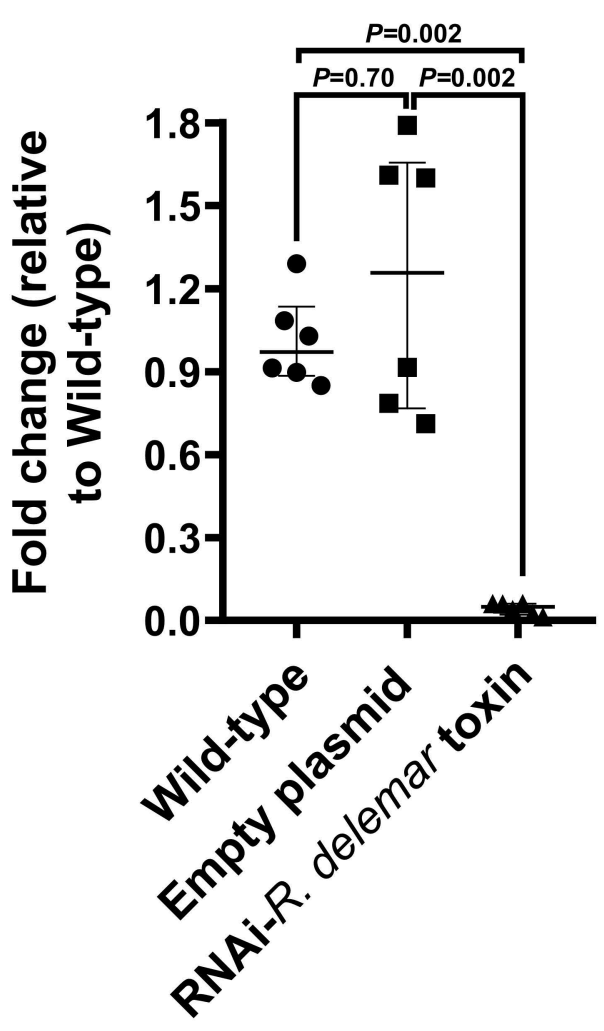

b $\begin{aligned} & \text { Wild- } \\ & \text { type }\end{aligned} \quad \begin{aligned} & \text { Empty } \\ & \text { plasmid }\end{aligned} \begin{gathered}\text { RNAi-R. } \\ \text { delemartoxin }\end{gathered}$

Toxin 17 kDa
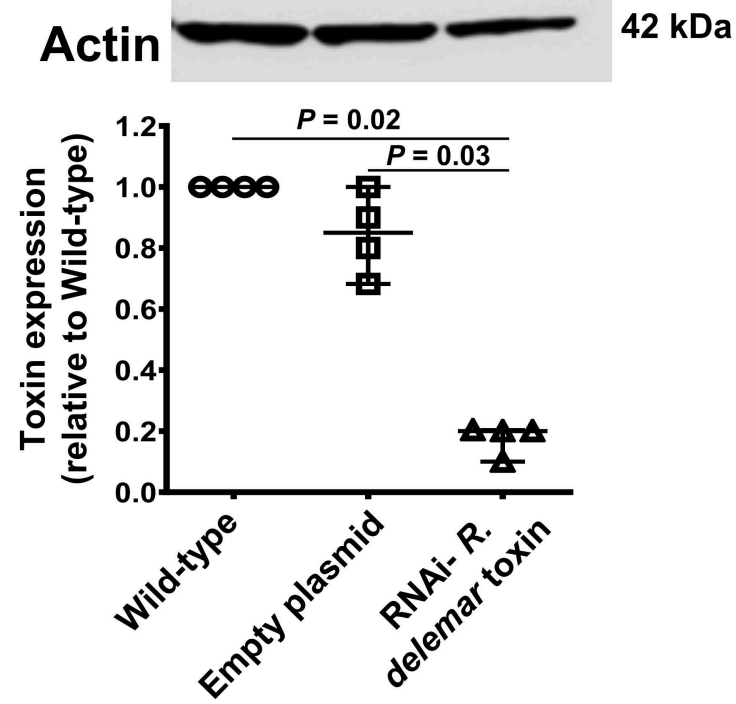

C
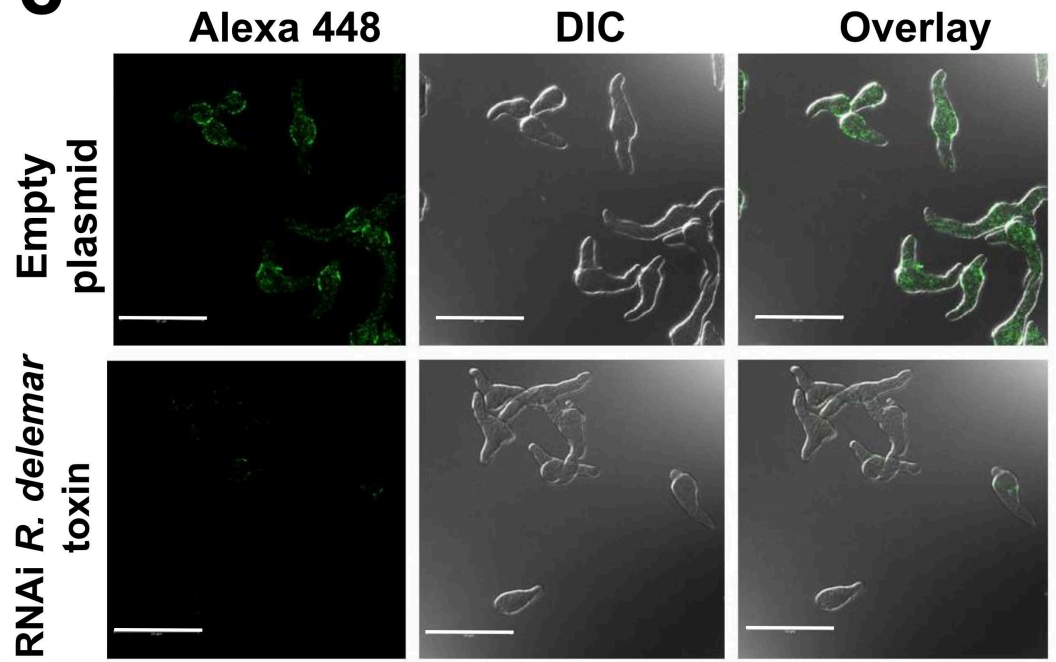


\section{Extended Data Figure 6.}

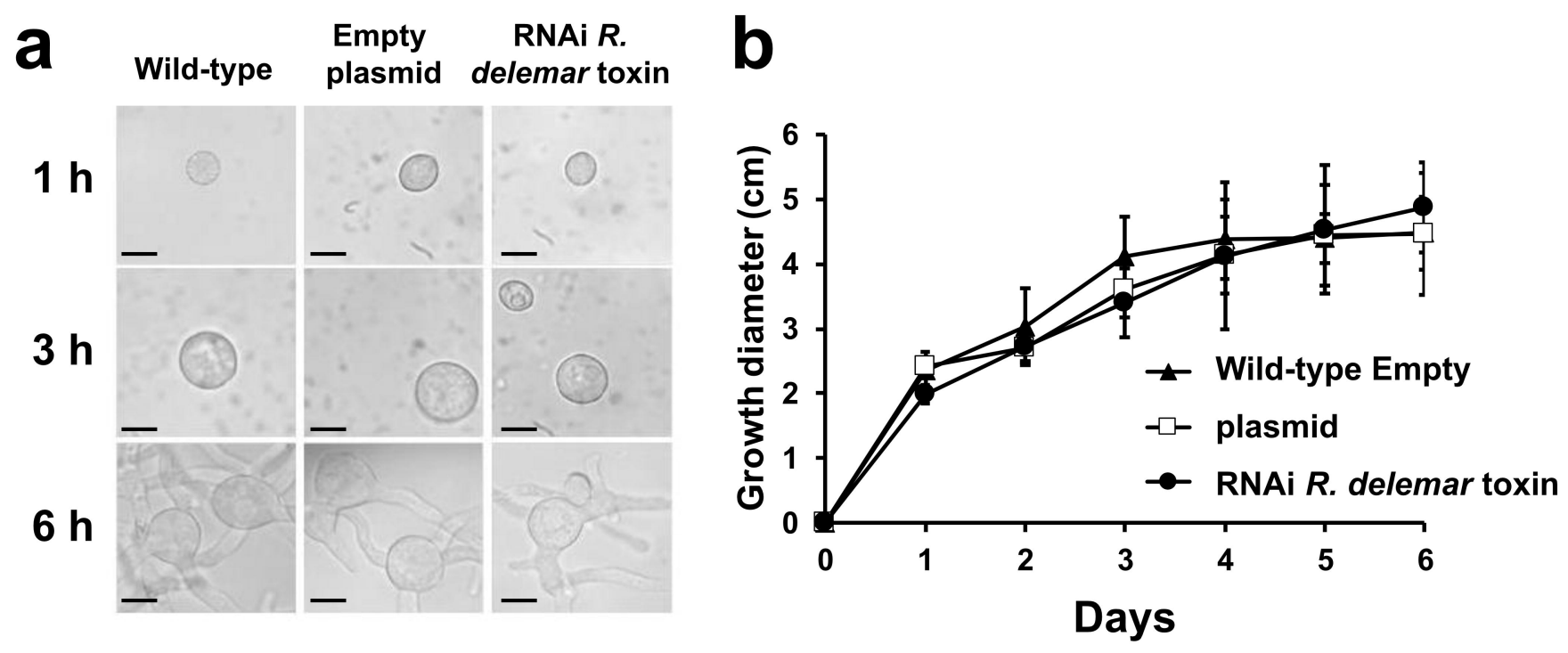




\section{Extended Data Figure 7.}
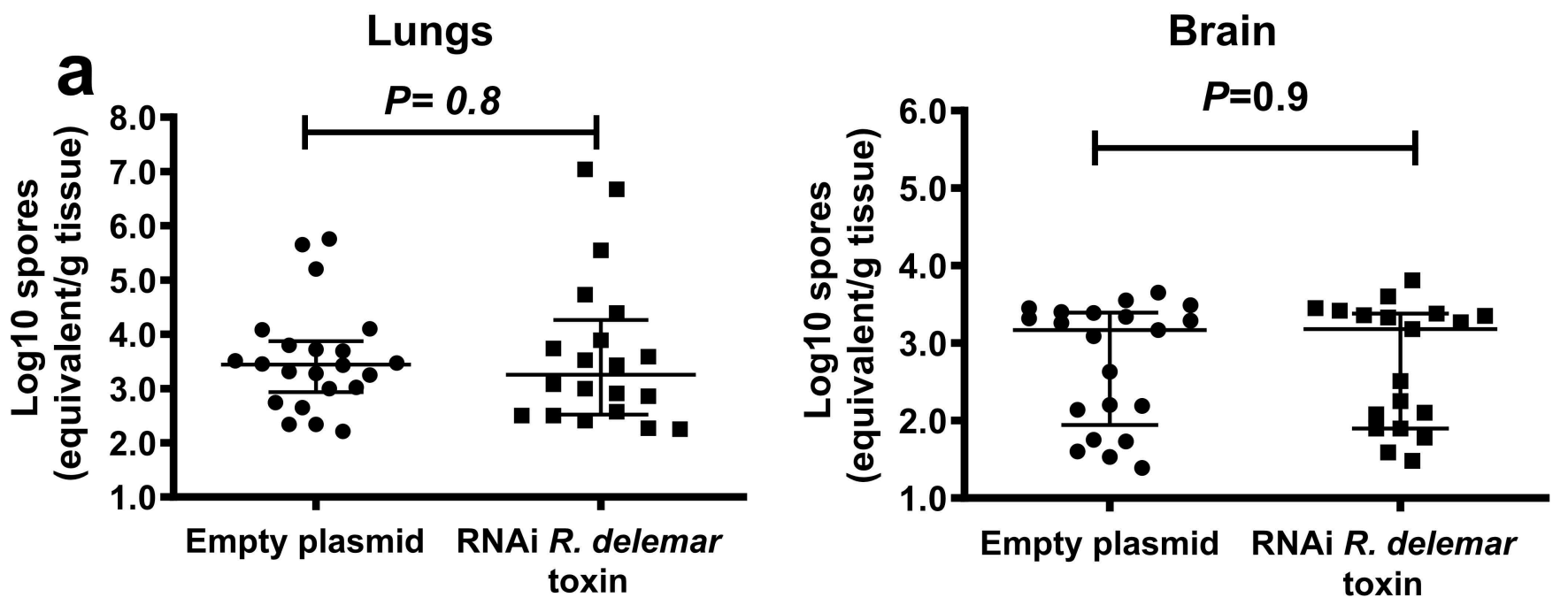

b

Lungs

Brain
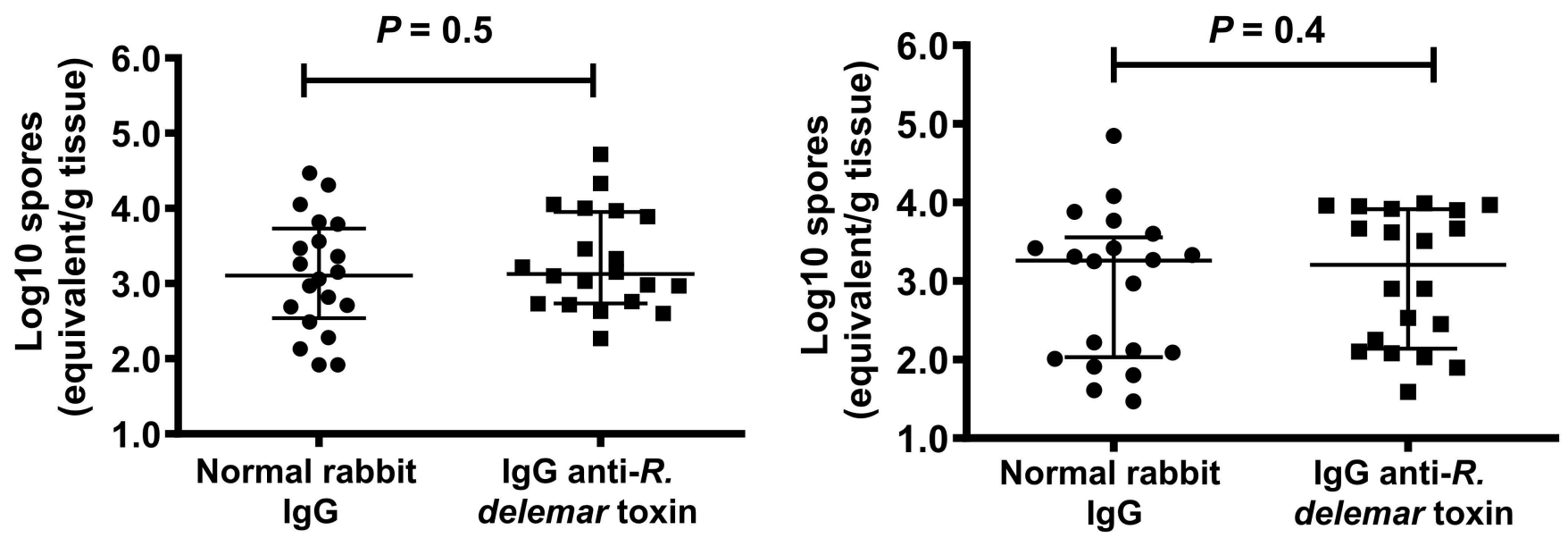


\section{Extended Data Figure 8}
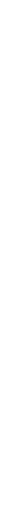

b

Normal rabbit IgG

IgG anti-R. delemar toxin
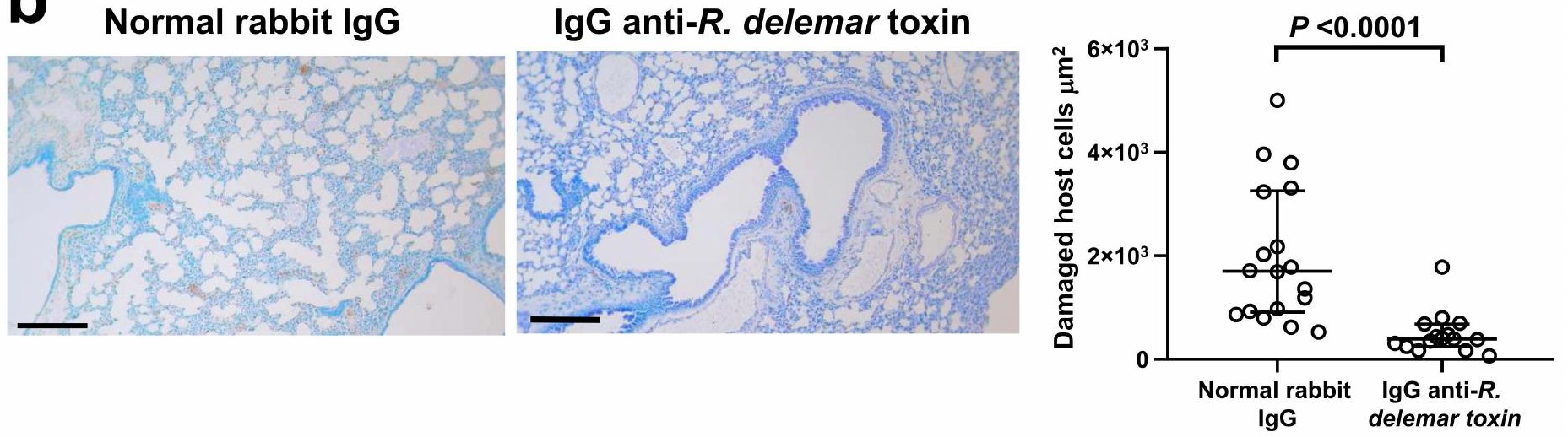


\section{Extended Data Figure 9}

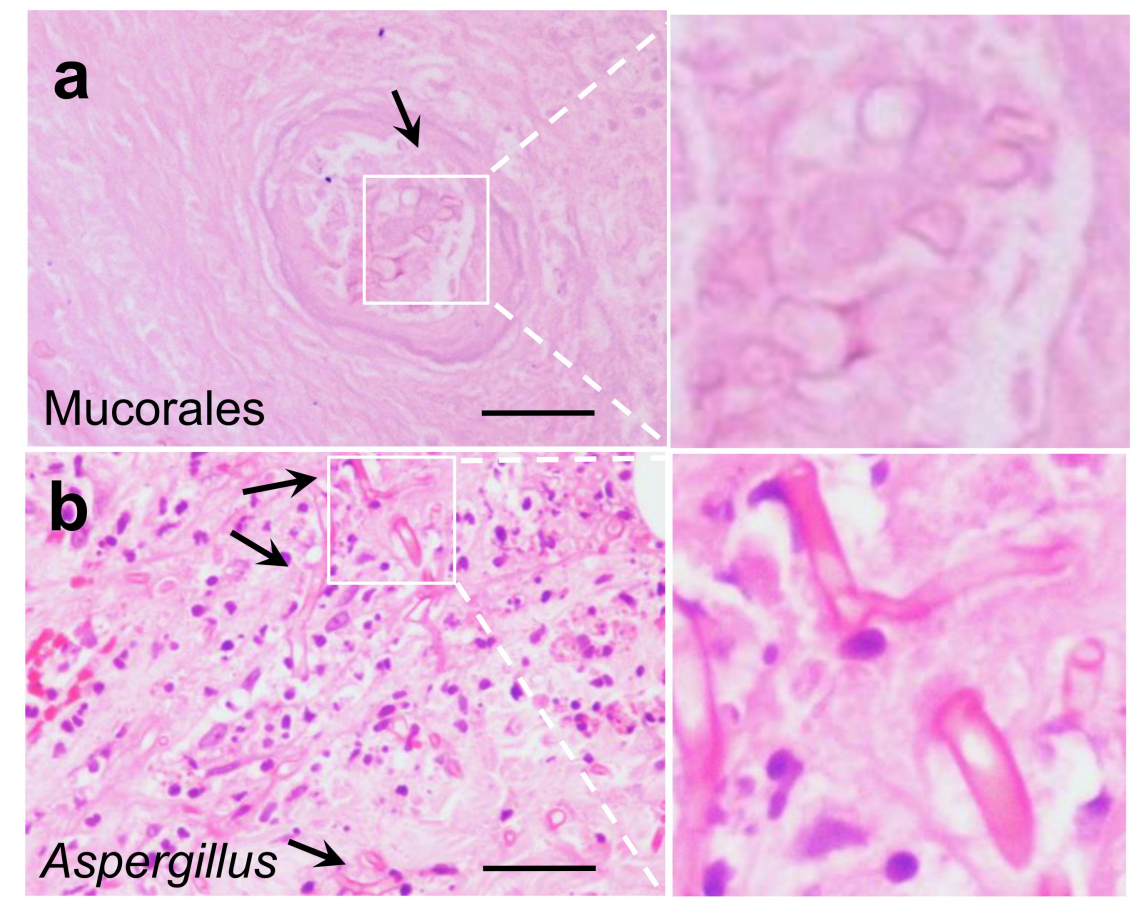

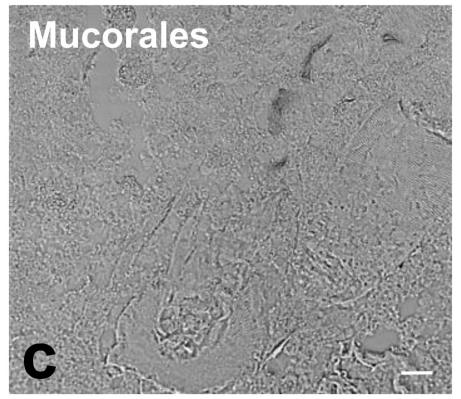

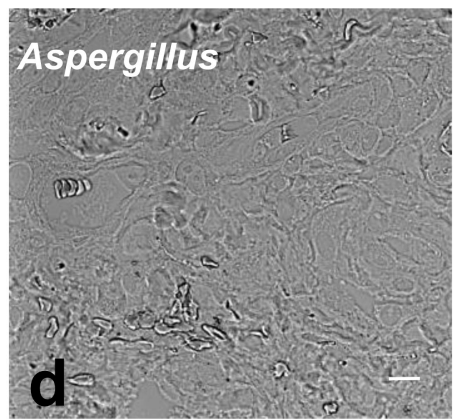

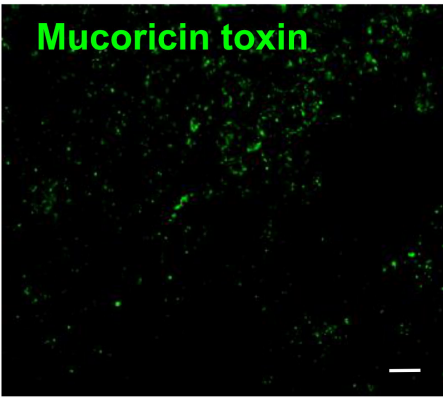

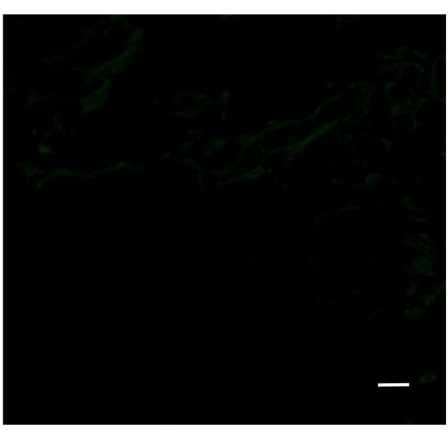

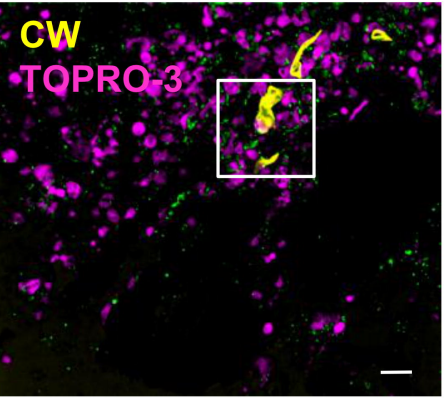
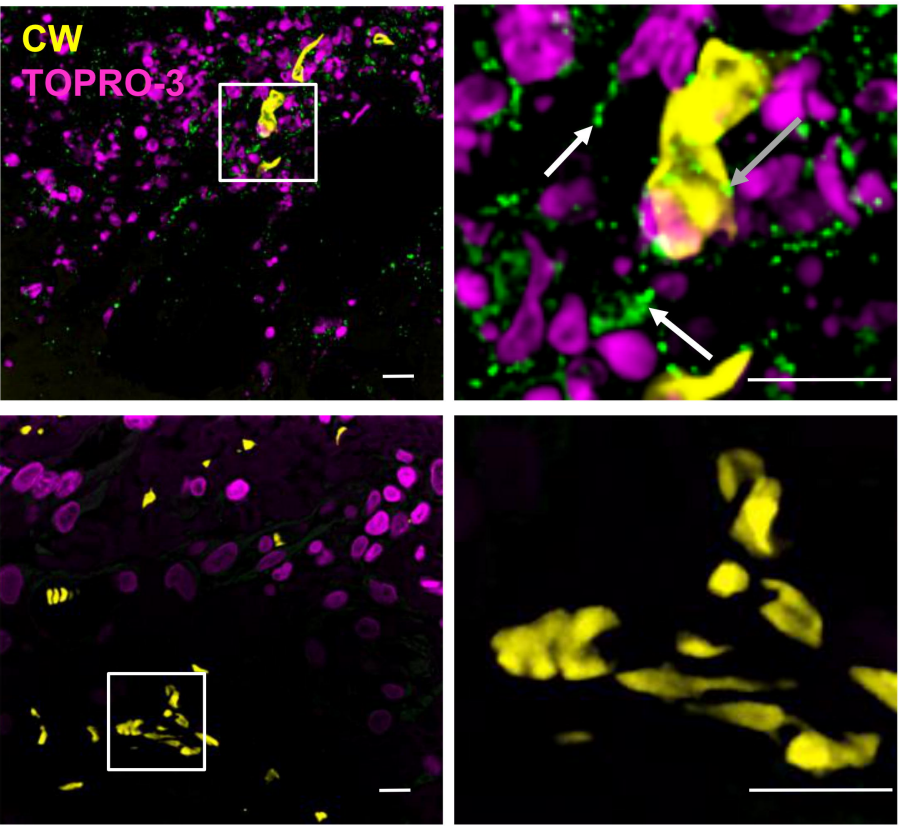
a

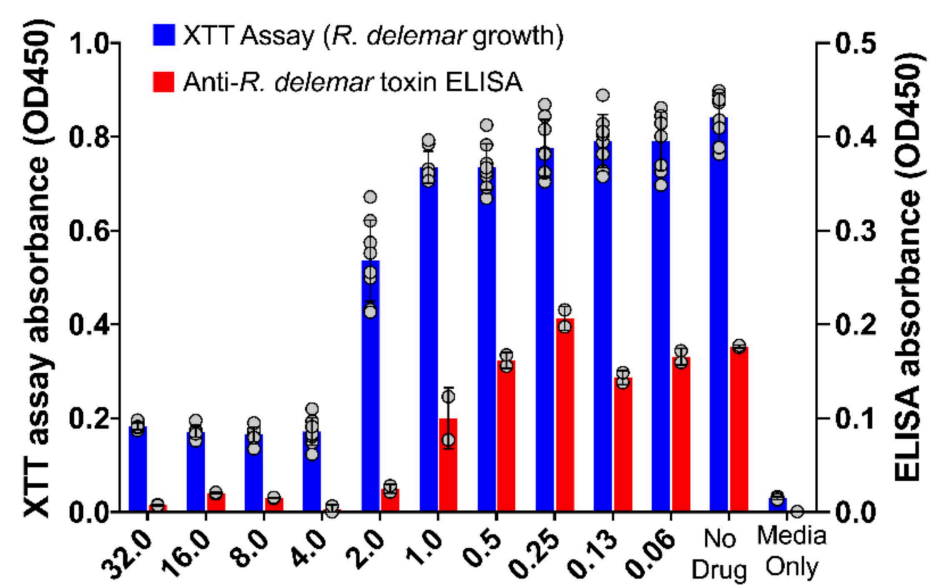

Amphotericin B concentration in culture $(\mu \mathrm{g} / \mathrm{ml})$ b

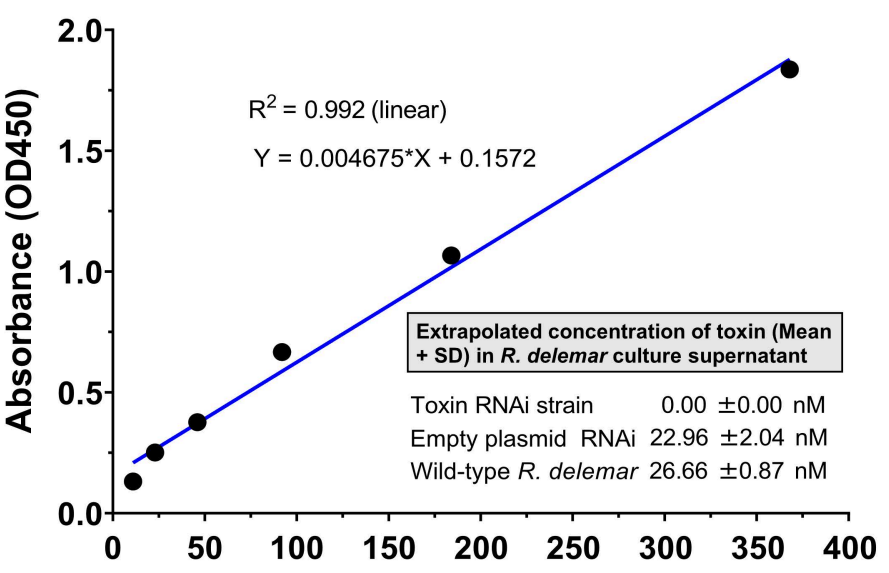

R. delemar toxin standard concentration (nM) 